\title{
Ueber die Hydrazinverbindungen *);
}

\author{
von Emil Fischer. \\ (Eingelaufen den 16. September 1877.) \\ Erste Abhandlung.
}

Im Vergleich zu den zahlreichen allgemeinen Reactionen, welche für die Synthese organischer Verbindungen durch sogenannte Kohlenstoffverkettung seit längerer Zeit in Anwendung kommen und welche allein den in den letzten Jahrzehnten mit so glänzendem Erfolge betriehenen Ausbau der organischen Chemie ermöglichten, sind die Methoden für einen ähnlichen Aufbau complicirter Stickstoffgruppen aufserordentlich spärlich und dazu meist nur auf ein verhältnifsmälsig kleines Gebiet beschränkt anwendbar.

Synthetisch erhaltene Verbindungen, in welchen man allgemein die Verkeltung mehrerer Stickstoffatome anzunehmen pflegt, sind die Azo-, Hydrazo- und Diazokörper und die durch Werthheim und Geuther fast gleichzeitig entdeckten, neuerdings gewöhnlich als „Nitrosamine" bezeichneten Nitrosoderivate der secundären Aminbasen; die drei ersteren kennt man nur in der aromatischen Reihe; die Bildung der letzteren ist dagegen eine allgemeine, für die meisten Imidbasen gültige Reaction.

An diese Körper schliefsen sich an die vereinzelt dastehenden und deshalb geringeres Interesse verdienenden Oxydationsproducte des Triamidophenols und Diamidonapthols, das Diimidoamidophenol und das Diimidonaphtol, in welchen ebenfalls eine der Chinonbildung ähnliche intramoleculare Ver-

*) Vorläufige Mittheilungen, Berichte der deutschen chemischen Gesellschaft $\mathbf{8}, 589,1005,1641 ; \mathbf{9}, 880,1840 ; 10,1331$. 
kuppelung zweier Stickstoffatome angenommen wird und endlich die in neuerer Zeit entdeckten, ein felles und ein aromatisches Radical enthaltenden gemischten Azoverbindungen *).

Von allen diesen Substanzen sind es nur die durch die schönen Untersuchungen von $P$. Griefs nach den verschiedensten Richtungen eingehend erforschten Diazokörper, bei welchen die Stickstoffgruppe in einer Reihe merkwürdiger Reactionen eine hervorragende Rolle spielt. Abgesehen von den zahlreichen interessanten Zersetzungen, welche die Eliminirung der beiden Stickstoffatome zur Folge haben, kennt man hier inshesondere die Bildung der Diazoamidoverbindungen, der Perbromide, des Diazobenzolimids und endlich die Umwandlung in Azoverbindungen.

Beim Azo- und Hydrazobenzol gelang zwar die Ueberführung des einen in das andere durch Reduction und $0 x y-$ dation, jede weitere tiefer gehende Veränderung der Stickstoffgruppe durch Einführung von Alkohol- und Säureradicalen oder anderer Atomgruppen scheiterte dagegen an der Unbeständigkeit des letzteren gegen alle energischer wirkenden Agentien. Dasselbe gilt von den Nitrosaminen, deren Kenntnifs sich fast ausschliefslich auf die Angaben von Werthheim und Geuther beschränkte, dafs Reductionsmittel und concentrirte Säuren die Abspaltung der Nitrosogruppe und die Rückbildung der ursprünglichen Aminbase veranlassen. Mit den Resultaten der Griefs'schen Arbeiten schien also die Zabl der Reactionen, welche für den Aufbau complicirter Stickstoffgruppen in Anwendung kommen konnten, erschöpft und mit der Synthese der Diazoamidoverbindungen und des Diazobenzolimids war vorläufig die Grenze der Stickstoffcondensation erreicht. Seit einiger Zeit ist es mir nun gelungen,

*) V. Meger und Ambühl, Berichte der deutschen chemischen Gesellschaft 8, 751 . 
zunächst in der aromatischen Gruppe durch Reduction der Diazokörper und später durch gleiche Behandlung der Nitros-amine auch in der Fettreihe eine neue Klasse von stickstoffreicheren Basen zu gewinnen, welche ihrer Zusammensetzung und Constitution zufolge den vorher erwähnten Verbindungen sehr nahe stehen, sich von den meisten derselben jedoch theils durch Beständigkeit, theils durch gröfsere Reactionsfähigkeit in vortheilhafter Weise unterscheiden und dadurch ein neues werthvolles Ausgangsmaterial nicht allein für dic Gewinnung zahlloser interessanter Substitutionsproducte, sondern auch für den weiteren Aufbau längerer Stickstoffketten geworden sind.

Die Synthese und das gesammte Verhalten dieser Basen führen übereinstimmend zu der Ansicht, dafs sie sämmtlich die im Hydrazobenzol schon seit längerer Zeit allgemein angenommene Atomgruppe $=\mathrm{N}-\mathrm{N}=$ enthalten, deren vier freie Affinitäten durch Wasserstoff und Alkoholradicale in wechselndem Verhältnifs gesättigt sind.

Es scheint deshalb gestattet und aus anderen Gründen zweckmäfsig, dieselben ähnlich der gebräuchlichen typischen Auffassung der gewöhnlichen Aminbasen als Abkömmlinge der einfachen Stickstoffwasserstoffverbindung $\mathrm{NH}_{2}-\mathrm{NH}_{2}$ zu betrachten. Letztere ist zwar bis jetzt nicht dargestellt worden, wennschon manche Beobachtungen für ihre Existenzfähigkeit sprechen; es wird diefs jedoch jener Betrachtungsweise kaum zum Vorwurf gemacht werden können, so lange man ein ähnliches Verfalıren in anderen Körpergruppen, z. B. bei den Derivaten des eben so hypothetischen Nitroacetonitrils, für erlaubt hält; man wird vielmehr aus dem experimentellen Theile dieser Abhandlungen leicht die Ueberzeugung gewinnen, dafs diese Auffassung besser, denn jede andere, die Classification jener Basen vereinfacht, ihre Bezjehungen zu den Azo- und Diazoverbindungen scharf hervor- 
treten läfst und selbst einen Vergleich mit den in manchen Reactionen sich ganz analog verhaltenden Aminbasen erleichtert; man wird es ferner gerechtfertigt finden, dafs für diese Körperklasse, welche an Zahl der Verbindungen und an Mannigfaltigkeit der Erscheinungen kaum von einem anderen Kapitel der organischen Chemie übertroffen wird, ein besonderer Name „Hydrazine ${ }^{\triangleleft}$ gewählt wurde. Dieser Name hat zwar in der kurzen Zeit seiner Existenz mancherlei unmotivirte Anfechtung erfahren; ich glaube dem gegenüber mich mit der fast selbstverständlichen Bemerkung begnügen zu können, dafs derselbe zunächst an das älteste Glied dieser Gruppe, das Hydrazobenzol, erinnern soll und dafs ferner die der Sylbe „Amin“ angepafste Endung „Azin* es ermöglicht, die Nomenclatur der meisten Derivate der bei den Aminbasen allgemein gebräuchlichen nachzubilden.

Von den beiden bisher für die Darstellung der Hydrazine bekannten Methoden ist die Reduction der Diazokörper natürlich auf die aromatische Reihe beschränkt und liefert hier nur die primären Basen. Weit allgemeiner und als Synthese wichtiger ist die Reduction der Nitrosamine; sie ermöglicht die Gewinnung der secundären Basen in der fetten, aromatischen und Alkaloïd-Gruppe und führte weiter in der Fettreihe zur Entdeckung der durch ihre Beziehungen zu den noch unbekannten Diazoverbindungen doppelt interessanten primären Basen.

Die Untersuchung der Hydrazine hat namentlich durch die letztere Reaction einen solchen Umfang angenommen, dafs ich mich genöthigt sah, dieselbe vorläufig in jeder Gruppe auf die einfachsten Repräsentanten zu beschränken; es wurde dazu in der aromatischen Reiho das Phenylhydrazin gewählt, welches durch leichte Gewinnungsweise, Beständigkeit und Schönheit der Derivate vor allen Gliedern der Gruppe ausgezeichnet ist; die hier gewonnenen und im Nachfolgenden 
ausführlich beschriebenen Resultate werden genügen, um das eigenthümliche Verhalten der primären Hydrazine in allgemeinen Umrissen zu beleuchten, sie werden voraussichtlich auch für die Darstellung und Bearbeitung der zahlreichen Homologen wenigstens in der aromatischen Reihe als Richtschnur dienen können.

\section{Phenylhydrazin.}

Bildungsweisen. - Das Phenylhydrazin entsteht durch Reduction des Diazobenzols; hierzu eignen sich jedoch die gewöhnlichen Salze des letzteren keineswegs, da selbst bei Einhaltung der günstigsten Bedingungen, niedriger Temperatur und Anwendung wenig energisch wirkender Reductionsmittel, wie Zinkstaub und Essigsäure, der gröfste Theil derselben unter Stickstoffentwickelung zersetzt wird. Keine besseren Resultate gaben ăhnliche Versuche beim Diazobenzolimid, welches in alkoholischer Lösung mit Zink und Schwefelsäure behandelt nach den Angaben von $P$. Grie s $^{*}$ ) in Anilin und Ammoniak gespalten wird.

Mit der gröfsten Leichtigkeit läfst sich dagegen die beabsichtigte Reduction bei den Verbindungen des Diazobenzols mit schwefligsauren Alkalien oder bei den Diazoamidokörpern, welche beide die Diazogruppe in weit beständigerer Form enthalten, ausführen.

Erstere Methode führte zur Entdeckung des Phenylhydrazins und ist für die Darstellung desselben vorzuziehen.

Verbindungen des Diazobenzols mit Alkalisulfiten.

Ueber die Einwirkung von schwefligsauren Alkalien auf Diazokörper sind die ersten Angaben von Schmitt und

*) Diese Annalen 187, 77. 
Glutz *) gemacht, welche aus Diazophenol und $\mathrm{KHSO}_{3}$ ein gelbgefärbtes Salz von der Formel $\mathrm{C}_{6} \mathrm{H}_{4}(\mathrm{OH}) \cdot \mathrm{N}_{2} \mathrm{SO}_{3} \mathrm{~K}+\mathrm{H}_{2} \mathrm{O}$ erhielten und zugleich die Vermuthung aussprechen, dafs diese Reaction allen Diazokörpern eigenthümlich sei.

$\mathrm{Zu}$ anderen Resultaten gelangten Strecker und Römer **) später beim Diazobenzol; sie erhielten hier ein farbloses Salz von der Formel $\mathrm{C}_{6} \mathrm{H}_{5} \cdot \mathrm{N}_{2} \mathrm{H}_{2} \mathrm{SO}_{9} \mathrm{~K}+\mathrm{H}_{2} \mathrm{O}$, welches sich also durch einen Mehrgehalt von zwei Wasserstoffatomen von der ersten Klasse unterscheidet; sie beobachteten die reducirende Wirkung dieser Verbindung auf Silber-, Quecksilber- und Kupfersalze, fanden, dafs beim Kochen mit Salpetersäure aller Schwefel als Schwefelsäure abgespalten wird und steliten auf Grund dieser Thatsachen für das Kalisalz die rationellen Formeln :

auf.

$$
\left.\left.\underset{\mathrm{NH}}{\mathrm{C}_{6} \mathrm{H}_{6}} \cdot \underset{\mathrm{NH}}{\mathrm{NH}} \cdot \mathrm{SO}_{3} \mathrm{~K} * * *\right) \text { oder } \mathrm{C}_{6} \mathrm{H}_{5} \cdot \mathrm{NH}-\mathrm{NH} . \mathrm{SO}_{8} \mathrm{~K} \dagger\right)
$$

Eine hiervon anscheinend ebenfalls wieder verschiedene Reaction beobachteten diestlben Chemiker bei der gleichen Behandlung der Diazobenzolsulfosäure. Da das hier entstehende Kalisalz wegen seiner Löslichkeit nicht isolirt werden konnte, so wurde die Lösung zur Gewinnung der freien Säure mit Salzsäure eingedampft und so in der That eine in Wasser schwer lösliche Verbindung von der Formel $\mathrm{C}_{6} \mathrm{H}_{8} \mathrm{~N}_{2} \mathrm{SO}_{3}$ erhalten.

In der Meinung, das Kalisalz dieser Säure entstehe direct bei der Einwirkung des schwefligsauren Kalis auf die Diazoverbindung, erklärten sie den Vorgang durch die Gleichung : $\mathrm{C}_{6} \mathrm{H}_{4} \cdot \mathrm{N}_{2} \cdot \mathrm{SO}_{8}+2 \mathrm{KHSO}_{8}+2 \mathrm{H}_{2} \mathrm{O}=\mathrm{C}_{6} \mathrm{H}_{8} \mathrm{~N}_{2} \mathrm{SO}_{3}+2 \mathrm{KHSO}_{4}$.

*) Berichte der deutschen chemischen Gesellschaft $\boldsymbol{D}, 51$.

**) Daselbst 4, 784; Zoitschrift für Chemio 1871, 483 und Römer's Inauguraldissertation, Tübingen 1872.

***) Strecker, 8. a. 0 .

†) Römer, a. a. 0 . 
Das richtig erkannte verschiedene Verhalten dieser Säure und ihrer Salze von der vorigen Verbindung veranlafste sie weiter, für dieselbe die rationelle Formel $\mathrm{C}_{6} \mathrm{H}_{4} \backslash \mathrm{N}_{2} \mathrm{H}_{3}$ aufzustellen, deren Richtigkeit heute keinem Zweifel mehr unterliegen kann; der Körper ist nichts anderes, als die der Sulfanilsäure entsprechende Hydrazinverbindung und man wird ihn zweckmäfsig als Hydrazinbenzolsulfosäure bezeichnen.

Strecker und P. Römer gehört also unstreitig das Verdienst, die erste primäre aromatische Hydrazinverbindung entdeckt zu haben; die Entstehung derselben und ihre Beziehungen $\mathrm{zu}$ den von mir gewonnenen Basen wurden von denselben jedoch zum Theil, wie ich unten zeigen werde, nicht erkannt und es mag diefs der Grund gewesen sein, warum sie es unterliefsen, bei dem aus Diazobenzol erhaltenen Kalisalz dieselbe Reaction, $d$. h. die Zersetzung durch Salzsäure, welche ihnen das Phenylhydrazin geliefert haben würde, zul untersuchen.

Bei der Wiederholung der verschiedenen Versuche von Schinitt und Glutz einerseits und Strecker und Römer andererseits mit Diazobenzol zeigte sich zunächst, dafs beide Angaben eben so richtig, wie unvollständig sind, indem je nach den Bedingungen ein Kalisalz der ersten oder der zweiten Klasse, gewöhnlich aber beide zusammen, erhalten werden.

Trägt man Diazobenzolnitrat in eine kalt gehaltene neutrale oder besser noch schwach alkalische Lösung von schwefligsaurem Kali ein, so erstarrt die sich gelbroth färbende Flüssigkeit bei genügender Concentration oder besser auf $\mathrm{Zu}-$ satz von concentrirter Kalilauge bald zu einer Masse von gelben Krystallen, welche aus heifsem Wasser mehrmals umkrystallisirt und im Vacuum über Schwefelsäure getrocknet die Formel $\mathrm{C}_{6} \mathrm{H}_{5} . \mathrm{N}_{2} . \mathrm{SO}_{3} \mathrm{~K}$ haben. 
$0,204 \mathrm{Grm}$. Substanz gaben $0,239 \mathrm{CO}_{8}$ und $0,046 \mathrm{H}_{2} \mathrm{O}$.

$\begin{array}{ccc} & \text { Gefunden } & \text { Berechnet für } \\ \text { C } & 31,95 & \mathrm{C}_{6} \mathrm{H}_{3} \cdot \mathrm{N}_{2} \mathrm{SO}_{3} \mathrm{~K} \\ \text { H } & 2,5 & 32,13 \\ & & 2,23 .\end{array}$

Wendet man dagegen saures schwefligsaures Kali an und läfst die Temperatur über 20 bis $25^{\circ}$ steigen, so geht die anfangs rothe Färbung der Lösung sehr bald in schwach Gelb über und es scheidet sich das von Strecker und $R$ ö mer beschriebene Salz $\mathrm{C}_{6} \mathrm{H}_{5} \cdot \mathrm{N}_{2} \cdot \mathrm{H}_{2} \cdot \mathrm{SO}_{3} \mathrm{~K}+\mathrm{H}_{2} \mathrm{O}$ durch eine geringe Menge des vorigen verunreinigt in schwach gelb gefärbten Blättchen $\mathbf{a b}$.

Das erste Salz entsteht aus Diazobenzol nach der Gleichung :

$$
\mathrm{C}_{8} \mathrm{H}_{5} \cdot \mathrm{N}_{2} \cdot \mathrm{NO}_{3}+\mathrm{K}_{8} \mathrm{SO}_{3}=\mathrm{C}_{8} \mathrm{H}_{6} \cdot \mathrm{N}_{8} \cdot \mathrm{SO}_{8} \mathrm{~K}+\mathrm{KNO}_{3}
$$

und gehört unzweifelhaft noch zur Klasse der Diazokörper, wenn es sich auch von den meisten derselben durch Beständigkeit unterscheidet; man kann dasselbe als diazobenzolsulfonsaures Kali bezeichnen. Beim Erhitzen verpufft es ziemlich heftig; beim längeren Kochen der wässerigen Lösung zersetzt es sich, wenn auch langsam, unter Bildung von dunkel gefärbten harzigen Producten; mit Brom in wässeriger Lösung behandelt liefert es ziemlich glatt Tribromphenol; gegen Phenol und concentrirte Schwefelsäure zeigt es in eclatanter Weise das Verhalten der Diazoverbindungen, welche ähnlich den salpetrigsauren Salzen und den leicht zersetzlichen Nitrosoderivaten hierbei die von C. Liebermann *) entdeckten Farbstoffe liefern; mit Benzoylchlorid behandelt giebt es neben complicirten harzigen Producten kleinere Mengen von Benzoylphenoläther; beim Kochen mit concentrirter Salzsäure wird ein Theil unter Entwickelung von schwefliger

*) Berichte der deutschen chemischen Gesellachaft Ba yer und Caro, daselbst $\mathbf{7}, 966$. 
Säure und Stickstoff, ähnlich den gewöhnlichen Diazoverbindungen, zersetzt, während ein anderer Theil durch die frei werdende schweflige Sãure zu Hydrazin reducirt wird; endlich geht es mit reducirenden Agentien, schwefliger Săure oder besser Zinkstaub und Essigsäure behandelt in das zweite weifse Salz über. Letzteres ist also nur ein Reductionsproduct des ersten und entsteht durch Addition von zwei Wasserstoffatomen nach der Gleichung :

$$
\mathrm{C}_{6} \mathrm{H}_{5} \cdot \mathrm{N}_{2} \cdot \mathrm{SO}_{8} \mathrm{~K}+\mathrm{H}_{2}=\mathrm{C}_{6} \mathrm{H}_{5} \cdot \mathrm{N}_{8} \mathrm{H}_{2} \cdot \mathrm{SO}_{8} \mathrm{~K}
$$

Die Ergebnisse der Analyse und sämmtliche Reactioneu der Verbindung bestätigen diese Ansicht. Das Salz verglimmt beim Erhitzen; es zeigt die Li ebermann'sche Reaction nicht, reducirt Gold-, Platin-, Silber-, Quecksilber- und Kupfersalze und läfst sich durch Oxydation, am besten in heifser wässeriger Lösung, durch gelbes Quecksilberoxyd oder saures chromsaures Kali in das gelbe Salz zurückverwandeln. Ich werde dasselbe künftighin als phenylhydrazinsulfonsaures Kali bezeichnen. Besonders interessant ist sein Verhalten gegen concentrirte Mineralsäuren; beim Kochen der wässerigen Lösung mit Salzsäure entsteht nicht, wie man erwarten sollte, die dem Kalisalze entsprechende, jedenfalls sehr unbeständige Sulfosäure, sondern die schwefelhaltige Gruppe wird vollständig in Form von Schwefelsäure abgespalten und es bildet sich das Hydrochlorat der Base $\mathrm{C}_{6} \mathrm{H}_{5} \cdot \mathrm{N}_{2} \mathrm{H}_{3}$, des Phenylhydrazins. Der Vorgang wird durch folgende Gleichung veranschaulicht :

$$
\mathrm{C}_{6} \mathrm{H}_{5} \cdot \mathrm{N}_{8} \mathrm{H}_{2} \cdot \mathrm{SO}_{3} \mathrm{~K}+\mathrm{H}_{8} \mathrm{O}+\mathrm{HCl}=\mathrm{C}_{6} \mathrm{H}_{6} \cdot \mathrm{N}_{2} \cdot \mathrm{H}_{8} \cdot \mathrm{HCl}+\mathrm{KHSO}_{4}
$$

Ganz dieselben Erscheinungen beobachtet man nun bei der Behandlung der Diazobenzolsulfosãure mit schwefligsauren Alkalien und ich trug deshalb kein Bedenken, schon in der ersten Mittheilung über die Hydrazine* ${ }^{*}$ die Entstehung der

*) Berichte der deutschen chemischen Gesellschaft 8, 589. 
Hydrazinbenzolsulfosäure abweichend von Strecker und Römer analog der Bildung des Phenylhydrazins zu interpretiren.

Die Richtigkeit meiner Ansicht, welche inzwischen von Hrn. Kolbe *) ohne jeden ersichtlichen Grund bezweifelt worden ist, wird durch folgende Thatsachen bestätigt. Trägt man reine krystallisirte Diazosulfobenzolsäure *) in eine verdünnte, gut gekühlte Lösung von neutralem oder besser schwach alkalischem, schwefligsaurem Kali ein, so wird dieselbe rasch gelöst und die Flüssigkeit färbt sich intensiv roth; diese Farbe hält sich in der Kälte dauernd, verschwindet aber sofort beim Ansäuren oder gelindem Erwärmen und geht in Hellgelb über; die Flüssigkeit zeigt jetzt gegen reducirbare Metallsalze das charakteristische Verhalten der Hydrazinverbindungen; es erfolgt jedoch keine Ausscheidung des sulfonsauren Salzes. Diese Lösung kann nun ohne Veränderung zur Trockne verdampft werden; der Rückstand löst sich vollständig und leicht in kaltem Wasser und zeigt alle Eigenschaften der ersten Lösung; eben so wenig wird dieselbe durch concentrirte Salzsäure in der Kälte verändert; es erfolgt bei starker Concentration höchstens die Ausscheidung von Chlorkalium.

Erhitzt man aber die mit Salzsäure stark übersättigte Flüssigkeit zum Kochen, so beginnt in der Siedehitze plötzlich eine reichliche Krystallisation der in Wasser schwer löslichen, von Strecker und Römer beschriebenen Hydrazinbenzolsuifosäure. Letztere löst sich nun weiter wieder sehr

*) Journal für praktische Chemie $18,322$.

**) Man erlält dieselbe leichter, als nach der Methode von Schmitt, auf folgende Weise : Die in Wasser schwor lösliche Sulfanilsure wird in mälsig verdünnter Natronlauge gelöst, mit etwas mehr als der berechneten Menge salpetrigsauren Natrons versetzt und das Gemisch in überschüssige, kaltgehaltene, verdünnte Schwefelsăure eingetragen, wobei sich die Diazoverbindung sehr bald in weifsen Krystallen abscheidet. 
leicht in ätzenden oder schwefligsauren Alkalien, wird aber auch aus sehr verdünnter kalter Lösung durch Säuren sofort krystallinisch abgeschieden. lhre Praeexistenz in der noch nicht nit Salzsäure zersetzten Lösung ist dem gegenüber undenkbar und es kann nicht weiter zweifelhaft sein, dafs sie entsprechend dem Phenylhydrazin aus dem diazo- und hydrazinsulfonsauren Salze entsteht.

Die verschiedenen Phasen dieses Vorgangs werden durch folgende Gleichungen veranschaulicht :

1. $\mathrm{C}_{6} \mathrm{H}_{4}{ }_{-\mathrm{SO}_{3}}^{-\mathrm{N}_{3}}+\mathrm{K}_{8} \mathrm{SO}_{3}=\mathrm{C}_{6} \mathrm{H}_{4}-\mathrm{SO}_{3} \mathrm{~K}$

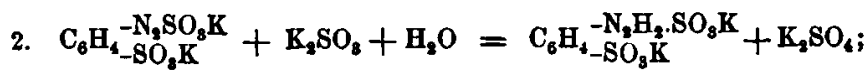

3. $\mathrm{C}_{6} \mathrm{H}_{4-\mathrm{SO}_{2} \mathrm{~K}}^{-\mathrm{N}_{2} \mathrm{H}_{2} \cdot \mathrm{SO}_{3} \mathrm{~K}}+\mathrm{HCl}+\mathrm{H}_{2} \mathrm{O}=\mathrm{C}_{6} \mathrm{H}_{4}{ }_{-\mathrm{SO}_{8} \mathrm{H}}^{-\mathrm{N}_{2} \mathrm{H}_{8}}+\mathrm{KCl}+\mathrm{KHSO}_{4}$.

Vollständig analog ist das Verhalten der ebenfalls von Schmitt beschriebenen Diazodibrombenzolsulfosäure, wovon ich mich durch qualitative Versuche leicht überzeugen konnte.

\section{Bildung der Hydrazine aus Diazoamidoverbindungen.}

Directer als vermittelst der sulfonsauren Salze erhält man das Phenylhydrazin durch Reduction der Amide des Diazobenzols.

Diazoamidobenzol oder das von Baeyer und Jäger beschriebenen Diazobenzoldiäthylamid *) werden in kalter alkoholischer Lösung von Zinkstaub und Essigsäure unter bedeutender Wärmeentwickelung rasch angegriffen und zerfallen dabei glatt in Anilin resp. Diäthylamin und Phenylhydrazin; letzteres wurde als salzsaures Salz von den anderen Basen getrennt und durch die Analyse und alle übrigen Reactionen als identisch mit dem auf anderem Wege gewonnenen Präparate erkannt.

\footnotetext{
*) Berichte der deutschen chemischen Gesellschaft 8, 148.
} 
Die Reaction erfolgt durch Addition von vier Wasserstoffatomen und Spaltung der Stickstoffgruppe für das Diazoamidobenzol nach dem Schema :

$\mathrm{C}_{8} \mathrm{H}_{5} \cdot \mathrm{N} \cdot \mathrm{N} . \mathrm{NH} \cdot \mathrm{C}_{6} \mathrm{H}_{5}+2 \mathrm{H}_{2}=\mathrm{C}_{6} \mathrm{H}_{5} \cdot \mathrm{N}_{8} \mathrm{H}_{8}+\mathrm{B}_{2} \mathrm{~N} \cdot \mathrm{C}_{6} \mathrm{H}_{5}$.

Ein Zwischenproduct, welches den hydrazinsulfosauren Salzen entsprechen würde, von der Formel $\mathrm{C}_{6} \mathrm{H}_{5}$.NH.NH.NHC $\mathrm{N}_{6} \mathrm{H}_{5}$ wurde nicht beobachtet. Diese Bildungsweise der Hydrazine ist insofern von besonderem Interesse, als sie durch directe Umwandlung der Diazo- in die Hydrazingruppe ohne Zwischenproducte erfolgt; praktische Bedeutung hat dieselbe in der Phenylreihe nicht, da hier die andere Methode zur Darstellung vorzuziehen ist; bessere Dienste dagegen wird dieselbe voraussichtlich beim Naphtylamin, Orthophenylendiamin und anderen aromatischen Aminen, bei welchen die gewõhnlichen Diazosalze entweder überhaupt nicht bekannt sind, oder doch nur weit schwieriger, als die Diazoamidoverbindungen gewonnen werden, zur Herstellung der beireffenden Hydrazinbasen leisten.

\section{Darstellung des Phenylhydrazins.}

Zur Darstellung der Base empfiehlt sich folgendes Verfahren, welches durch Anwendung von salpetrigsauren Salzen das lästige Arbeiten mit gasförmiger salpetriger Säure umgeht, die Isolirung der Diazokörper und sulfonsauren Salze überflüssig macht und so die Gewinnung der primären aromatischen Hydrazine in beliebiger Menge und auf wenig kostspielige Weise ermöglicht.

20 Th. Anilin werden in 50 Th. Salzsäure (spec. Gew. 1,19) und $80 \mathrm{Th}$. Wasser gelöst und in der Kälte durch $\mathrm{Zu}-$ gabe der berechneten Menge salpetrigsauren Natrons *), wel-

*) Dasselbe kommt seit einiger Zeit in vorzïglicher Qualität and zu billigem Preise auf den Markt und ist ans beiden Gründen dem meist sebr schlechten käuflichen salpetrigsauren Kali vorzuziehen; ich habe zu dieser und den nachfolgenden Operationen ein Product benutzt, welches $28 \mathrm{pC} . \mathrm{N}_{2} \mathrm{O}_{3}$ enthielt. 
ches in der doppelten Menge Wasser gelöst und mit Salzsăure schwach angesäuert ist, in Diazobenzolchlorid verwandelt; diese Lösung wird sofort in eine kalt gesättigte und durch Eis gekühlte Lösung von überschüssigem käuflichem $\mathrm{Na}_{2} \mathrm{SO}_{3}$ allmälig unter stetem Umrühren eingetragen; der Gehalt des letzteren an schwefliger Säure ist vorher zu ermitteln, da der Werth des Handelsproductes ein sehr schwankender ist; man wendet am besten $2 \mathrm{Mol} . \mathrm{Na}_{2} \mathrm{SO}_{3}$ auf $1 \mathrm{Mol}$. Anilin an, entsprechend der Gleichung :

$\mathrm{C}_{6} \mathrm{H}_{5} \cdot \mathrm{N}_{8} \cdot \mathrm{Cl}+2 \mathrm{Na}_{8} \mathrm{SO}_{3}+\mathrm{H}_{8} \mathrm{O}=\mathrm{C}_{6} \mathrm{H}_{5} \cdot \mathrm{N}_{8} \mathrm{H}_{8} \cdot \mathrm{SO}_{8} \mathrm{Na}+\mathrm{NaCl}+\mathrm{Na}_{8} \mathrm{SO}_{4}$.

Die Lösung färbt sich intensiv rothgelb und scheidet zum Schlufs eine reichliche Menge des diazosulfonsauren Natrons ab. Eine Probe derselben darf unter keinen Umständen beim Erwärmen noch die Reactionen des Diazobenzols, Stickstoffentwickelung und Phenolbildung zeigen, sondern mufs sich mit rein gelber Farbe klar lösen; im anderen Falle fehlt es an schwefligsaurem Alkali.

Ist bei diesen Operationen für gute Abkühlung gesorgt, so kann man 30 bis $40 \mathrm{Grm}$. Anilin ohne jede Gefahr auf einmal verarbeiten.

Mehrere solcher Portionen werden jetzt vereinigt, das ausgeschiedene sulfonsaure Salz durch gelindes Erwärmen auf dem Wasserbade grö fstentheils gelöst und die Flüssigkeit mit Salzsäure vorsichtig neutralisirt; die hierbei frei werdende schweflige Säure genügt, um den gröfsten Theil des gelben Salzes in das weifse umzuwandeln; schliefslich säuert man mit Essigsäure an und versetzt die warme Lösung bis zur vollständigen Entfärbung mit Zinkstaub; das heifse Filtrat scheidet beim Erkalten die gröfste Menge des hydrazinsulfonsauren Natrons ab; man läfst einen Theil der Lösung krystallisiren, vereinigt das ausgeschiedene Salz mit einem anderen Theile derselben, um eine möglichst starke Concentration zu erhalten, erwärmt zum Sieden und versetzt mit etwa 
$1 / 3$ Volumen rauchender Salzsäure; die Flüssigkeit erstarrt sofort zu einer schwachbraun gefärbten Krystallmasse von salzsaurem Phenylhydrazin; nach dem Erkalten colirt man das ausgeschiedene Salz, vereinigt die Mutterlaugen mit den von der Krystallisation des sulfonsauren Salzes zurückgebliebenen und verdampft dieselben nach weiterem Zusatz von Salzsäure auf ein möglichst kleines Volumen. Man erhält so eine zweite reichliche Krystallisation des Hydrochlorats, welche mit der ersten vereinigt wird. Durch Zersetzen des rohen Salzes mit Natronlauge in concentrirter Lösung wird die Base als 0elschicht abgeschieden und kann gröfstentheils abgehoben werden; den Rest gewinnt man durch Extraction mit Aether; die ersten stark salzsauren Mutterlaugen kann man mit Kalk neutralisiren und mit Aether extrahiren oder mit Wasserdämpfen destilliren; ihre Verarbeitung lohnt sich indessen bei der dadurch erzielten geringen Ausbeute und bei der Billigkeit der Materialien für Arbeiten im Laboratorium kaum.

Nach Verdampfen des Aethers wird das ölige, dunkelgefärbte Rohproduct mit kohlensaurem Kali scharf getrocknet und in einer Retorte über freiem Feuer destillirt. Nach Entfernung der letzten Spuren Aether und Alkohol geht das Thermometer rasch auf $220^{\circ}$ und steigt von da langsam bis $240^{\circ}$, bei welcher Temperatur der allergröfste Theil des Oels übergegangen ist und die Operation zweckmäfsig unterbrochen wird; bei der ersten Destillation entweichen beträchtliche Mengen Ammoniak, welche hauptsächlich das Schwanken des Siedepunkts veranlassen und von der Zersetzung complicirterer, in der Rohbase enthaltener Substanzen herrühren; als Rückstand bleibt in der Retorte eine geringe Menge nicht flüchtiger harziger Producte.

Das von dem Destillat absorbirte Ammoniak entfernt man am besten durch Aufbewahren desselben in flachen Gefäfsen neben concentrirter Schwefelsäure unter einer Vacuumglocke; 
die zweite Destillation liefert dann ein von 225 bis $235^{\circ}$ siedendes Product von fast reinem Phenylhydrazin.

Weitere Reinigung der Base durch Fractioniren ist nicht rathsam, da bei der Destillation gröfserer Mengen stets geringe Ammoniakentwickelung stattindet, welche das Schwanken des Siedepunkts bedingt.

Es wurde deshalb nur für die Analyse und die Bestimmung der physikalischen Constanten durch wiederholtes Fractioniren, Trocknen mit $\mathrm{K}_{2} \mathrm{CO}_{3}$ und Entfernen des Ammoniaks im Vacuum ein constant siedendes Präparat dargestellt. Für die Darstellung aller Derivate eignet sich das einmal destillirte Product eben so gut.

Die Ausbeute, welche nach diesem Verfahren erzielt wurde, lärst wenig zu wünschen übrig; 2 Kilo Anilin gaben $1600 \mathrm{Grm}$. Hydrazinbase, was circa $70 \mathrm{pC}$. der theoretischen Menge entspricht. Berücksichtigt man die bei derartigen Arbeiten im Laboratorium unvermeidlichen Verluste, so kann der Verlauf aller Reactionen ein nahezu quantitativer genannt werden.

\section{Eigenschaften und Balze des Phenylhydrazins.}

Die Zusammensetzung des Phenylhydrazins entspricht der Formel $\mathrm{C}_{6} \mathrm{H}_{8} \mathrm{~N}_{2}$, wie die Analyse *) eines constant bei 233 bis $234^{\circ}$ siedenden Products zeigt.

*) Bezüglich der Analysen sei bemerkt, dafs allo Verbrennangen wegen deg hohon Stickstoffgehalts und der leichten Zersetzlichkeit mancher Producte im Bayonnetrohr und allo Stickstoffbestimmangen nach der Methode von Dumas ausgefuliht wurden; die bei den letzteren zur Verdrängung der Luft nöthige $\mathrm{CO}_{2}$ wurde nicht wio gewöhnlich aus Magnesit oder doppelt-kohlensaurem Natron, sondern aus einem Koblensäureapparate entwickelt, vorher sorgfältig gewaschen and getrocknet und in ziemlich raschem Strom, aber nur kurze Zeit, durch die hinten zu einer Capillaren ausgezogene Verbrennungaröhre geleitet. - Diese Vorsichtsmafs- 
$0,2358 \mathrm{Grm}$. gaben $0,5765 \mathrm{CO}_{2}$ und $0,1624 \mathrm{H}_{2} \mathrm{O}$.

0,1618 Grm. gaben 37 CC. $N$ bei $18^{\circ} \mathrm{C}$. und $749 \mathrm{MM}$. Barometerstand.

$\begin{array}{ccc} & \text { Gefunden } & \text { Berechnet } \\ \text { C } & 66,67 & 66,67 \\ \text { H } & 7,65 & 7,41 \\ \text { N } & 25,93 & 25,92 .\end{array}$

Dieselbe Formel resultirt aus den Analysen der Salze.

Frisch destillirt ist es ein fast farbloses 0el von schwach aromatischem Geruch; in einer Kältemischung erstarrt es sofort, ebenso beim längeren Aufbewahren in kühlen Räumen und bildet dann tafelförmige, glasglänzende Krystalle vom Schmelzpunkt $23^{\circ}$ ); vom Licht wird es nicht verändert, färbt sich aber an der Luft durch Oxydation bald roth bis dunkelbraun; der Siedepunkt liegt bei 750 MM. Druck zwischen 233 und $234^{*}$ ). Das specifische Gewicht ist bei $21^{\circ}$ 1,091, bezogen auf Wasser von gleicher Temperatur; es dreht die Ebene des polarisirten Lichts nicht. In kaltem Wasser ist es schwer löslich, etwas leichter in heirsem, fast unlöslich in concentrirten Alkalien; mit Alkohol, Aether, Aceton, Chloroform, Benzol mischt es sich in jedem Verhältnifs; schwieriger wird es von Ligroin aufgenommen.

Mit Wasserdämpfen verfüchtigt es sich etwas schwieriger als Anilin.

Gegen Reductionsmittel ist das Phenylhydrazin und seine Salze sehr beständig; von oxydirenden Agentien wird es dagegen aufserordentlich leicht zerstört, wobei je nach den Bedingungen die verschiedensten Zersetzungsproducte auf-

regeln sind nöthig, da manche der später beschriebenen Körper bereits durch wenig erwärmte $\mathrm{CO}_{2}$ zersetzt oder in beträchtlicher Menge verflüchtigt werden, wodurch bedentende Analysenfehler veranlalst werden können.

*) Alle Schmelz- und Siodepunkte eind mit oinem Geifsler'schen Normslthermometer bestimmt und uncorrigirt angegeben. 
treten; besonders charakteristisch ist sein Verhalten zu Fe hling'scher Lösung; die Reduction derselben erfolgt schon in der Kälte und in sehr verdünnter Lösung; gleichzeitig findet lebhafte Stickstoffentwickelung statt. Man kann diese Erscheinungen als empfindliche Reaction auf alle primären Hydrazine und indirect auch auf die Diazoverbindungen benutzen; handelt es sich um den Nachweis der letzteren in wässeriger Lösung, so versetzt man dieselbe mit $\mathrm{KHSO}_{3}$ im Ueberschurs, erwärmt zum Sieden, neutralisirt mit Kalilauge und prüft mit Kupferlösung. Die in der Flüssigkeit etwa vorhandenen, aus den Diazoverbindungen entstandenen hydrazinsulfonsauren Salze bewirken alle ohne Ausnahme die sofortige Abscheidung von Kupferoxydul; ist das Vorhandensein von Hydroxylamin, welches bei der Reduction von salpetriger Säure leicht entstehen kann, zu befürchten, so hält man die alkalische Lōsung zur Zerstörung desselben vorher einige Zeit im Sieden.

Das Phenylhydrazin ist eine einsäurige Base und liefert mit Mineralsäuren und einigen organischen Säuren beständige und gut krystallisirende Salze.

Das Hydrochlorat, $\mathrm{C}_{6} \mathrm{H}_{5} \cdot \mathrm{N}_{2} \mathrm{H}_{3} \cdot \mathrm{HCl}$, wird durch Zersetzung der hydrazinsulfonsauren Salze oder durch Neutralisation der Base mit Salzsäure erhalten und bildet feine seideglänzende farblose Blăttchen.

1. 0,1645 Grm. gaben $0,3002 \mathrm{CO}_{2}$ and $0,0922 \mathrm{H}_{2} \mathrm{O}$.

$0,2588 \mathrm{Grm}$. gaben $40 \mathrm{CC}$. Stickstoff bei $8^{\circ}$ und $754 \mathrm{MM}$. Drack. 0,1923 Grm. gaben $0,1978 \mathrm{AgCl}$.

2. $0,2297 \mathrm{Grm}$. gaben $0,2367 \mathrm{AgCl}$.

3. 0,2198 Grm. des ans Diazoamidobenzol orhaltenen Prăparats gaben $0,3995 \mathrm{CO}_{2}$ und $0,1285 \mathrm{H}_{2} \mathrm{O}$.

\begin{tabular}{ccccc} 
& \multicolumn{3}{c}{ Gefunden } & Berechnet für \\
\cline { 2 - 5 } $\mathrm{C}$ & 1. & 2. & 3. & $\mathrm{C}_{6} \mathrm{H}_{6} \cdot \mathbf{N}_{8} \mathrm{H}_{3} \cdot \mathbf{H C l}$ \\
$\mathrm{H}$ & 49,77 & - & 49,57 & 49,83 \\
$\mathrm{~N}$ & 6,3 & - & 6,5 & 6,23 \\
$\mathrm{Cl}$ & 28,5 & - & - & 19,38 \\
& 25,5 & 25,4 & - & $24,56$. \\
& & & & $6 *$
\end{tabular}


Das Salz ist leicht löslich in heifsem Wasser, etwas schwerer in kaltem und fast unlöslich in rauchender Salzsäure; aus heifsem Alkohol krystallisirt es in feinen glänzenden Blättchen, beim vorsichtigen Erhitzen sublimirt es unzersetzt in derselben Form. Seine wässerige Lösung reducirt Gold-, Platin-, Silber- und Quecksilbersalze in der Kälte; durch concentrirte Salzsäure wird es aus der wässerigen Lösung ziemlich vollständig ausgefällt, worauf eine bequeme Trennungsmethode desselben von dem Anilin und vielen anderen Aminbasen beruht.

Alle Versuche, ein Salz des Phenylhydrazins mit 2 Mol. $\mathrm{HCl}$ zu gewinnen, blieben erfolglos; ein aus rauchender Salzsäure umkrystallisirtes Product, welches rasch abfiltrirt, mit rauchender $\mathrm{HCl}$ gewaschen und nur kurze Zeit in einer Chlorwasserstoffatmosphäre im Vacuum getrocknet war, enthielt die dem neutralen Salze entsprechende Chlormenge.

0,2022 Grm. gaben 0,1964 $\mathrm{AgCl}$.

$\begin{array}{ccc} & \text { Gefunden } & \text { Berechnet } \\ \text { C1 } & 24,04 & 24,56 .\end{array}$

Die Base ist also nicht im Stande, wie das Aethylhydrazin *), bei gewöhnlicher Temperatur 2 Mol. Salzsäure zu binden und es geht daraus deutlich hervor, dafs der herabmindernde Einflufs des Benzolrestes auf die Basicität der $\mathrm{NH}_{\mathbf{2}}$ Gruppe, welchen Thomsen für das Anilin gegenüber dem Aethylamin calorimetrisch nachgewiesen und bestimmt hat, sich nicht minder stark in der Hydrazingruppe geltend macht. Das Sulfat, $\left(\mathrm{C}_{6} \mathrm{H}_{5} \cdot \mathrm{N}_{2} \mathrm{H}_{3}\right)_{8} \mathrm{H}_{8} \mathrm{SO}_{4}$, wird durch Neutralisation der Base mit verdünnter Schwefelsäure in feinen weifsen Blättchen erhalten.

0,385 Grm. gaben 0,2895 BaSO.

$\begin{array}{ccc}\text { Gefunden } & \text { Berechnet } \\ \text { S } & 10,33 & 10,2 .\end{array}$

*) Berichte der deutachen chemischen Gesellschaft $9,115$. 
Es ist leicht löslich in heifsem Wasser, schwer in Alkohol, unlöslich in Aether; beim Erhitzen für sich oder mit concentrirter Schwefelsäure wird es erst bei hoher Temperatur unter Entwickelung von schwefliger Säure zersetzt.

Das Nitrat wird durch Neutralisation der Base mit mäfsig verdünnter, gut gekühlter Salpetersäure in weifsen glänzenden Blättchen erhalten, welche in Wasser sehr leicht löslich sind.

Rauchende Salpetersãure zersetzt das Phenylhydrazin unter Feuererscheinung.

Das pikrinsaure Salz scheidet sich beim Zusammenbringen von Pikrinsäure und Phenylhydrazin in ätherischer Lösung sofort in feinen gelben Nadeln ab, welche im Vacuum getrocknet die Formel $\mathrm{C}_{6} \mathrm{H}_{5} \cdot \mathrm{N}_{2} \mathrm{H}_{3} \cdot(\mathrm{OH}) \mathrm{C}_{6} \mathrm{H}_{2}\left(\mathrm{NO}_{8}\right)_{3}$ haben.

$0,2181 \mathrm{Grm}$. gaben $40 \mathrm{CC}$. Stickstoff bei $17,5^{\circ}$ und 750 MM. Druck.

$\begin{array}{ccc} & \text { Gefunden } & \text { Berechnet } \\ \text { N } & 20,95 & 20,6 .\end{array}$

Dasselbe ist in Alkohol leicht, in Wasser schwer löslich; beim Erhitzen auf $100^{\circ}$ zersetzt es sich bereits langsam unter Braunfärbung, bei höherer Temperatur verpufft es mit Feuererscheinung; beim Kochen seiner wässerigen oder alkoholischen Lösung tritt ebenfalls Zersetzung ein, indem die Hydrazinhase reducirend auf die Nitrogruppen der Pikrinsäure einwirkt.

Das neutrale Oxalat, $\left(\mathrm{C}_{6} \mathrm{H}_{3} \cdot \mathrm{N}_{2} \mathrm{H}_{3}\right)_{2} \mathrm{H}_{2} \mathrm{C}_{2} \mathrm{O}_{4}$, entsteht beim Neutralisiren von Oxalsăure mit einem Ueberschufs der Base in ätherischer Lösung; es krystallisirt aus heifsem Wasser in farblosen Blättchen.

0,269 Grm. gaben $0,542 \mathrm{CO}_{2}$ und $0,1466 \mathrm{H}_{2} \mathrm{O}$.

$\begin{array}{ccc} & \text { Gefunden } & \text { Berechnet } \\ \text { C } & 54,96 & 54,9 \\ \text { H } & 6,06 & 5,9 .\end{array}$

In heifsem Wasser ziemlich leicht löslich, schwer in kaltem, fast unlöslich in Alkohol und Aether. 


\section{Constitution des Phenylhydrazins.}

Das Phenylhydrazin hat die Formel $\mathrm{C}_{6} \mathrm{H}_{8} \mathrm{~N}_{2}$, ist also isomer mit den verschiedenen Phenylendiaminen, unterscheidet sich von denselben jedoch scharf durch sein gesammtes Verhalten; es entsteht durch Reduction des Diazobenzols und zwar, wenn man das Endresultat des Vorgangs empirisch betrachtet, durch Zufuhr von vier Wasserstoffatomen; für das salpetersaure Salz nach der Gleichung :

$$
\mathrm{C}_{8} \mathrm{H}_{8} \cdot \mathrm{N}_{2} \cdot \mathrm{NO}_{3}+2 \mathrm{H}_{2}=\mathrm{C}_{8} \mathrm{H}_{8} \cdot \mathrm{N}_{9} \mathrm{H}_{3} \cdot \mathrm{HNO}_{3} \text {. }
$$

Da diese Reaction als Synthese der Base zunächst der einzige Anhaltspunkt für die Beurtheilung ihrer Constitution war, so mufste bei der Aufstellung einer rationellen Formel vor Allem den Anschauungen über die Natur der Diazoverbindungen Rechnung getragen werden. Zur Zeit, als das Phenylhydrazin entdeckt wurde, waren aber gerade über diesen Punkt die Ansichten noch sehr verschieden.

Neben der älteren und längere Zeit ziemlich allgemein angenommenen K e kulé 'schen Diazobenzolformel $\mathrm{C}_{6} \mathrm{H}_{5}-\mathrm{N}=\mathrm{N}-\mathrm{NO}_{3}$ hatte sich die von Strecker aufgestellte Formel $\mathrm{C}_{6} \mathrm{H}_{5}-\mathrm{N}-\mathrm{NO}_{3}$

eingebürgert und aus Mangel an entscheidenden Thatsachen als gleichberechtigt behauptet.

Ging man nun von der einen oder anderen Anschauungsweise aus, so gelangte man für die diazo- und hydrazinsulfonsauren Salze und endlich für das Phenylhydrazin selbst ebenfalls zu den nachfolgenden, wesentlich verschiedenen Formeln :

$$
\begin{aligned}
& \mathrm{C}_{6} \mathrm{H}_{6}-\mathrm{N}=\mathrm{N}-\mathrm{SO}_{9} \mathrm{~K} ; \quad \mathrm{C}_{8} \mathrm{H}_{5}-\mathrm{N}-\mathrm{SO}_{3} \mathrm{~K} \text {; } \\
& \text { N } \\
& \mathrm{C}_{8} \mathrm{H}_{6}-\mathrm{NH}-\mathrm{NH}-\mathrm{SO}_{3} \mathrm{~K} ; \quad \mathrm{C}_{6} \mathrm{H}_{6}-\mathrm{NH}-\mathrm{SO}_{3} \mathrm{~K} \text {; } \\
& \text { NH } \\
& \mathrm{C}_{8} \mathrm{H}_{5}-\mathrm{NH}-\mathrm{NH}_{2} \text {; } \\
& \mathrm{C}_{6} \mathrm{H}_{6}-\mathrm{NH}_{2} \\
& \text { NH. }
\end{aligned}
$$


Gerade der Umstand, dafs S trecker bei der Entdeckung der hydrazinsulfonsauren Salze diese seine Ansicht geltend machte und auch sofort auf jene Verbindungen übertrug, war für mich Veranlassung, beim Phenylhydrazin ebenfalls die Wahl zwischen den vorstehenden beiden Formeln, deren erstere allerdings durch ihre Einfachheit weit mehr Gewinnendes hatte, bis zur Beschaffung des ausreichenden Beweismaterials unentschieden zu lassen.

Die Gewinnung der secundären Hydrazinbasen, deren Constitution leicht und sicher aus ihrer Synthese gefolgert werden konnte, und die Beobachtung dafs dieselben sich in vieler Beziehung dem Phenylhydrazin analog verhalten, bestimmte mich später, der Formel $\mathrm{C}_{6} \mathrm{H}_{5}$. NH- $\mathrm{NH}_{2}$ den Vorzug zu geben.

Bei der Bedeutung, welche die endgültige Entscheidung dieser Frage für die Constitution nicht allein der zahlreichen primären aromatischen Hydrazine und ihrer Derivate, sondern in zweiter Linie auch der nahe verwandten Diazokörper hatte, schien es jedoch wünschenswerth, die Richtigkeit derselben durch weitere experimentelle Daten zu bestätigen.

Die Untersuchung der genetischen Beziehungen des Phenylhydrazins zum Aethylphenylhydrazin haben diese in entscheidender Weise geliefert.

Das Phenylhydrazin giebt bei der Behandlung mit Bromatthyl, wie unten ausführlicher beschrieben wird, eine Ammoniumverbindung von der Formel $\mathrm{C}_{6} \mathrm{H}_{5} \cdot \mathrm{N}_{2} \mathrm{H}_{2} \cdot\left(\mathrm{C}_{2} \mathrm{H}_{5}\right) \cdot \mathrm{C}_{2} \mathrm{H}_{5} \mathrm{Br}$. Dieselbe Substanz bildet sich nun auch durch directe Anlagerung von $\mathrm{C}_{2} \mathrm{H}_{5} \mathrm{Br}$ an das Aethylphenylhydrazin; da letzteres aus Aethylanilin durch Einführung der $\mathbf{N H}_{2}$-Gruppe an Stelle des letzten Ammoniakwasserstoffs entsteht und mithin unzweifelhaft die Formel ${\underset{\mathrm{C}}{6} \mathrm{H}_{5}}_{\mathrm{C}_{5}}^{\mathrm{H}_{5}}>\mathrm{N}-\mathrm{NH}_{2}$ hat, so mufs in der Ammoniumverbindung dieselbe Atomgruppe angenommen werden 
und es folgt daraus weiter für das Phenylhydrazin, wenn man von der ganz willkürlichen Annahme molecularer Umlagerungen absieht, unzweideutig, dafs es ebenfalls die Gruppe $=\mathrm{N}-\mathrm{NH}_{2}$ enthält, woraus sich die Formel $\mathrm{C}_{6} \mathrm{H}_{5} \cdot \mathrm{NH}-\mathrm{NH}_{2}$ von selbst ergiebt. Berücksichtigt man ferner, dafs keine der im Nachfolgenden beschriebenen zahlreichen Reactionen und Derivate der Base mit dieser aus synthetischen Gründen hergeleiteten Formel in Widerspruch steht, dafs vielmehr die meisten derselben sich als gewissermafsen nothwendige Consequenzen derselben ergeben, so wird ihre Berechtigung keinem Zweifel mehr unterliegen.

Versucht man nun mit Zugrundelegung dieser Formel das im Nachfolgenden ausführlich beschriebene Verhalten der Base kurz zu charakterisiren und auf bekannte Verhältnisse zurückzuführen, so liegt ein Vergleich mit den gewöhnlichen Aminen einerseits und den Diazo- und Azokörpern andererseits am nächsten.

Auf die Basen des Ammoniaktypus bezogen erscheint das Phenylhydrazin auf der einen Seite des Moleculs als primäre, auf der anderen als secundäre Base.

Das Vorhandensein der Imidgruppe geht besonders aus der eigenthümlichen Veränderung der Substanz durch salpetrige Säure und Bromäthyl deutlich hervor; in fast allen übrigen Reactionen, welche durch den basischen Charakter der Verbindung bedingt sind, kommt dagegen nur die Amidogruppe zur Geltung; sie scheint der Hauptsitz der Basicität zu sein; der Eintritt von Säureradicalen und Harnstoffresten findet ausschliefslich hier statt, wie diefs in den meisten Fällen direct experimentell nachgewiesen werden konnte und dasselbe gilt höchst wahrscheinlich für die Anlagerung von Säuren bei der Salzbildung. Mit den Diazoverbindungen ist das Phenylhydrazin schon durch seine Synthese eng verknüpft; durch die Zufuhr von vier Wasserstoffatomen hat allerdings die Stick- 
stoffgruppe den eigenthümlichen Charakter, welchen sie bei jenen zeigt, vollständig verloren; derselbe erscheint aber sofort wieder bei allen Zersetzungen, welche durch oxydirende Agentien eingeleitet werden. Durch die directe Umwandlung der Base in Diazobenzol und durch ihre Ueberführung in Derivate des Azobenzols werden diese Beziehungen noch in auffallender Weise vervollstāndigt.

Vom Anilin endlich, welches unter den Aminbasen dem Phenylhydrazin am nächsten steht, unterscheidet sich dasselbe vorzüglich durch seine grofse Unbeständigkeit gegen alle Oxydationsmittel; die Folge davon ist, dafs die Darstellung der gewöhnlichen Substilutionsproducte, der Chlor-, Brom-, Jod- und Nitroderivate nach den dort gebräuchlichen Methoden hier nicht gelingt; letzteres kommt jedoch um so weniger in Betracht, als jene Verbindungen aus den betreffenden Derivaten des Anilins mit Leichtigkeit gewonnen werden können.

Diefs sind im Allgemeinen die bemerkenswerthesten Eigenschaften des Phenylhydrazins, durch welche dasselbe in mehr oder weniger nahe Beziehungen zu bereits bekannten Körpern tritt; einige hiermit nicht in Zusammenhang stehende und den Hydrazinen, wie es scheint, besonders eigenthümliche Erscheinungen sollen erst in dem nachfolgenden experimentellen Theile speciell besprochen werden.

\section{Einwirkung der salpetrigen Säure.}

Beim Einleiten von gasförmiger salpetriger Säure in eine wässerige oder ätherische Lösung des Phenylhydrazins wird dieses auch in der Kälte sofort zersetzt und es bildet sich neben dunkelgefärbten harzigen Producten Diazobenzolimid. Weit glatter und in den verschiedenen Phasen leichter zu verfolgen ist dieselbe Reaction bei der Einwirkung von salpetrigsauren Salzen auf salzsaures Phenylhydrazin; bringt man 
zu einer gut gekühiten Lösung des letzteren in der zehnfachen Menge Wasser überschüssiges neutrales $\mathrm{NaNO}_{2}$ in wässeriger Lösung, so wird die Flüssigkeit bald trübe, nimmt den betäubenden Geruch des Diazobenzolimids an und scheidet nach kurzer Zeit gelbbraune krystallinische Flocken ab; dieselben wurden rasch filtrirt, mit Wasser gewaschen, zwischen Fliefspapier geprefst, in warmem reinem Aether gelöst und mit Ligroin gefällt. Die so erhaltenen, nur kurze Zeit im Vacuum getrockneten, schwach gelben Blättchen gaben bei der Analyse die der Formel $\mathrm{C}_{6} \mathrm{H}_{5} \cdot \mathrm{N}_{2} \mathrm{H}_{2}$. NO entsprechenden Werthe.

0,2706 Grm. gaben 0,5222 $\mathrm{CO}_{2}$ und $0,1342 \mathrm{H}_{2} \mathrm{O}$.

0,1494 Grm. gaben 40 CC. Stickstoff bei $19^{\circ}$ und 749 MM. Druck.

$\begin{array}{ccc} & \text { Gefunden } & \text { Berechnet } \\ \mathbf{C} & 52,63 & 52,55 \\ \mathbf{H} & 5,5 & 5,1 \\ \mathbf{N} & \mathbf{3 0 , 3 3} & 30,65 \\ \mathbf{O} & - & 11,7 .\end{array}$

Die Bildung der Substanz wird veranschaulicht durch die Gleichung :

$\mathrm{C}_{6} \mathrm{H}_{5} \cdot \mathrm{N}_{2} \mathrm{H}_{8} \cdot \mathrm{HCl}+\mathrm{NaNO}_{2}=\mathrm{C}_{6} \mathrm{H}_{5} \cdot \mathrm{N}_{8} \mathrm{H}_{2} \cdot \mathrm{NO}+\mathrm{NaCl}+\mathrm{H}_{8} \mathrm{O}$.

Die Verbindung zeigt in jeder Beziehung das Verhalten der Nitrosokörper. Mit Phenol und concentrirter Schwefelsäure liefert sie ebenso, wie alle Nitrosamine, die Liebermann'schen Farbstoffe; zu bemerken ist dabei jedoch, dafs die blaue Farbe derselben auf Zusatz von Kali hier nicht sogleich, sondern erst beim Schütteln mit Luft erscheint; es rührt diefs daher, dafs gleichzeitig mit der Bildung der Farbstoffe eine Reduction derselben durch die Hydrazingruppe erfolgt, ähnlich wie es Liebermann bei der Behandlung mit Zinkstaub beobachtet hat.

Dasselbe gilt von den meisten Nitrosoderivaten der $\mathrm{Hy}-$ drazinbasen.

Beim Erhitzen zersetzt sich die Substanz unter Entwickelung von rothen Dämpfen; oxydirende Agentien wirken ebenso ; mit Zink und Schwefelsäure oder Zinkstaub und Essig- 
säure in alkoholischer Lösung reducirt liefert sie beträchtliche Mengen Anilin. An der Luft läfst sie sich besonders in feingepulverteın Zustande und in dünnen Schichten mehrere Tage ohne wesentliche Veränderung aufbewahren, während sie in verschlossenen Gefäfsen eigenthümlicherweise in sehr kurzer Zeit, bei Sommertemperatur meist im Verlauf mehrerer Stunden, vollständig zersetzt und in eine dunkelbraune, heftig riechende Flüssigkeit verwandelt wird *). Bemerkenswerth ist die in hohem Grade giftige Wirkung ihrer Dämpfe, welche der des Amylnitrits ähnlich ist, dieselbe an Intensität aber weit übertrifft; schon in geringer Menge eingeathmet erzeugen dieselben Blutandrang nach dem Kopfe, heftigen Kopfschmerz und Uebelkeit.

Die Constitution dieser eigenthümlichen Verbindung lăfst sich mit genügender Sicherheit aus folgenden Thatsachen entwickeln.

Die Reduction zu Anilin und die Verschiedenheit von den aromatischen Nitrosokörpern **), welche die NO-Gruppe

*) Ein ahnliches Verhalten zeigen auch manche andere Nitrosoderivate der Hydrazine, wenngleich keine in so auggezeichneter Weise, wie diese. Dieselbe Beobachtnng hat V. Mejer (diese Annalen 175, 138) ferner bei den Nitrolsauren gemacht und die Erscheinung durch die Annahme erklärt, dafs die bei der spontanen Zersetzung eines kleinen Theils der Molecule entwickelte Wärmemenge die rapide Zersetzung der übrigen zur Folge habe. Für den vorliegenden Nitrosokörper kann ich mit Bestimmtheit behaupten, dafs die in verschlossenen Gefärsen so auffallend rasch verlaufende Zersetzung hauptsăchlich durch die Zersetzungsproducte selbst, worunter sich die Oxyde des Stickstoffs befinden, bedingt ist. Dieselben wirken sehr rasch auf die noch unzersetzto Substanz ein; sobald sie dagegen an der Luft in Gasform entweichen können, wird ihr Einflufs versehwindend kloin und der ganze Zersetzungsprocels selbst dadurch ein langsamer und zugleich continuirlicher.

**) Baeyer und Caro, Berichto der dentschen chemischen Gesellschaft $z, 809$. 
im Benzolkern enthalten, beweisen, dafs dieselbe hier mit dem Stickstotf der Hydrazingruppe in Bindung getreten ist.

Nun kann es aber durch die Untersuchungen von $W$. Heintz *) u. A. für die gewöhnlichen Aminbasen als eine bewiesene Thatsache angesehen werden, dafs die Bildung eines sogenannten Nitrosamins ausschliefslich bei Imidgruppen stattfindet; es wird dadurch ein Gleiches für die Hydrazine in hohem Grade wahrscheinlich und es folgt daraus bei Zugrundelegung der Hydrazinformel $\mathrm{R}-\mathrm{NH}-\mathrm{NH}_{2}$ für diese Nitrosoverbindung die Constitutionsformel :

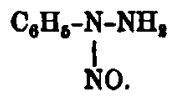

lch will dieselbe als Phenylnitrosohydrazin bezeichnen.

Eine wichtige Bestätigung erfährt diese Ansicht durch die Beobachtung, dafs die später beschriebenen secundären aromatischen Hydrazine, bei welchen das letzte Wasserstoffatom der NH-Gruppe durch Alkoholradicale ersetzt ist, von salpetriger Säure in einer hiervon total verschiedenen Weise zersetzt werden.

Von besonderem Interesse ist die Zersetzung des Phenylnitrosohydrazins durch verdünnte Alkalien, wobei es glatt in Wasser und das von Griefs **) entdeckte Diazobenzolimid zerfällt. Der Vorgang entspricht der Gleichung :

$$
\mathrm{C}_{6} \mathrm{H}_{6} \cdot \mathrm{N}_{9} \mathrm{H}_{2} \cdot \mathrm{NO}=\mathrm{C}_{6} \mathrm{H}_{6} \cdot \mathrm{N}_{9}+\mathrm{H}_{2} \mathrm{O} \text {. }
$$

Erwärmt man dasselbe gelinde mit verdünnter wässeriger Kalilauge, so schmilzt es zunächst und löst sich allmälig vollständig auf; beim stärkeren Erhitzen trübt sich die Flüssigkeit durch Ausscheidung von Diazobenzolimid. Zur Reinigung wurde letzteres mit Wasserdämpfen destillirt, mit Chlorcalcium

*) Diese Annalen $189,316$.

**) Daselbst 187,65 . 
getrocknet und nochmals im Vacuum auf dem Wasserbade destillirt; die Analyse des so erhaltenen fast farblosen Oels gab die der Formel $\mathrm{C}_{6} \mathrm{H}_{5} . \mathrm{N}_{3}$ entsprechenden Werthe.

0,1105 Grm. gaben $0,2444 \mathrm{CO}_{2}$ und $0,0444 \mathrm{H}_{8} \mathrm{O}$.

$\begin{array}{ccc} & \text { Gefunden } & \text { Berechnet } \\ \text { C } & 60,35 & 60,5 \\ \text { H } & 4,46 & 4,2 .\end{array}$

Der Vergleich mit einem nach der Methode von Griefs aus Diazobenzolperbromid und Ammoniak dargestellten Präparate ergab aufserdem eine vollständige Uebereinstimmung beider Producte in physikalischem und chemischem Verbalten, so dafs über ihre Identität kein $\mathrm{Zw}$ eifel herrschen kann.

Diese glatte Bildungsweise des Diazobenzolimids ist geeignet, Aufschlufs über die Constitution des eigenthümlichen, für die Theorie der Stickstoffverbindungen höchst interessanten Körpers zu geben.

Die Wasserabspaltung findet bei dem Nitrosokörper unzweifelhaft zwischen der NO- und $\mathrm{NH}_{\mathbf{2}}$-Gruppe statt, deren beide Stickstoffatome dadurch in doppelte Bindung treten und es resultirt daraus in ungezwungener Weise für das Imid die bereits von $\mathrm{Kekule} \mathrm{*)} \mathrm{als} \mathrm{wahrscheinlich} \mathrm{aufgestellte} \mathrm{Formel}$ $\mathrm{C}_{6} \mathrm{~B}_{5}-\mathrm{N}-\mathrm{N}$

Ferner eignet sich diese Methode in etwas modificirter Weise sehr gut zur Darstellung des Diazobenzolimids und ist, was Ausbeute und leichte Ausführbarkeit betriff, jedenfalls der von Griefs angegebenen vorzuziehen.

Die Bildung des Nitrosohydrazins erfolgt nur in neutraler und gut gekühlter Lösung; überschüssige Säure und höhere Temperatur bewirken seine sofortige Umwandlung in das Imid. Zur Gewinnung des letzteren verfährt man demzufolge bei Operationen in gröfserem Mafsstabe folgendermafsen.

*) Kekul6, Lehrbuch $\mathbf{8}, 230$. 
Das durch Zersetzung der hydrazinsulfonsauren Salze mit Salzsäure erhaltene rohe Hydrochlorat wird in der fünfzehnfachen Menge Wasser gelöst, auf Zimmertemperatur abgekühlt und mit einem Ueberschufs von salpetrigsaurem Natron allmälig unter stetem Umrühren behandelt; das Diazobenzolimid scheidet sich sofort als dunkelgefärbtes $0 \mathrm{el}$ ab ; zur Vervollstăndigung der Reaction erhitzt man die Lösung am Rückflufskühler langsam zum Sieden, bis die nicht bedeutende Gasentwickelung beendet ist, extrahirt mit Aether und reinigt den nach Verdampfen des letzteren bleibenden öligen Rückstand durch ein- bis zweimalige Destillation mit Wasserdämpfen. Die Ausbeute an reinem Diazobenzolimid betrug nach diesem Verfahren etwa $50 \mathrm{pC}$. des angewandten Anilins.

\section{Einwirkung von Diazobenzol auf Phenylhydrazin.}

Das Verhalten der gewöhnlichen primären und secundären Aminbasen gegen Diazobenzol, wodurch die sogenannten Amide des letzteren entstehen, liefs die Bildung ähnlicher Producte aus den Hydrazinen der aromatischen Reihe erwarten.

Alle Versuche, die zur Gewinnung dieser Verbindungen unter mannigfach verānderten Bedingungen angestellt wurden, gaben jedoch nur negative Resultate, und es scheint, dars solche Körper entweder nicht existenzfähig sind, oder doch nur bei ganz besonders günstigen Verhältnissen entstehen können. Dafür erfolgt aber eine andere, höchst merkwürdige Reaction, welche für die primären Hydrazine nicht minder charakteristisch ist, als die Einwirkung der salpetrigen Säure.

Bringt man reines salpetersaures oder schwefelsaures Diazobenzol mit salzsaurem Phenylhydrazin in kalter wässeriger Lösung zusammen, so trübt sich diese sehr bald durch Ausscheidung von Diazobenzolimid und die Lõsung enthält eine entsprechende Menge Anilin. 
Dieselbe Reaction hat inzwischen P. Griefs bei der von ihm dargestellten Hydrodiazobenzoësäure *), welche man wohl besser, um eine unnöthige Verwirrung der Nomenclatur zu vermeiden, Hydrazinbenzoësäure nennen wird, beobachtet und dabei weiter noch die interessante Thatsache festgestellt, dafs bei der Einwirkung von salpetersaurem Diazobenzol auf diese Base, neben Diazobenzoësäureimid und Anilin auch Diazobenzolimid und Amidobenzoësäure entsteht; er führt die Entstehung aller dieser Körper auf die Bildung eines Zwischenproducts $\mathrm{C}_{13} \mathrm{H}_{12} \mathrm{~N}_{4} \mathrm{O}_{2}$ zurück, welches offenbar nichts anderes sein würde, als die dem Diazoamidobenzol entsprechende Verbindung der Hydrazinbenzoësäure. Diese einfache und summarische Erklärung hat auf den ersten Anschein viel Gewinnendes; berücksichtigt man indessen, dafs die Isolirung eines derartigen Products, wenn es überhaupt gebildet wird, nach den guten Eigenschaften der Diazoamidoverbindungen zu schliefsen, nicht so schwierig sein dürfte, dafs ferner die Bildung desselben in saurer Lösung kaum zu erwarten ist und dafs endlich die Annahme von zwei so total verschiedenen Spaltungen einer unbekannten Verbindung immerhin etwas sehr Gewagtes hat, so verliert die Griefs'sche Ansicht an Wahrscheinlichkeit.

Dem gegenüber dürfte nachfolgende Interpretation entschieden den Vorzug verdienen, weil sie von sicher bekannten Thatsachen ausgehend die Bildung der oben erwähnten verschiedenen Producte auf zwei verschiedene, leicht verständliche Vorgänge zurückführt.

Die Einwirkung der Diazobenzolsalze auf die Hydrazine hat einmal die gröfste Aehnlichkeit mit der vorher beschriebenen Bildung von Diazobenzolimid aus Phenylhydrazin und salpetriger Säure; da das Diazobenzol aber aus Anilin und

\footnotetext{
*) Berichte der deutgchen chemischen Gesellschaft $9,1657$.
} 
$\mathrm{HNO}_{2}$ durch Wasserabspaltung entsteht, so ist eine Rückbildung der Generatoren durch Wasseraufnahme unter besonderen Verhältnissen leicht denkbar; die dabei entstehende $\mathrm{HNO}_{2}$ würde aber sogleich auch in saurer Lösung die Hydrazinbase in das Imid verwandeln.

Man bekommt auf diese Weise für die Bildung des Diazobenzoësăureimids aus Hydrazinbenzoësăure und Diazobenzol die Gleichungen :

$$
\begin{aligned}
\mathrm{C}_{6} \mathrm{H}_{6} \cdot \mathrm{N}_{2} \cdot \mathrm{NO}_{3}+2 \mathrm{H}_{3} \mathrm{O}=\mathrm{C}_{6} \mathrm{H}_{6} \cdot \mathrm{NH}_{2} \mathrm{HNO}_{3}+\mathrm{HNO}_{2} ; \\
\mathrm{C}_{7} \mathrm{H}_{8} \mathrm{~N}_{2} \mathrm{O}_{8}+\mathrm{HNO}_{2}=\mathrm{C}_{7} \mathrm{H}_{8} \mathrm{~N}_{3} \mathrm{O}_{8}+2 \mathrm{H}_{2} \mathrm{O} .
\end{aligned}
$$

Für die gleichzeilige Entstehung von Amidobenzoësäure und Diazobenzolimid ist dagegen eine Sprengung der Hydrazingruppe und ein Transport von Stickstoff nach dem Diazobenzol anzunehmen; diefs kann ebenfalls durch Wasseraufnahme erfolgen, wobei das Hydrazin die entsprechende Aminbase und Hydroxylamin liefern würde :

$$
\text { R. NH- } \mathrm{NH}_{2}+\mathrm{H}_{2} \mathrm{O}=\mathrm{R} \cdot \mathrm{NH}_{2}+\mathrm{NH}_{\mathrm{a}} \mathrm{O} \text {. }
$$

Der letzte Vorgang ist zwar bis jelzt noch nicht in so einfacher Weise beobachtet worden; es sind aber Gründo genug vorhanden, besonders bei den secundären Hydrazinen, welche für die Möglichkeit einer derartigen Spaltung sprechen.

Das Hydroxylamin müfste dann in der zweiten Phase der Reaction sich mit Diazobenzol zu Diazobenzolimid und Wasser umsetzen nach dem Schema :

$$
\mathrm{C}_{6} \mathrm{H}_{6} \cdot \mathrm{N}_{2} \mathrm{NO}_{3}+\mathrm{NH}_{8} \mathrm{O}=\mathrm{C}_{6} \mathrm{H}_{3} \cdot \mathrm{N}_{3}+\mathrm{HNO}_{3}+\mathrm{H}_{7} \mathrm{O} \text {. }
$$

Dafs dem in der That so ist, beweist folgender Versuch.

Beim Vermischen kalter wässeriger Lösungen von schwefelsaurem Diazobenzol und salzsaurem Hydroxylamin tritt keine Reaction ein; trägt man aber dieses Gemisch in eine verdünnte kalte Lösung von kohlensaurem Natron ein, so erfolgt sofort die Ausscheidung von Diazobenzolimid und zwar in nahezu quantitativer Weise. 
Eine weitere Stütze für die Wahrscheinlichkeit der letzten Erklärung liefert der unten geführte Nachweis, dafs auch das secundäre Methylphenylhydrazin von Diazobenzol in ähnlicher Weise zersetzt wird, wobei Diazobenzolimid und Methylanilin entsteht.

\section{Umwandlung der Bydrazine in Diazokörper.}

Die Rückverwandlung dieser Basen in Diazoverbindungen, welche für die Untersuchung der primären fetten Hydrazine ein besonderes Interesse hat, gelingt in der aromatischen Reihe fast eben so leicht, wie die umgekehrte Reaction. Man kann sich dazu der sulfonsauren Salze oder auch der gewöhnlichen Salze der Basen bedienen; erstere Methode ist allerdings weit glatter und leichter auszuführen, letztere dagegen um so interessanter, als sie die gewöhnlichen Salze der Diazokörper liefert.

Für die Gewinnung der hydrazinsulfonsauren Salze aus dem Phenylhydrazin, welche längere Zeit an dem Mangel einer geeigneten Methode für die Synthese solcher Verbindungen scheiterte, benutzte ich mit Vortheil das pyroschwefelsaure Kali. Erhitzt man ein Gemenge von 1 Mol. fein gepulvertem $\mathrm{K}_{2} \mathrm{~S}_{2} \mathrm{O}_{7}$ (dargestellt durch Erhitzen von $\mathrm{KHSO}_{4}$ ) und $2 \mathrm{Mol}$. der Base auf $80^{\circ}$, so erstarrt die breiige Masse in Kurzem vollständig und enthālt nun neben schwefelsaurem Kali und Hydrazin das phenylhydrazinsulfonsaure Kali.

Der Vorgang wird durch folgende Gleichung veranschaulicht :

$4 \mathrm{C}_{6} \mathrm{H}_{8} \cdot \mathrm{N}_{8} \mathrm{H}_{8}+2 \mathrm{~K}_{8} \mathrm{~S}_{2} \mathrm{O}_{7}=2 \mathrm{C}_{6} \mathrm{H}_{5} \cdot \mathrm{N}_{8} \mathrm{H}_{2} \cdot \mathrm{SO}_{3} \mathrm{~K}+\mathrm{K}_{8} \mathrm{SO}_{4}+\left(\mathrm{C}_{6} \mathrm{H}_{5} \cdot \mathrm{N}_{8} \mathrm{H}_{4}\right)_{8} \mathrm{SO}_{4}$.

Um letzteres zu isoliren löst man die Schmelze in heifsem Wasser und entfernt den gröfsten Theil der Schwefelsäure mit $\mathrm{BaCO}_{3}$, wodurch die in Lösung befindliche Base gröfstentheils ölförmig abgeschieden wird; aus der heifs filtrirten Flüssigkeit fällt auf Zusatz von concentrirter Kalilauge die 
Hauptmenge des sulfonsauren Salzes krystallinisch aus; einmaliges Umkrystallisiren aus heifsem Wasser genügt, um dasselbe vollständig rein zu erhalten.

Die Analyse gab dieselben Zahlen, wie bei dem aus Diazobenzol erhaltenen Präparate.

$0,6574 \mathrm{Grm}$. lufttrockenes Salz verloren bei $120^{\circ} 0,0486 \mathrm{H}_{8} \mathrm{O}$.

$$
\begin{array}{ccc} 
& \text { Gefunden } & \begin{array}{c}
\text { Berechnet für } \\
\mathrm{H}_{2} \mathrm{O}
\end{array} \mathrm{C}_{6} \mathrm{H}_{6} \cdot \mathrm{N}_{2} \mathrm{H}_{2} \cdot \mathrm{SO}_{8} \mathrm{~K}+ \\
7,38 & 7,37 .
\end{array}
$$

$0,2613 \mathrm{Grm}$. des bei $120^{\circ}$ getrockneten Salzes gaben $0,10 \mathrm{~K}_{9} \mathrm{SO}_{4}$.

$\begin{array}{ccc} & \text { Gefunden } & \text { Berechnet } \\ & 17,2 & 17,2 \text {. }\end{array}$

Dieselbe Uebereinstimmung zeigte sich in Krystallform, Löslichkeitsverhältnissen und allen Reactionen beider Substanzen.

Dieses Salz läfst sich nun, wie ich oben bereits erwähnt mit der gröfsten Leichtigkeit durch 0xydation in das gelbe diazosulfonsaure Kali überführen; versetzt man die heifse wässerige Lösung mit einem geringen Ueberschufs von gelbem Quecksilberoxyd oder saurem chromsaurem Kali, so ist die Umwandlung sofort eine vollständige und das gelb gefärbte Filtrat giebt beim Erkalten oder noch besser auf Zusatz von concentrirter Kalilauge eine reichliche Krystallisation von diazosulfonsaurem Kali. Aus letzterem die gewöhnlichen Salze oder Derivate des Diazobenzols zu erhalten, ist nun allerdings bisher nicht gelungen: da aber das ganze Verhalten desselben keinen Zweifel darüber läfst, dafs es selbst zur Klasse der Diazoverbindungen gehört, so kann vorstehende Reaction immerhin als eine glatte Umwandlung der Hydrazin- in die Diazogruppe gelten.

Weniger leicht ist die zweite Methode, die directe 0xydation der Hydrazinsalze auszuführen. Bringt man zu einer wässerigen kalten Lösung von salz- oder sohwefelsaurem Phenylhydrazin allmälig gelbes Quecksilberoxyd, so erfolgt 
alsbald fast ohne Gasentwickelung, welche in alkalischer Lösung stets bedeutend ist, die Ausscheidung von Diazobenzolimid und die saure Flüssigkeit enthält eine entsprechende Menge Anilin; die Entstehung dieser Producte ist offenbar erst die Folge einer secundären Reaction; zunächst findet jedenfalls die Bildung von Diazobenzol statt, welches sich jedoch sofort mit überschüssigem Hydrazin in der bekannten Weise zu Diazobenzolimid und Anilin umsetzt. Durch eine passende Aenderung der Bedingungen kann man in der That den letzten Vorgang theilweise wenigstens verhindern und alsdann die Bildung von Diazobenzol direct nachweisen.

Giefst man die kalte wässerige Lösung von schwefelsaurem Phenylhydrazin allmälig und unter stetem Umrühren zu gelbem, mit Wasser aufgeschlämmtem Quecksilberoxyd und zwar so, dafs letzteres stets im Ueberschufs vorhanden ist, so findet die Reduction desselben sofort statt; es scheidet sich nur wenig Diazobenzolimid ab und die filtrirte Lösung enthält eine beträchtliche Menge Diazobenzolsulfat; letzteres wurde allerdings bisher noch nicht in reinem Zustande aus der verdünnten und durch Quecksilbersalze verunreinigten Lösung gewonnen, sein Vorhandensein konnte jedoch durch die beim Erwärmen eintretende Stickstoffentwickelung und Phenolbildung aufser $Z_{\text {weifel gestellt werden. }}$

Die Reaction verläuft für das schwefelsaure Salz nach der Gleichung :

$$
\left(\mathrm{C}_{8} \mathrm{H}_{6} \mathrm{~N}_{8} \mathrm{H}_{4}\right)_{2} \cdot \mathrm{SO}_{4}+4 \mathrm{O}=\left(\mathrm{C}_{6} \mathrm{H}_{5} \cdot \mathrm{N}_{8}\right)_{8} \mathrm{SO}_{4}+4 \mathrm{H}_{8} \mathrm{O} .
$$

Durch diese beiden Reactionen werden die Beziehungen der Hydrazine zu den Diazoverbindungen in einer Weise vervollständigt, dafs es hier am Platze erscheint, dieselben nochmals kurz zusammenzustellen und die Consequenzen hervorzuheben, welche sich daraus für die Structurformel der letzteren ergeben. 


\section{Constitution der Diazoverbindungen.}

Die verschiedenen Anschauungen von $K$ ekule $\mathrm{e}^{i}$ und Strecker über die Natur dieser Körper, welche sich allein bis in neuere Zeit allgemeiner behauptet haben, sind früher einander gegenüber gestellt worden. Die K eku lésche Formel $\mathrm{C}_{6} \mathrm{H}_{5}-\mathrm{N}=\mathrm{N}-\mathrm{OH}$, obschon zum Theil auf das heutzutage sehr zweifelhafte Dogma von der constanten Trivalenz des Stickstoffs gegründet, hat unstreitig den Vorzug der Einfachheit, sie erklärt aufserdem die früher allerdings nur in vereinzelten Fällen beobachtete Umwandlung von Diazo- in Azokörper in ungezwungener Weise und scheint aus diesen Gründen auch von den meisten Chemikern dauernd bevorzugt worden zu sein. Dem gegenüber gab die $S$ trecker'sche Formel $\mathrm{C}_{6} \mathrm{H}_{5}-\mathrm{N}-\mathrm{OH}$, seitdem man gewohnt ist, mit fünfN

werthigem Stickstoff zu rechnen und die Salze der Aminbasen als Derivate desselben $\mathrm{zu}$ betrachten, für die Bildung der Diazoverbindungen aus Anilinsalzen und salpetriger Säure schematisch eine einfachere Erklärung; dagegen machte sie für die Entstehung von Azokörpern aus Diazoverbindungen die Annahme einer' molecularen Umlagerung nothwendig; in neuerer Zeit ist aber gerade diese Reaction durch die Entdeckung der gemischten Azokörper *) und durch die von Griefs ${ }^{* *}$ ) beobachtete Bildung von Azoverbindungen aus Diazobenzol und tertiären aromatischen Basen sehr verallgemeinert worden und hat dadurch an Bedeutung für die Entscheidung jener Frage gewonnen. Sollte man jedoch diesen einzelnen Grund, zumal da die Unwandlung des Diazobenzols in Azobenzol in einfacher Weise bisher nicht gelungen, für

*) V. Meger und Ambübl, Berichte der deutachen chemischen Gesellschaft 8, 751.

**) Daselbst 10, 525 . 
die Bevorzugung der Kekulë'schen Formel nicht genügend halten, so werden diese Bedenken doch schwinden müssen gegenüber den entscheidenden Resultaten, welche die vorstehende Untersuchung der aromatischen Hydrazine ergeben hat. Für das Phenyllydrazin ist die Formel $\mathrm{C}_{6} \mathrm{H}_{5}$. $\mathrm{NH}^{-\mathrm{NH}_{2}}$ aus einer Reihe von Thatsachen entwickelt worden, die keiner weiteren Erörterung bedürfen. Dasselbe ist nun durch vier glatte Uebergänge mit dem Diazobenzol aufs engste verknüpft.

1) Die Ueberführung des Diazobenzols durch das diazound phenylhydrazinsulfonsaure Kali in Phenylhydrazin,

2) die Umwandlung des letzteren in hydrazin- und diazosulfonsaures Kali,

3) die Bildung des Hydrazins durch Reduction der Diazoamidoverbindungen, und

4) endlich die Ueberführung von Diazobenzol einerseits und Phenylhydrazin andererseits in Diazobenzolimid $\mathrm{C}_{6} \mathrm{H}_{5} \cdot \mathrm{N}-\mathrm{N}$.

N

Dazu kommt noch die directe Umwandlung der Salze des Phenylhydrazins in Diazobenzolsalze und endlich die später beschriebene Bildung von Benzoyl- und Acetyldiazobenzol aus den entsprechenden Derivaten des Hydrazins. Für alle diese Reactionen würde die Stre ck er'sche Formel moleculare Umlagerungen, und zwar die Umwandlung von fünfwerthigem Stickstoff in dreiwerthigen durch Wasserstoffzufuhr und von drei- in fünfwerthigen durch Wasserstoffentziehung verlangen, eine Annahme, welche jeder Wahrscheinlichkeit entbehrt.

Oxydation des Phenylhydrazins in alkalischer Lösung.

Während aus Hydrazin bei Gegenwart von Mineralsäuren durch Oxydation in der Kälte ohne Gasentwickelung Diazobenzol oder dessen Umwandlungsproduct, das Diazobenzolmid, gebildet wird, ist dieselbe Reaction in alkalischer Lö- 
sung stets mit lebhafter Stickstoffentwickelung verbunden; genauer untersucht wurde nur die Zersetzung durch Fe h lingsche Lösung, weil dieselbe als empfindliches Erkennungsmittel für diese Basen ein besonderes Interesse hat.

Schüttelt man eine kalte wässerige Emulsion des Phenylhydrazins mit einem Ueberschufs von F e hl in g 'scher Lösung, so erfolgt sehr bald die Ausscheidung von Kupferoxydul und die Reaction ist bei nicht zu grofsen Mengen im Verlauf einiger Minuten beendigt; als Producte derselben wurden Stickstoff, Anilin und Benzol nachgewiesen. Die Entstehung der beiden letzten läfst sich nur auf zwei verschiedene, gleichzeitig verlaufende Vorgänge zurückführen. Während das Anilin uur durch Sprengung der Hydrazingruppe entstehen kann, vielleicht nach der Gleichung :

$$
2 \mathrm{C}_{6} \mathrm{H}_{5}-\mathrm{NH}-\mathrm{NH}_{2}+\mathrm{O}=2 \mathrm{C}_{6} \mathrm{H}_{5} \cdot \mathrm{NH}_{3}+\mathrm{H}_{2} \mathrm{O}+\mathrm{N}_{8},
$$

erinnert die Bildung des Benzols vielmehr an die Zersetzung der Diazokörper durch reducirende Agentien, wobei sämmtlicher Stickstoff in Gasform ausgeschieden wird und dafür der Eintritt von Wasserstoff in den Benzolrest erfolgt.

\section{Phenylhydrazin und Bromäthyl.}

Ein Gemisch von gleichen Moleculen Phenylhydrazin und Jodäthyl erwärmt sich nach einiger Zeit von selbst und die Reaction wird bei gröfseren Mengen so heftig, dafs die ganze Masse sich mit explosionsartiger Gasentwickelung zersetzt. Glatter verläuft die Einwirkung von Bromäthyl.

Die Reaction beginnt auch hier schon in der Kälte und wird durch zeitweises Einstellen des Gefäfses in kaltes Wasser und schliefsliches gelindes Erwärmen am Rückflufskühler ohne Gefahr zu Ende geführt; die Lösung erstarrt bei Anwendung von $1 \mathrm{Mol}$. Base und etwa 1\%/4 Mol. Bromäthyl (ein geringer Ueberschufs des letzteren ist vortheilhaft) vollständig zu einem Magma von feinen weifsen nadelförmigen Krystallen, welche 
von der geringen Menge des überschüssigen $\mathrm{C}_{2} \mathrm{H}_{5} \mathrm{Br}$ durch Erwärmen auf dem Wasserbade leicht befreit werden. Das Product löst sich vollständig in Wasser und liefert mit Natronlauge zersetzt ein complicirtes Gemenge von flüssigen flüchtigen Basen, für deren Trennung bisher keine brauchbare Methode gefunden wurde. Das Oel ging bei der Destillation zwischen 180 und $240^{\circ}$ über; constante Intervallen im Siedepunkte wurden nicht beobachtet und die Analyse der verschiedenen Fractionen gab keine entscheidenden Zahlen; eben so wenig führten die bisher für derartige Basengemenge üblichen Trennungsmethoden durch Oxaläther, Acetyl- und Benzoylchlorid oder salpetrige Saure hier zum Ziel. Durch Uebersättigen mit concentrirter Salzsäure konnte zwar der gröfste Theil des unveränderten Phenylhydrazins als schwer lösliches Hydrochlorat entfernt werden; die Untersuchung der übrigen Producte wurde indessen vorläufig aufgeschoben, nachdem in der Reduction der Nitrosamine eine weit bequemere Methode zur Darstellung der secundären unsymmetrischen Hydrazine gefunden war; sie soll aber möglichst bald wieder aufgenommen werden, da bei dieser Reaction die gleichzeitige Bildung des dem Hydrazobenzol entsprechenden Aethylphenylhydrazins mit ziemlicher Gewifsheit zu erwarten ist.

Weit leichter gelang es, aus der wässerigen, durch $\mathrm{Ex}-$ traction mit Aether von den flüchtigen Basen befreiten alkalischen Lösung einen Körper zu isoliren, der als eigenthümliche Ammoniumverbindung sowohl für die Theorie dieser Verbindungen, als auch für die Constilution des Phenylhydrazins von besonderer Bedeutung ist.

Derselbe scheidet sich aus der nicht zu verdünnten Lösung auf Zusatz von concentrirter Natronlauge in feinen weifsen Nadeln ab; durch Filtriren, Abpressen zwischen Fliefspapier und Umkrystallisiren aus siedendem Alkohol erhält man 
ihn in wasserhellen kurzen Prismen, deren Analyse zu der Formel $\mathrm{C}_{6} \mathrm{H}_{5} \cdot \mathrm{N}_{2} \mathrm{H}_{2} \cdot \mathrm{C}_{8} \mathrm{H}_{5} \cdot \mathrm{C}_{2} \mathrm{H}_{5} \cdot \mathrm{Br}$ führte.'

0,2762 Grm. gaben $0,4978 \mathrm{CO}_{2}$ und $0,182 \mathrm{H}_{8} \mathrm{O}$.

$0,4458 \Rightarrow n \quad 0,3411 \mathrm{AgBr}$.

$0,4012 " \quad$ 40,5 CC. Stickstoff bei $20^{\circ}$ und 752 MM. Druck.

$\begin{array}{lcc} & \text { Gefunden } & \text { Berechnet } \\ \text { C } & 49,12 & 48,98 \\ \text { H } & 7,3 & 6,94 \\ \text { N } & 11,43 & 11,43 \\ \text { Br } & 32,55 & 32,65 .\end{array}$

Beim langsamen Verdunsten einer alkoholischen Lösung scheidet sich die Verbindung in glänzenden, prachtroll ausgebildeten, rhombischen Krystallen ab. Mr. Dr. Arzruni ${ }^{*}$ ) hat die krystallographische Untersuchung derselben freundlichst übernommen und theilt darüber Folgendes mit :

${ }_{n}$ Krystallsystem : rhombisch.

a : b : c $=0,8219: 1: 0,8265$.

Schōne wasserhelle, stark lichtbrechende Krystalle. Beobachtete Formen : $m=110=\infty \mathrm{P}, \mathrm{d}=101=\mathrm{P}-$ $c=001=0 \mathrm{P}$. $\mathrm{m}$ und $\mathrm{d}$ oft gleich grofs entwickelt, c schmal und nach der Combinationskante cd gestreift. Die Krystalle meistens lang nach der Axe b.

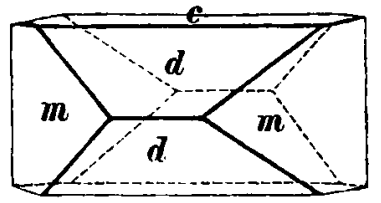

$\begin{array}{lcc} & \text { Gemessen } & \text { Berechnet } \\ (110)(110) & * 78^{0} 50^{\prime} & - \\ (101)(101) & * 9019 & - \\ (101)(001) & 4511^{1 / 2} & 45^{0} 9^{1} / 2 \\ (101)(110) & 5646 & 5647 .\end{array}$

Ebeno der optischen Axen parallel $010=\infty \mathrm{P} \dot{\infty}$, erste Mittellinio $=\mathrm{Axe}$.

$$
\begin{aligned}
& 2 \mathrm{H}_{\text {. für Natrium }}=91^{\circ} 36^{\prime} \\
& 2 \mathrm{H}_{0}, n=105^{\circ} \text { approximativ. } \\
& \text { also } 2 \mathrm{~V}_{0} n, n
\end{aligned}
$$

Dispersion der optischen Axen : $\rho<v$. Doppelbrechung positiv, stark."

*) Vgl. Grotb's Zeitschrift f. Krystall. u. Min. 1877, S. 388. 
Die Substanz ist in Wasser sehr leicht löslich, sehr schwer in concentrirten Alkalien, unlöslich in Aether; beim Erhitzen auf $180^{\circ}$ fängt sie an sich braun zu färben, gegen $193^{\circ}$ erfolgt rasche Zersetzung, verbunden mit Gasentwickelung und Destillation einer gelben öligen Flüssigkeit; als Rückstand bleibt eine halb verkohlte Masse.

Sie zeigt in jeder Beziehung das charakteristische Verhalten der Ammoniumverbindungen und man könnte sie als Phenyldiäthylazoniumbromid *) bezeichnen; von Alkalien wird sie nicht verändert, dagegen durch Silberoxyd und Silbersalze leicht entbromt; ersteres liefert das in Wasser leicht lösliche, alkalisch reagirende Hydroxyd. Beim Schütteln der wässerigen Lösung mit frisch gefälltem Chlorsilber wird das Brom rasch durch Chlor ersetzt und es entsteht das in Wasser ebenfalls sehr leicht lösliche Chlorid; dieses liefert mit Platinchlorid ein schwer lösliches, aus heifsem Wasser in braungelben kleinen Krystallen anschiefsendes Doppelsalz von der Formel : $\left[\mathrm{C}_{6} \mathrm{H}_{6} \mathrm{~N}_{2} \mathrm{H}_{2} \cdot\left(\mathrm{C}_{2} \mathrm{H}_{6}\right)_{8} \mathrm{Cl}_{2} \mathrm{PtCl}_{4}\right.$.

0,3774 Grm. gaben 0,1006 Pt.

$$
\begin{array}{ccc} 
& \text { Gefunden } & \text { Berechne } \\
\text { Pt } & 26,66 & 26,62 .
\end{array}
$$

Fehling'sche Lösung wird von der Substanz auch in

*) Bezüglich der Nomenclatur dieser und der nachfolgenden Verbindungen, welche einige Schwierigkeiten bietet, sehe ich mich zu folgenden Vorschlïgen veranlafst.

Die bei den Basen des Ammoniaktypus allgemein gebrüuchlichen Endungen Amin, Amid, Ammonium sollen einfach in Azin, Azid, Azonium für die betreffenden Derivate der Hydrazine umgewandelt werden. Für die Harnstoffabkömmlinge ergiebt sich darans die Bezeichnung Carbazid, Sulfocarbazid; bei Harnstoffabkömmlingen und Skureamiden, welche eine Amid- und Azidgruppe onthalten, wird diefs durch Beifügung der Sylbe nsemi“ ausgedrilickt. Der Nachtheil der Inconsequenz, welchen diese Bezeichnungsweise gegenäber der Endang nhydrazid* Carbohydrazid u. s. w. hat, scheint mir durch den Vorzug der Kürze und des Wohlklangs reicblich aufgewogen zu werden. 
der Wärme nicht verändert, eben so wenig wird dieselbe durch weiteres Kochen mit Brom- oder Jodäthyl angegriffen; basische Eigenschaften scheint dieselbe nicht mehr zu besitzen, da Verbindungen mit Salzsäure oder Schwefelsäure nicht erhalten werden konnten.

Ihre Zusammensetzung und Verhalten sind von besonderem Interesse für die Frage der Ammoniumbildung.

Bekanntlich hat A. W. Hofmann durch seine schönen Untersuchungen über die substituirten Amine mit Sicherheit nachgewiesen, dafs bei den Basen des Ammoniaktypus die Bildung von sogenannten Ammoniumverbindungen erst eintritt, wenn alle typischen, d. h. an Stickstoff gebundenen Wasserstoffatome durch Alkoholradicale ersetzt sind; man hat diesen Schlufs später auch auf die complicirteren Di- und Triamine ausgedehnt und die Ammoniumbildung theilweise als Reaction benutzt, um in diesen Verbindungen die Zahl der typischen Wasserstoffatome zu ermitteln.

Demzufolge war a priori ein gleiches Verhalten bei den Hydrazinen zu erwarten. Diese. Ansicht hat sich jedoch nicht bestätigt; vielmehr beweist die Zusammensetzung obiger Substanz in eclatanter Weise, dafs hier die Bildung von Ammoniumkörpern bereits eintritt, wenn von den drei Wasserstoffatomen der Hydrazingruppe nur eins durch Aethyl ersetzt ist und die Indifferenz derselben gegen Alkyljodüre zeigt ferner, dafs mit der Anlagerung von $\mathrm{C}_{2} \mathrm{H}_{5} . \mathrm{Br}$ der weiteren Einführung von Alkoholradicalen ein Ziel gesetzt ist.

Mit dem ersten fundamentalen Satze der Theorie der Ammoniumverbindungen, dafs dieselbe nur bei tertiären Amingruppen eintreten könne, läfst sich die Existenz dieses Körpers nichts desto weniger leicht in Uebereinstimmung bringen durch die Annahme, dafs die Anlagerung von Bromäthyl hier an die ursprüngliche Imidogruppe des Phenylhydrazins stattfindet, nachdem das letzte Wasserstoffatom derselben vorher 
durch Aethyl ersetzt worden. Dafs dem in der That so ist, geht fast mit voller Gewifsheit aus der Bildung derselben Substanz bei der Einwirkung von Bromäthyl auf Aethylphenylhydrazin hervor.

Erhitzt man ein Gemisch beider Substanzen in äquivalenten Mengen längere Zeit am Rückflufskühler, so erstarrt die Flüssigkeit allmälig zu einer weifsen, in Wasser leicht löslichen Krystallmasse, welche zum grofsen Theil aus Phenyldiäthylazoniumbromid besteht; letzteres wurde wie oben beschrieben gereinigt. Die Verbindung zeigte in jeder Beziehung dasselbe Verhalten, wie das aus Phenylhydrazin gewonnene Präparat.

Die Analyse gab dieselben Zahlen.

0,2477 Grm. gaben 25,5 CC. Stickstoff bei $10^{\circ}$ und 717 MM. Druck.

0,3793 Grm. nach der Methode von Volhard titrirt verbrauchten 15,5 CC. $1 / 10^{-N o r m a l s i l b e r l o ̈ s u n g . ~}$

$\begin{array}{ccc} & \text { Gefunden } & \text { Berechnet } \\ \text { N } & 11,64 & 11,43 \\ \text { Br } & 32,7 & 32,65 .\end{array}$

Und die von Hrn. Dr. Arz runi freundlichst ausgeführte krystallographische Untersuchung endlich, welche mit der früheren scharf übereinstimmende Resultate gab, läfst keinen Zweifel über die Identităt beider Producte. Da das Aethylphenylhydrazin die Constitution $\mathrm{C}_{6} \mathrm{H}_{5} \backslash \mathrm{H}_{5}>\mathbf{N}-\mathrm{NH}_{2}$ hat, so würde daraus für die Ammoniumverbindung bei der heute gebräuchlichen atomistischen Anschauungsweise die Formel :

resultiren.

$$
\begin{gathered}
\mathrm{C}_{6} \mathrm{H}_{6} \backslash \\
\left(\mathrm{C}_{8} \mathrm{H}_{6}\right)_{2}=\mathrm{N}-\mathrm{NH}_{2} \\
\mathrm{Br} /
\end{gathered}
$$

Dagegen scheint mir die Zusammensetzung dieser Substanz und besonders noch ihre Indifferenz gegen Alkyljodüre ein deutlicher Beweis, dafs der Eintritt der Ammoniumbildung sowohl bei den Hydrazinen, als bei den gewöhnlichen Polyaminen nicht 
als absolut zuverlässiges Erkennungsmittel für die Zahl der an Stickstoff gebundenen Wasserstoffatome angesehen werden darf; der Schlufs, der sich aus dieser Reaction mit Sicherheit ziehen läfst, ist vielmehr dahin zu modificiren, dafs die Anlagerung von je einem Molecul Jodäthyl das Vorhandensein von je einer tertiären Amingruppe anzeigt, dafs neben derselben aber noch beliebig viele intacte Imid- oder Amidgruppen vorhanden sein können.

Das Phenyldiäthylazoniumbromid ist übrigens nicht das erste, mit Sicherheit bekannte Beispiel, welches für die Richtigkeit dieser Ansicht spricht. Man weifs u. A. schon längst, dafs das Kreatinin *) direct ein Molecul $\mathrm{C}_{2} \mathrm{H}_{5} \cdot \mathrm{Br}$ fixirt und eine Ammoniumverbindung bildet, trotzdem dasselbe noch zwei intacte Imidgruppen enthält.

Auch die Schlüsse, welche A. W. Hofmann aus der Untersuchung der Ammoniumverbindungen des Rosanilins zieht, dafs in demselben nur drei typische Wasserstoffatome enthalten seien, können heute nicht mehr als zutreffend angesehen werden, seitdem Caro und $W$ anklyn **) gezeigt, dafs durch salpetrige Säure aller Stickstoff in Gasform ausgeschieden wird und später Otto Fischer und ich***) durch die Analysen der dabei zuerst entstehenden Diazoverbindung bestimmt nachgewiesen haben, dafs dieselbe drei Diazogruppen enthält. Aehnliche Verhältnisse werden sich voraussichtlich auch bei den gewöhnlichen Polyaminen der aromatischen Reihe zeigen, deren bezügliche Untersuchung in mancher Beziehung interessante Resultate verspricht, aber bis jetzt kaum in Angriff genommen worden ist.

*) Neubauer, diese Annalen 187, 288.

**) Proced. Royal Society 15, 210.

***) Berichte der deutschen chemischen Gesellschaft 9, 891. 
Harnstoffablömmlinge des Phenylhydrazins.

Bezüglich der Harnstoffbildung zeigt das Phenylhydrazin die gröfste Aehnlichkeit mit dem Ammoniak und den Aminbasen; alle Reactionen, die hier in Anwendung kommen, sind auch dort leicht auszuführen; dagegen wurden bei den Producten selbst manche auffallende und von dem Verhalten der gewöhnlichen Harnstoffe sehr abweichende Erscheinungen beobachtet. Der modificirende Einflufs der Hydrazingruppe kornmt besonders bei der Einwirkung von salpetriger Säure und noch mehr bei der eigenthümlichen Zersetzung der Sulfoharnstoffe durch Alkalien zur Geltung.

\section{Aethylphenylsemicarbazid.}

Dieser Harnstoff entsteht durch directe Vereinigung von Phenylhydrazin und Isocyansäureäther; zur Darstellung gröfserer Mengen bringt man gleiche Molecule der Agentien in nicht zu verdünnter ätherischer Lösung zusammen. Der gröfste Theil des Harnstoffs scheidet sich bald krystallinisch ab; den Rest gewinnt man durch Abdampfen des Aethers. Durch einmaliges Umkrystallisiren aus heifsem Alkohol wird der Körper in rein weirsen Blättchen von der Formel $\mathrm{C}_{6} \mathrm{H}_{5} \cdot \mathrm{N}_{\mathbf{2}} \mathrm{H}_{\mathbf{8}}$. CO.NH. $\mathrm{C}_{2} \mathrm{H}_{5}$ erhalten.

0,2587 Grm. gaben $0,574 \mathrm{CO}_{2}$ und $0,1707 \mathrm{H}_{2} \mathrm{O}$.

0,1785 " 36 CC. Stickstoff bei $6^{\circ}$ und 717 MM. Druok.

$\begin{array}{ccc} & \text { Gefunden } & \text { Berechnet } \\ \text { C } & 60,54 & 60,34 \\ \text { H } & 7,33 & 7,26 \\ \text { N } & 23,24 & 23,46 .\end{array}$

Die Substanz ist in Wasser schwer löslich, ebenso in Aether, fast unlöslich in Alkalien; von heifsem Alkohol wird sie ziemlich leicht aufgenommen, aus einer verdünnten alkoholischen Lösung wurde sie beim langsamen Verdunsten in gut ausgebildeten tafelförmigen Krystallen erhalten. Hr. Dr. 
Arzruni *) hat dieselben gemessen und theilt darüber Folgendes mit :

${ }_{n}$ Krystallsystem : monosymmetrisch.

$$
\begin{gathered}
\mathrm{a}: \mathrm{b}: \mathrm{c}=0,8268: 1: 1,1457 . \\
\beta=61^{\circ} 0^{\circ} .
\end{gathered}
$$

Beobachtete Formen : $\mathrm{m}=110=\infty \mathrm{P}, \mathrm{c}=001=$ $0 \mathrm{P}, \mathrm{p}=\overline{1} 11=+\mathrm{P}, \mathrm{q}=011=\mathrm{P} \infty$. Weirse durchsichtige Krystalle, tafelartig nach 001.

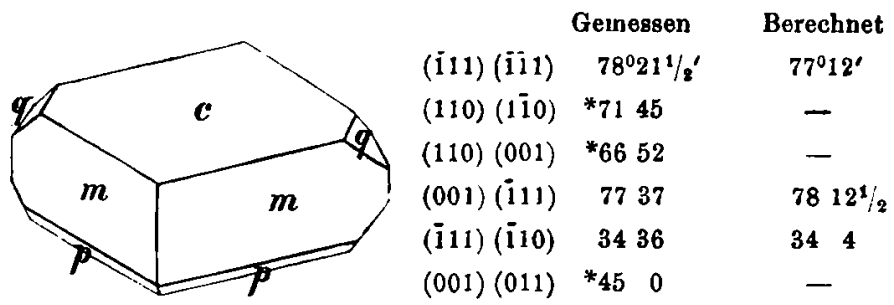

Ebene der optischen Axen senkrecht zur Symmetrieebene; erste Mittellinie im spitzen Winkel $\beta$. Durch 001 gesehen ist das Axenbild aufserhalb des Gesichtsfeldes.*

Die Substanz schmilzt bei $151^{\circ}$ und zersetzt sich erst bei sehr hoher Temperatur unter starker Gasentwickelung, wobei nur eine geringe Menge Kohle zurückbleibt. In concentrirter Salzsäure löst sie sich leicht und bildet damit ein unbeständiges Salz. Bei längerem Erhitzen mit rauchender Salzsäure im zugeschmolzenen Rohr auf $100^{\circ}$ wird sie glatt in Kohlensäure, Aethylamin und Phenylhydrazin gespalten, eben so durch längeres Kochen mit alkoholischem Kali. Die wässerige Lösung giebt mit Fehling'scher Lösung eine blauschwarze Färbung und einen eben so gefärbten flockigen Niederschlag; in verschlossenen Gefäfsen geht diese Farbe bald in Gelb über, wird jedoch beim Schütteln mit Luft wieder hergestellt, beim gelinden Erwärmen der Lōsung erfolgt schliefslich vollständige Zersetzung und die Abscheidung von Kupferoxydul. Die

*) Vgl. Groth's Zeitschr. f. Krystall. u. Min. 1877, S. 387. 
dnnkeln Flocken sind wahrscheinlich eine Kupferverbindung des Harnstoffs; ihre Bildung ist für diesen eine eben so empfindliche und charakteristische Reaction, wie die bekannte Biuretprobe.

Von besonderem Interesse ist die Veränderung der Substanz durch salpetrige Säure, wobei ein gut krystallisirendes und ziemlich beständiges Nitrosoderivat entsteht; am leichtesten wird dasselbe erhalten, wenn man die mit einem geringen Ueberschufs von rauchender Salzsäure versetzte alkoholische Lösung des Harnstoffs in der Kälte mit $\mathrm{NaNO}_{2}$ in sehr concentrirter wässeriger Lösung behandelt, nach beendeter Reaction mit Wasser fällt und das in feinen gelben Nadeln abgeschiedene Nitrosamin durch Coliren rasch von der Mutterlauge trennt. Etwa unveränderten Harnstoff, der übrigens nur bei Mangel an salpetriger Säure beigemengt sein kann, entfernt man leicht durch Auflösen des Products in verdünntem Alkali, Filtriren und Ausfällen mit Essigsäure. Einmaliges Umkrystallisiren aus warmem reinem Aceton liefert die reine Substanz in feinen gelben Nadeln, welche nur kurze Zeit im Vacuum getrocknet zur Analyse verwandt wurden. Die erhaltenen Zahlen führen zu der Formel $\mathrm{C}_{9} \mathrm{H}_{12} \mathrm{~N}_{4} \mathrm{O}_{\mathbf{2}}$.

0,1801 Grm. gaben 41,5 CC. Stickstoff bei $8^{\circ}$ und 730 MM. Druck.

$\begin{array}{rrcc}0,2315 & & 0,441 \mathrm{CO}_{2} \text { und } & 0,1268 \mathrm{H}_{2} \mathrm{O} . \\ \text { Gefụnden } & \text { Boreobnet } \\ \mathrm{C} & 51,96 & 51,92 \\ \mathrm{H} & 6,08 & 5,77 \\ \mathrm{~N} & 26,72 & 26,92 .\end{array}$

Die Reaction verläuft ganz analog der gewöhnlichen Nitrosaminbildung und die Substanz selbst zeigt in jeder Beziehung das Verhalten dieser Körper; man kann sie demzufolge als Aethylphenylnitrososemicarbazid bezeichnen.

Sie ist leicht löslich in Aceton, weniger in Alkohol, sehr schwer in Wasser, Chloroform, Benzol und Ligroin; von 
warmem Eisessig wird sie leicht, jedoch unter theilweiser Zersetzung aufgenommen. Frisch bereitet schmilat sie bei $86,5^{\circ}$, wobei schon geringe Gasentwickelung eintritt; beim Aufbewahren, besonders in verschlossenen Gefäfsen, färbt sie sich bald rothbraun und zerfliefst allmälig zu einer öligen, ziemlich intensiv riechenden Flüssigkeit; mit Phenol und Schwefelsäure giebt sie leicht die Li e berma n n'schen Farbstoffe.

Bemerkenswerth ist ihr Verhalten gegen verdünnte Alkalien; sie löst sich darin in der Kälte mit der gröfsten Leichtigkeit und wird durch Säuren unverändert wieder abgeschieden; durch den Eintritt der Nitrosogruppe und des Harnstoffrestes ist also die Basicität der Hydrazingruppe nicht allein vollständig aufgehoben, sondern in das gerade Gegentheil umgewandelt und die Verbindung zeigt ähnlich manchen complicirteren Harnstoffabkömmlingen ausgeprägt saure Eigenschaften.

Beim Kochen der alkalischen Lösung findet dagegen Zersetzung statt und der Körper zerfällt glatt in Kohlensäure, Aethylamin und Diazobenzolimid nach dem Schema :

$$
\mathrm{C}_{9} \mathrm{H}_{18} \mathrm{~N}_{4} \mathrm{O}_{2}=\mathrm{C}_{6} \mathrm{H}_{5} \cdot \mathrm{N}_{3}+\mathrm{C}_{8} \mathrm{H}_{5} \cdot \mathrm{NH}_{8}+\mathrm{CO}_{2} \text {. }
$$

Diese Reaction giebt genügenden Aufschlufs über die Constitution dieser und der vorigen Verbindung und zwar auf Grund folgender Betrachtungen. Das aus dem Phenylhydrazin durch Einwirkung von salpetriger Säure entstehende Nitrosoderivat hat unzweifelhaft die Formel $\mathrm{C}_{6} \mathrm{H}_{5} \cdot \mathrm{N}-\mathrm{NH}_{2}$ und liefert ño

beim Kochen mit Alkalien Diazobenzolimid, woraus für letzteres die Formel $\mathrm{C}_{6} \mathrm{H}_{5} . \mathrm{N}-\mathrm{N}$ hergeleitet wurde; für das Aethylily

phenylnitrososemicarbazid, dessen Spaltung in Diazobenzolimid und die übrigen Zersetzungsproducte des Harnstoffs dieser Reaction offenbar analog ist, folgt daraus mit Gewifsheit, dafs 
die NO-Gruppe ebenfalls mit dem Stickstoff der ursprünglichen Imidgruppe des Phenylhydrazins in Bindung steht, dafs mithin die Constitution der Verbindung durch die Formel $\mathrm{C}_{6} \mathrm{H}_{5}-\mathrm{N}-\mathrm{NH}$. CO.NH- $\mathrm{C}_{2} \mathrm{H}_{5}$ ausgedrückt ist; für das AethylN่o

phenylsemicarbazid ergiebt sich daraus weiter die entsprechende Formel $\mathrm{C}_{6} \mathrm{H}_{5}-\mathrm{NH}-\mathrm{NH} . \mathrm{CO} . \mathrm{NH}-\mathrm{C}_{2} \mathrm{H}_{5}$ und es ist endlich wohl kein zu weit gehender Schlufs, wenn man auf Grund dieser Thatsachen auch bei allen übrigen Hydrazinharnstoffen, für welche der directe experimentelle Beweis nicht so leicht zu erbringen ist, den Harnstoffrest mit der ursprünglichen $\mathrm{NH}_{2}$-Gruppe des Phenylhydrazins verbunden annimmt.

Zahlreiche Versuche, aus obigem Nitrosokörper durch Reduction mit Zinkstaub und Essigsäure eine Base mit drei unter einander verbundenen Stickstoffatomen zu gewinnen, waren erfolglos und es scheint hier in der That die Abspaltung der NO-Gruppe bei der Reduction, welche man früher irrthümlicher Weise als charakteristisch für die Nitrosamine angesehen hatte, nicht vermicden werden zu können.

Phenylsemicarbazid, $\mathrm{C}_{6} \mathrm{H}_{5}-\mathrm{NH}-\mathrm{NH}$. CO. $\mathrm{NH}_{2}$.

Diese Verbindung entsteht durch Einwirkung von cyansaurem Kali auf die neutralen Salze des Phenylhydrazins; zur Darstellung derselben bringt man äquivalente Mengen der Agentien in nicht zu verdünnter Lösung zusammen. In gelinder Wärme vollzieht sich die Reaction sehr rasch und der gröfste Theil des Harnstoffs fällt als wenig gefärbte Krystallmasse aus; durch Umkrystallisiren aus heifsem Wasser oder verdünntem Alkohol wird derselbe in rein weifsen Blättchen von der Formel $\mathrm{C}_{7} \mathrm{H}_{9} \mathrm{~N}_{9} \mathrm{O}$ erhalten.

$0,2252 \mathrm{Grm}$. gaben $0,46 \mathrm{CO}_{2}$ und $0,127 \mathrm{H}_{2} \mathrm{O}$.

$0,161 \quad \leadsto \quad 40,5 \mathrm{CC}$. Stickstoff bei $12^{0}$ und 713 MM. Druck. Anoalen der Chemie 190. Bd. 


$\begin{array}{ccc} & \text { Gefunden } & \text { Berechnet } \\ \text { C } & 55,7 & 55,63 \\ \text { H } & 6,26 & 5,96 \\ \text { N } & 28 & 27,81 .\end{array}$

Die Substanz ist in heifsem Wasser, Alkohol, Aceton und Holzgeist leicht löslich, schwer in kaltem Wasser, Aether, Benzol und Ligroïn. Der Schmelzpunkt liegt bei $170^{\circ}$. Beim Verdunsten der alkoholischen oder wässerigen Lösung scheidet sie sich in weifsen Krystallaggregaten von wenig charakteristischer Form ab.

Ihr gesammtes Verhalten gleicht dem der vorigen Verbindung aufs Vollständigste. Durch rauchende Salzsäure wird sie in Kohlensäure, Phenylhydrazin und Ammoniak gespalten; sie reducirt Fehling'sche Lösung in gelinder Wärme und liefert in salzsaurer Lösung mit salpetrigsaurem Natron behandelt ein in farblosen Blättchen krystallisirendes Nitrosoderivat, welches beim Kochen mit Alkalien in Diazobenzolimid, Kohlensäure und Ammoniak zerfällt und bei der Reduction mil Zinkstaub ebenfalls unter Abspaltung der NOGruppe in den Harnstoff zurückverwandelt wird.

\section{Phenylhydrazin und Schwefelkohlenstoff.}

Während Ammoniak und die primären Amine der Fettreihe sich direct mit Schwefelkohlenstoff zu Salzen der Sulfocarbaminsäure oder ihrer Derivate vereinigen, sind ähnliche Verbindungen der aromatischen Aminbasen nicht bekannt; das Anilin wird bekanntlich von Schwefelkohlenstoff nur langsam angegriffen und liefert direct unter $\mathrm{H}_{\mathrm{z}} \mathrm{S}$-Entwickelung das Sulfocarbanilid. Die primären Hydrazine der aromatischen Reihe zeigen im Gegensatz hierzu wieder ein den fetten Aminbasen ganz analoges Verhalten.

Phenylhydrazin und Schwefelkohlenstoff vereinigen sich in der Kälte schon unter starker Wärmeentwickelung zu der kry- 
stallinischen Verbindung $\left(\mathrm{C}_{6} \mathrm{H}_{5} \mathrm{~N}_{2} \mathrm{H}_{9}\right)_{2} \mathrm{CS}_{2}$, welche als phenylsulfocarbazinsaures Phenylhydrazin bezeichnet werden kann. Bei der Darstellung dieser leicht veränderlichen Substanz ist jede Temperaturerhöhung möglichst zu verineiden; man verdünnt deshalb die Base vor dem Zusatz des Schwefelkohlenstoffs mit dem vierfachen Volumen Aether, oder wendet gleich von ersterem eine dieser Verdünnung entsprechende Menge an. Unter heftigem Aufkochen der Lösung findet sofort die Ausscheidung des festen Salzes statt; dasselbe wird durch Abfiltriren und Auswaschen mit Aether sogleich rein erhalten.

Die Analyse eines nur wenige Stunden im Vacuum getrockneten Präparates gab die der Formel $\left(\mathrm{C}_{6} \mathrm{H}_{5} \cdot \mathrm{N}_{8} \mathrm{H}_{3}\right)_{8} \mathrm{CS}_{2}$ entsprechenden Werthe.

\begin{tabular}{|c|c|c|c|}
\hline \multirow[t]{5}{*}{0,2788} & $n$ & 46,5 CC. & i $18,5^{\circ}$ und 750 MM. Druck. \\
\hline & & Gefunden & Berechnet \\
\hline & $\mathbf{C}$ & 53,27 & 53,43 \\
\hline & $\mathbf{H}$ & 5,4 & 5,5 \\
\hline & $\mathbf{N}$ & 19,0 & 19,18 \\
\hline
\end{tabular}

Die Substanz ist schwer löslich in Aether, Schwefelkohlenstoff, Chloroform und Ligroïn, leicht in warmem Aceton; diese Lösung giebt mit essigsaurem Blei einen weifsen krystallinischen Niederschlag, welcher durch überschüssiges Bleisalz roth gefärbt wird und dessen Zusammensetzung nicht nit Sicherheit ermittelt wurde. Frisch bereitet schmilzt sie beim raschen Erhitzen im Capillarrohr zwischen 96 und $97^{\circ}$ unter geringer Gasentwickelung zu einer schwachgelben Flüssigkeit; bei längerem Erhitzen wird sie dagegen schon bei weit niedrigerer Temperatur, ohne zu schmelzen, vollständig zersetzt. Aus Aether krystallisirt sie beim Verdunsten in feinen sechsseitigen Tafeln oder Prismen. Was die Constitution der Verbindung betrift, so erscheint es aus ver- 
schiedenen Gründen, wenn auch nicht gerade bewiesen, so doch in hohem Grade wahrscheinlich, dafs dieselbe durch die Formel $\mathrm{C}_{6} \mathrm{H}_{5}$-NH-NH-CS.S. $\mathrm{H}_{4} \mathrm{~N}_{8} \cdot \mathrm{C}_{6} \mathrm{H}_{5}$ ausgedrückt ist.

Dafs die Anlagerung des Schwefelkohlenstoffs an die Amidogruppe des Phenylhydrazins erfolgt, kann kaum noch zweifelhaft sein, nachdem dasselbe für die gewöhnlichen Harnstoffe direct nachgewiesen ist und die in der Formel angenommene Structur der schwefelhaltigen Gruppe ist nur eine nothwendige Consequenz der modernen Anschauung über die Constitution der sulfocarbaminsauren Salze.

Eine wichtige Bestätigung erhält diese Ansicht durch die Spaltung der Verbindung mittelst Säuren in Phenylhydrazin und die freie Phenylsulfocarbazinsäure $\mathrm{C}_{6} \mathrm{H}_{5}-\mathrm{NH}-\mathrm{NH}$. CS .SH.

Das frisch bereitete und noch nicht zersetzte Salz löst sich in verdünntem wässerigem Kali leicht und ohne Farbenerscheinung; verdünnte: Schwefelsäure fällt aus dieser Lösung die Säure in feinen glänzenden Blättchen, welche in reinem Zustand ganz farblos, bei der Darstellung gröfserer Mengen aber stets durch Beimengung eines dunkeln Farbstoffs schwach grünlich gefärbt sind. Durch Abfiltriren, Abpressen, Anrühren mit möglichst wenig absolutem Alkohol und nochmalige Filtration erhält man dieselbe rein weifs. Die Analyse eines Products, welches ganz farblos war, sich in Kali ohne Farbe löste und nur einige Stunden im Vacuum getrocknet wurde, gab folgende Zahlen :

$0,3072 \mathrm{Grm}$. gaben 0,5122 $\mathrm{CO}_{9}$ und $0,124 \mathrm{H}_{2} \mathrm{O}$.

0,2092 " $0,5336 \mathrm{BaSO}_{4}$.

\begin{tabular}{|c|c|c|}
\hline & Gefunden & $\begin{array}{l}\text { Berechnet für } \\
\mathrm{C}_{6} \mathrm{H}_{3} \mathrm{~N}_{2} \mathrm{II}_{3} \cdot \mathrm{CS}_{8}\end{array}$ \\
\hline C & 45,47 & 45,65 \\
\hline $\mathbf{H}$ & 4,49 & 4,35 \\
\hline $\mathbf{s}$ & 35,03 & 34,78 . \\
\hline
\end{tabular}

Die Verbindung hat ausgesprochen saure Eigenschaften; sie löst sich in Alkalien leicht und ohne Zersetzung; gut 
charakterisirte Metallderivate habe ich indessen nicht erhalten. Die Alkalisalze können wegen ihrer Löslichkeit und Unbeständigkeit nicht isolirt werden und ein Bleisalz, welches durch Zusatz von Bleiacetat zu einer Lösung der Säure in Aceton als röthlich gefärbter krystallinischer Niederschlag erhalten wurde, schien identisch mit der Bleiverbindung der vorigen Substanz zu sein und gab bei der Analyse Zahlen, aus denen sich keine wahrscheinliche Formel berechnen liers.

Sie ist leicht lōslich in Aether, Aceton, Eisessig und Alkohol, zersetzt sich jedoch in diesen Lösungen aufserordentlich leicht; die nur einigermafsen concentrirte ätherische Lösung scheidet schon nach einigen Minuten reichliche Mengen des vorigen Salzes ab und es läfst sich in derselben eine entsprechende Menge freien Schwefelkohlenstoffs nachweisen. Dieselbe Zersetzung erleidet die Säure, wenn auch weit langsamer, in trockenem Zustande schon bei gewöhnlicher Temperatur; rasch erfolgt dieselbe beim gelinden Erwärmen, wobei jedoch der Vorgang durch secundäre Zersetzungen des zuerst gebildeten phenylsulfocarbazinsauren Phenylhydrazins complicirter wird. Beim Erhitzen der freien Säure auf $40^{\circ}$ erfolgt zunächst eine reichliche Destillation von Schwefelkohlenstoff; sobald diese beendigt, tritt der Geruch nach Schwefelwasserstoff auf, welcher beim stärkeren Erhitzen auf 80 bis $90^{\circ}$ in Strömen entweicht; die Masse schmilzt dabei theilweise und färbt sich schmutziggrün; schliefslich wird der Schwefelwasserstoff durch Ammoniak verdrängt. Als das Erhitzen auf diesem Punkte unterbrochen wurde, konnte aus dem teigartigen schmutziggrünen Rückstande durch Umkrystallisiren aus heifsem Alkohol ein Körper in farblosen kleinen Prismen isolirt werden, welcher die Zusammensetzung $\left(\mathrm{C}_{6} \mathrm{H}_{5} \cdot \mathrm{N}_{2} \mathrm{H}_{2}\right)_{2} \mathrm{CS}$ hat und mit der später beschriebenen, direct aus phenylsulfocarbazinsaurem Phenylhydrin entstehenden Substanz identisch ist. 
0,2608 Grm. gaben $0,5792 \mathrm{CO}_{2}$ and $0,135 \mathrm{H}_{2} \mathrm{O}$.

$\begin{array}{ccc} & \text { Gefunden } & \text { Berechnet } \\ \text { C } & 60,67 & 60,47 \\ \text { H } & 5,75 & 5,42 .\end{array}$

Seine Bildung erfolgt, nach dem chronologischen Auftreten der übrigen Producte zu schliefsen, offenbar in der Weise, dafs aus zwei Moleculen der Säure durch Abspaltung von Schwefelkohlenstoff zunächst letzteres Salz entsteht, welches dann weiter durch Schwefelwasserstoffverlust in die Verbindung $\left(\mathrm{C}_{6} \mathrm{H}_{5} \cdot \mathrm{N}_{2} \mathrm{H}_{2}\right)_{2} \mathrm{CS}$ übergeht.

Weit leichter wird diese natürlich aus dem phenylsulfocarbazinsauren Phenylhydrazin direct gewonnen; da dieselbe die Zusammensetzung eines Sulfoharnstoffs hat und ferner durch dieselbe Reaction wie jene entsteht, so darf man ihr wohl eine ähnliche Constitution zuschreiben und einen entsprechenden Namen geben.

\section{Diphenylsulfocarbazid.}

Zur Darstellung grôlserer Mengen wird das aus Phenylhydrazin und Schwefelkohlenstoff bereitete rohe Salz durch Abpressen und Trocknen an der Luft von Aether befreit, fein zerrieben und in nicht zu dicken Schichten im Oelbade auf 100 bis $110^{\circ}$ erhitzt; die Masse schmilzt langsam, bläht sich auf und entwickelt reichliche Mengen von Schwefelwasserstoff; die gasförmigen Zersetzungsproducte entfernt man zweckmärsig durch einen Kohlensäurestrom, befördert die Einwirkung der Wärme durch zeitweises Umrühren der teigartigen Masse und unterbricht die Operation, sobald der Schwefelwasserstoffgeruch durch Ammoniak verdrängt ist. Die bei diesem Verfahren nur wenig grünlich gefärbte Schmelze erstarrt beim Erkalten krystallinisch; dieselbe wird zerrieben und mit wenig absolutem Alkohol ausgezogen, wobei der gröfste Theil der dunkel gefärbten Nebenproducte in Lösung 
geht; durch Umkrystallisiren des fast weifsen Rückstandes aus viel heifsem Alkohol, wobei jedoch längeres Kochen möglichst zu vermeiden ist, erhält man den Harnstoff vollständig rein in farblosen harten dreiseitigen Prismen.

Die Analyse gab folgende Zahlen :

0,2522 Grm. gaben $0,5595 \mathrm{CO}_{2}$ und $0,1302 \mathrm{H}_{2} \mathrm{O}$.

0,2132 n 42 CC. Stickstoff bei $23,5^{\circ}$ und 757 MM. Druck. $0,3094 n, 0,272 \mathrm{BaSO}_{4}$.

$\begin{array}{ccc} & \text { Gefunden } & \begin{array}{c}\text { Berechnet für } \\ \left(\mathrm{C}_{8} \mathrm{H}_{5} \cdot \mathrm{N}_{8} \mathrm{H}_{9}\right)_{8} \mathrm{CS}\end{array} \\ \text { C } & 60,5 & 60,47 \\ \text { H } & 5,74 & 5,43 \\ \text { N } & 22,05 & 21,7 \\ \text { S } & 12,1 & 12,4 .\end{array}$

Die Substanz ist in Alkohol, Aceton, Chloroform, Benzol und Eisessig in der Kälte schwer löslich, leichter in der Wärme; hierbei findet jedoch je nach der Temperatur eine mehr oder weniger starke Zersetzung statt. Die Lösung in Eisessig färbt sich beim Kochen rasch grün bis dunkelroth, langsam erfolgt dieselbe Veränderung in heifsem Alkohol, Benzol oder Chloroform; sie ist bedingt durch die eigenthümliche Umwandlung des Sulfoharnstoffs in den unten beschriebenen Farbstoff. Am auffallendsten ist die Erscheinung bei einer Lösung in Anilin; letzteres nimmt die farblose Substanz beim Erwärmen init tiefgrüner, in dickeren Schichten dunkelrother Farbe auf und beim Auflösen in verdünnter Salzsäure bleibt der Farbstoff in ziemlich reinem Zustande zurück.

Dieselbe Veränderung findet ferner, wenn auch in geringerem Grade, beim blofsen Erhitzen der trockenen Substanz statt; bei $130^{\circ}$ beginnt dieselbe sich grün zu färben und schmilzt gegen $150^{\circ}$ zu einer dunkelgrünen Flüssigkeit, welche bei stärkerem Erhitzen verkohlt.

Am glattesten endlich gelingt die Bildung des Farbstoffs 
bei der Behandlung des Diphenylsulfocarbazids mit verdünnten Alkalien. Dasselbe löst sich in alkoholischer oder wässeriger Kalilauge beim gelinden Erwärmen leicht, die Flüssigkeit nimmt eine dunkelrothe Farbe an und scheidet beim Ansäuern den Farbstoff in blauschwarzen Flocken ab.

Durch Abfiltriren, Auflösen in warmem Chloroform und Fällen mit Alkohol wird derselbe in blauschwarzen, mikroscopisch feinen Nadeln erhalten.

Die Analysen verschiedener Präparate gaben übereinstimmend Zahlen, aus welchen sich die Formel $\mathrm{C}_{19} \mathrm{H}_{12} \mathrm{~N}_{4} \mathrm{~S}$ berechnet.

Diese Formel unterscheidet sich von der des Diphenylsulfocarbazids nur durch einen Mindergehalt von zwei Wasserstoff und ich lege auf dieselbe einstweilen keinen besonderen Werth, da die analytischen Differenzen sehr geringe sind und die Bildungsweise des Farbstoffs, bei welcher dio Bedingungen einer Oxydation kaum vorhanden sind, über den Verbleib dieser beiden Wasserstoffatome keinen genügenden Aufschlufs giebt; es ist vielmehr wahrscheinlich, dafs der Vorgang, welcher unter so verschiedenen Bedingungen erfolgt, auf eine moleculare Umlagerung des Diphenylsulfocarbazids zurückzuführen und der Körper selbst mit dem letzteren nur isomer ist. Es bedarf jedoch einer ausführlicheren analytischen Untersuchung, welche einstweilen aufgeschoben wurde, weil sie aufserhalb des engeren Rahmens dieser Arbeit lag, um diese Frage endgültig zu entscheiden und ich beschränke mich deshalb hier auf die kurze Beschreibung der auffallendsten Eigenschaften und Reactionen der Verbindung.

Dieselbe löst sich in ätzenden und kohlensauren Alkalien mit dunkelrother Farbe; diese Lösung färbt Wolle und Seide roth, gebeizte Zeuge dagegen nur sehr schwach; beim Reiben 
wird sie stark electrisch, ist unlöslich in Wasser, schwer in Alkohol und Aether, leichter in Chloroform löslich.

Die Lösung in Chloroform ist ausgezeichnet durch einen prachtvollen Dichroissmus; die in dickeren Schichten dunkelrothe Farbe geht beim Verdünnen in ein lebhaftes Grün über und ist so intensiv, dafs man damit die geringsten Spuren des Farbstoffs nachweisen und seine Bildung ferner neben der Kupferprobe als empfindliche Reaction auf Phenylhydrazin benutzen kann.

Von concentrirter Schwefelsäure wird der Farbstoff in der Kälte ohne Veränderung mit schön blauer Farbe gelöst, beim Erhitzen aber vollständig zerstört; in Chloroformlösung mit Brom behandelt liefert er gut krystallisirende Substitutionsproducte von prachtvoll metallischem Flächenreflex. Die alkalische Lösung wird durch Zinkstaub schon in der Kälte rasch verändert, wobei die Farbe durch Rothviolett in Weifs übergeht. An der Luft oxydirt sich die filtrirte Lösung aufserordentlich rasch, nimmt wieder die prachtvoll rothviolette Farbe an und scheidet beim Ansäuern einen neuen Farbstoff in rothen krystallinischen Flocken ab.

Kocht man dagegen die alkalische Lösung einige Zeit mit überschüssigem Zinkstaub, so findet eine tiefergehende Zersetzung statt und das farblose Filtrat oxydirt sich nicht mehr an der Luft.

Diese kurzen Angaben werden genügen, um erkennen zu lassen, dafs hier eine neue grofse Klasse von Farbstoffen vorliegt, deren Bearbeitung manche interessante Aufschlüsse über die merkwürdigen zahireichen Veränderungen der bei diesen Körpern besonders reactionsfähigen Stickstoffgruppe verspricht; im Allgemeinen erinnert das Verhalten derselben lebhaft an die B a e yer'schen Phenolfarbstoffe, oder noch mehr an die von Liebermann aus Phenol und salpetriger Säure dargestellten, bis jetzt wenig untersuchten stickstoffhaltigen 
Farbstoffe; von beiden unterscheiden sie sich jedoch wesentlich durch ihren bedeutenden Gehalt an Schwefel, der hier die Rolle des Sauerstoffs in der chromogenen Atomgruppe zu spielen scheint.

Für die Technik sind dieselben trotz ihrer leichten und wenig kostspieligen Gewinnungsweise von keiner Bedeutung, wenn es nicht gelingt, in den Derivaten oder bei den Homologen des Phenylhydrazins schönere und haltbarere Farbe zu gewinnen.

\section{Diphenylsulfosemicarbazid, $\mathrm{C}_{6} \mathrm{H}_{5} \cdot \mathrm{N}_{2} \mathrm{H}_{2} \cdot \mathrm{CS} \cdot \mathrm{NH} . \mathrm{C}_{6} \mathrm{H}_{5}$.}

Die Untersuchung dieser aus Phenylhydrazin und Phenylsenföl entstehenden Verbindung schien geeignet, darüber Aufklärung zu geben, inwiefern die eigenthümliche, beim Diphenylsulfocarbazid beobachtete Farbstoff bildung von der Zahl der Hydrazingruppen abhãngig ist.

Zur Darstellung derselben bringt man gleiche Molecule Basis und Senföl in nicht zu verdünnter alkoholischer Lösung zusammen; unter starker Wärmeentwickelung scheidet sich der Harnstoff sofort krystallinisch ab und wird durch einmaliges Umkrystallisiren aus heifsem Alkohol in rein weifsen farblosen Prismen erhalten.

Die Analyse der im Vacuum getrockneten Substanz gab folgende Zahlen :

$\begin{array}{cccc}0,2106 \text { Grm. gaben } & 0,4965 \mathrm{CO}_{2} \text { und } & 0,1075 \mathrm{H}_{2} \mathrm{O} . \\ 0,204 & \# & 32 \text { CC. Stickstoff bei } & 11,5^{\circ} \text { und } 716 \mathrm{MM} \text {. Druck. } \\ & & \text { Gefunden } & \text { Berechnet } \\ \mathrm{C} & 64,3 & 64,2 \\ \mathrm{H} & 5,67 & 5,35 \\ \mathrm{~N} & 17,57 & 17,28 .\end{array}$

Dieselbe ist unlöslich in Wasser, schwer löslich in Aether, Schwefelkohlenstoff und Ligroïn, leichter in Aceton und in heifsem Alkohol und Eisessig; aus den meisten Lōsungsmitteln 
krystallisirt sie in feinen, häufig sternförmig gruppirten Prismen. Schmelzpunkt $1 \mathbf{1 7 7}^{\circ}$; beim Reiben wird sie, wie die meisten Salze und Derivate des Phenylhydrazins, electrisch.

In verdünnten wässerigen Alkalien löst sie sich beim Erwärmen leicht, aber ohne Farbenerscheinung und wird beim Ansäuern wieder unverändert abgeschieden. Die Löslichkeit in Alkalien wird auch hier jedenfalls durch den sauermachenden Einflufs der Harnstoffgruppe veranlafst; die Beständigkeit des Körpers in dieser Lösung beweist dagegen, dafs bei der vorher besprochenen Farbstofl bildung beide Hydrazingruppen des Diphenylsulfocarbazids betheiligt sind. Durch längeres Kochen mit concentrirter Salzsāure wird die Substanz ähnlich dem Sulfocarbanilid in ihre Generatoren, Phenylhydrazin und Phenylsenföl gespalten.

Die heifse alkoholische Lösung reducirt Quecksilberoxyd sofort, färbt sich dabei dunkelroth und scheidet beim Erkalten krystallinische Flocken von derselben Farbe ab, welche nicht weiter untersucht wurden.

An die Harnstoffabkömmlinge des Phenylhydrazins schliefsen sich noch einige Verbindungen der Base mit Kohlensäure und schwefliger Säure an, durch welche die Analogie derselben mit dem Ammoniak und den Aminbasen vervollständigt wird.

\section{Phenylcarbazinsaures Phenylhydrazin.}

Phenylhydrazin absorbirt trockene Kolılensäure sehr begierig und erstarrt zu einer weifsen krystallinischen Masse; leichter noch wird die Verbindung erhalten, wenn man eine kalt gehaltene Emulsion von $1 \mathrm{Th}$. Basis und $10 \mathrm{Th}$. Wasser mit Kohlensãure sättigt; durch rasches Abfiltriren, Pressen zwischen Fliefspapier und Auswaschen mit Aether erhält man die Verbindung als rein weifse feine, weich anzufühlende Krystallmasse.

Die Analyse eines nur kurze Zeit im Vacuum getrock- 
neten Präparates gab die der Formel $\left(\mathrm{C}_{6} \mathrm{H}_{5} \cdot \mathrm{N}_{2} \mathrm{H}_{3}\right)_{2} \mathrm{CO}_{2}$ entsprechenden Werthe.

$0,2384 \mathrm{Grm}$. gaben $0,523 \mathrm{CO}_{2}$ und $0,1332 \mathrm{H}_{8} \mathrm{O}$.

$\begin{array}{cccc}0,2264 * & 43,7 \text { CC. Stickstoff bei } 19,5^{\circ} \text { und } 746 \text { MM. Druck *). } \\ & \text { Gefunden } & \text { Berechnet } \\ \text { C } & 59,83 & 60,0 \\ \text { H } & 6,2 & 6,15 \\ \text { N } & 21,73 & 21,54 .\end{array}$

Die Substanz ist in Wasser und Aether schwer löslich, leicht in Alkohol, konnte aber aus dieser Lösung nicht mehr isolirt werden; von Säuren und heifsem Wasser wird sie leicht zersetzt. An der Luft zerfliefst sie unter Kohlensäureverlust $\mathrm{zu}$ einer öligen, rothbraun gefärbten Masse; mit Kohlensäure ist sie ziemlich leicht flüchtig, reducirt Fehling'sche Lösung sofort und hat einen ziemlich intensiven, an Phenylhydrazin erinnernden Geruch.

Ihre Bildungsweise und alle Eigenschaften, welche vollstãndig dem Verhalten des carbaminsauren Ammoniaks entsprechen, machen für dieselbe die Structurformel $\mathrm{C}_{6} \mathrm{H}_{5}-\mathrm{NH}-\mathrm{NH}$. C0 .0. $\mathrm{H}_{4} \mathrm{~N}_{2} \cdot \mathrm{C}_{6} \mathrm{H}_{5}$ in hohem Grade wahrscheinlich.

\section{Phenylhydrazin und schwefige Säure.}

Schweflige Säure fällt aus der ätherischsn Lösung der Base eine weifse krystallinische Masse, welche die Zusammen-

*) Die Substanz ist mit Kohlensüure so flüchtig, dafs ich bei der Stickstoffbestimmung erst bei Anwendung folgender Vorsichtsmafsregeln die richtigen Zahlen erhielt. Die Substanz wurde mit gepulvertem Kupferoxyd in einem feinen Glasröhrchen sorgfältig gemischt, letzteres mit Kupferoxyd vollständig gefüllt und in die wie gewöhnlich beschickte Verbrennungsröhre eingeführt; nachdem die Luft durch einen raschen kalten Kohlensäurestrom verdrängt war, wurde die am hinteren Ende der Röhre befindlicho Capillare abgeschmolzen, whhrend das vordere Gasleitungarohr unter Quecksilber tauchte, dann durch vorsichtiges Aufklopfen die in dem engen Röhrchen befindliche Substanz in die Verbrennungsröbre gebracht und nun wie gewöhnlich rerbrannt. 
setzung $\mathrm{C}_{6} \mathrm{H}_{5} \cdot \mathrm{N}_{2} \mathrm{H}_{3} \cdot \mathrm{SO}_{2}$ zu haben scheint; dirselbe verliert schon bei gewöhnlicher Temperatur schweflige Säure, ohne ihr Aussehen wesentlich zu verändern und geht dabei wahrscheinlich in die Verbindung $\left(\mathrm{C}_{6} \mathrm{H}_{5} \cdot \mathrm{N}_{2} \mathrm{H}_{3}\right)_{2} \mathrm{SO}_{2}$ über; ich murs jedoch bemerken, dafs die Analysen weder für die eine, noch für die andere Formel scharf stimmende, sondern meist in der Mitte zwischen beiden liegende Zahlen gegeben haben und ich schliefse die Existenz beider Körper hauptsächlich aus dem Umstand, dafs die entsprechenden Verbindungen beim Anilin bekannt und genauer untersucht sind.

Beide Substanzen sind ziemlich unbeständig; schon beim Kochen mit Wasser entweicht schweflige Säure und es bleibt die freie Base zurück; dieselbe Zersetzung erfolgt beim Zusatz von Säuren.

\section{Amidartige Derivate des Phenylhydrazins.}

Im Phenylhydrazin lassen sich zwei Wasserstoffatome successive mit Leichtigkeit durch Säureradicale ersetzen; für das dritte Wasserstoffatom der Hydrazingruppe ist dasselbe bisher nicht gelungen. Die hierbei entstehenden Verbindungen zeigen im Allgemeinen das Verhalten der gewöhnlichen Säureamide; der Eintritt des ersten Säureradicals scheint ausschliefslich in der Amidgruppe des Hydrazins stattzufinden, wie es für einige Verbindungen durch die Umwandlung in Azo- und Diazokörper direct nachgewiesen werden konnte; über die Stellung des zweiten liegt bisher keine entscheidende Thatsache vor.

\section{Monobenzoylphenylhydrazin.}

Die Darstellung dieses Körpers erfordert einige Vorsicht; es ist dabei jeder Ueberschufs von Benzoylchlorid und erhöhte Temperatur zu vermeiden, weil sonst stets ein Gemenge von Mono- und Dibenzoylderivat erhalten wird, deren Trennung 
schwierig ist; am besten bringt man zu einer gekühlten Lösung von 2 Mol. Basis in der fünffachen Menge Aether allıälig 1 Mol. Benzoylchlorid. Neben salzsaurem Hydrazin scheidet sich der gröfste Theil des Benzoylderivats als feine weifse Krystallmasse $a b$; man filtrirt den Aether ab, um den etwaigen Ueberschufs des einen oder anderen Reagens zu entfernen, beseitigt das salzsaure Salz durch Auskochen mit Wasser und krystallisirt den Rückstand zur vollständigen Reinigung einmal aus siedendem Alkohol um, wobei die Verbindung in feinen weifsen Prismen erhalten wird.

Eine Stickstoffbestimmung gab für die bei $100^{\circ}$ getrockneten Krystalle die von der Formel $\mathrm{C}_{6} \mathrm{H}_{5} \cdot \mathrm{N}_{2} \mathrm{H}_{2} \cdot \mathrm{COC}_{6} \mathrm{H}_{5}$ verlangten Zahlen.

0,2276 Grm. gaben 28,5 CC. Stickstoff bei $20^{\circ}$ und 720 MM. Druck. Gefunden N $\quad 13,55$

Berechnet 13,21 .

Das Monobenzoylhydrazin ist in heifsem Wasser und Aether schwer löslich, ziemlich leicht in heifsem Alkohol, Aceton und Chloroform; es kystallisirt aus allen Lösungsmitteln in feinen weifsen Prismen. Schmelzpunkt 168 ; beim stärkeren Erhitzen tritt Zersetzung ein. Von verdünnter warmer Kalilauge wird die Substanz leicht gelöst und durch Säuren unverändert wieder abgeschieden. Beim längeren Erhitzen mit rauchender Salzsäure auf $100^{\circ}$ im zugeschmolzenen Rohr wird sie vollständig in Phenylhydrazin und Benzoésäure gespalten. Von besonderem Interesse ist ihre Umwandlung durch oxydirende Agentien. Versetzt man eine Lösung derselben in Chloroform mit gelbem Quecksilberoxyd, so wird dieses momentan reducirt und die Flüssigkeit färbt sich dunkelroth; Gasentwickelung ist hierbei nicht zu bemerken. Beim Verdampfen des Chloroforms hinterlälst das Filtrat ein dunkelrothes Oel, welches noch nicht im krystallisirten Zustande erhalten wurde; da dasselbe ebensowenig durch Destillation 
gereinigt werden konnte, so mulste von der Analyse Abstand genommen werden; indessen läfst das Verhalten der Substanz kaum einen Zweifel über ihre Natur. Sie ist leicht löslich in Alkohol, Aether und Chloroform, beim Erhitzen verpuff sie schwach, durch Kochen mit starken Säuren wird sie mit lebhafter Gasentwickelung vollständig zersetzt, ebenso beim längeren Kochen mit Wasser; sie verändert Fehling'sche Lösung oder andere Oxydationsmittel nicht mehr und wird durch Reduction endlich, am besten durch Zinkstaub und Essigsāure in alkoholischer Lösung, ganz glatt in das Monobenzoylphenylhydrazin zurückverwandelt. Aus alledem geht deutlich hervor, dafs die Verbindung zu letzterem in demselben Verhältnifs steht, wie das diazosulfonsaure Kali zu dem weilsen hydrazinsulfonsauren Salze; sie gehört, wie dieses, unzweifelhaft zur Klasse der Diazokörper und ist als ein Benzoylderivat des Diazobenzols aufzufassen.

Ihre Constitution wird mit Zugrundelegung der Ke kuléschen Diazobenzolformel durch das Schema $\mathrm{C}_{6} \mathrm{H}_{5} \cdot \mathrm{N}=\mathrm{N}$. CO. $\mathrm{C}_{6} \mathrm{H}_{5}$ ausgedrückt und man wird sie passend als Benzoyldiazobenzol bezeichnen.

Wie man sieht, steht die Verbindung, sowohl was ihre Constitution als ihr Verhalten betriff, in der Mitte zwischen Azo- und Diazokörpern und bildet gewissermafsen den Uebergang von den einen zu den anderen. Die Stickstoffgruppe ist wie in den Azoverbindungen beiderseitig an Kohlenstoff gebunden; die Leichtigkeit, mit welcher jedoch die Benzoylgruppe als Benzoësāure abgespalten wird, bedingt die verhältnifsmäfsig geringe Beständigkeit der Substanz.

Die Versuche, das Benzoyldiazobenzol synthetisch aus Diazobenzolsalzen und Bittermandelöl darzustellen, waren erfolglos.

Die weitere Untersuchung dieses eigenthümlichen Körpers läfst manche interessante Resultate, besonders bezüglich seiner 
Zersetzungen erwarten; vielleicht gelingt es, ähnlich den bekannten Umwandlungen der Diazoverbindungen, die Stickstoffgruppe glatt zu eliminiren und an ihre Stelle Benzoyl in den Benzolrest einzuführen, wodurch eine allgemeine Methode zur Darstellung von Ketonen gewonnen wäre.

\section{Dibenzoylphenylhydrazin.}

Dasselbe entsteht sowohl beim Erhitzen der vorigen Verbindung mit überschüssigem Benzoylchlorid auf dem Wasserbade, als auch bei der Einwirkung desselben Reagens auf das phenylhydrazinsulfonsaure Kali. Letztere Methode, durch welche die Verbindung zuerst erhalten wurde, ist zur Darstellung am meisten geeignet, da sie die Isolirung der freien Base überflüssig macht und aufserdem eine hessere Ausbeute liefert, als die andere Reaction, bei welcher die Hälfte des Hydrazins als salzsaures Salz der weiteren Einwirkung entzogen wird. Am glattesten gelingt die Operation nach folgendem Verfahren. $50 \mathrm{Th}$. des bei $100^{\circ}$ getrockneten sulfonsauren Salzes werden mit $60 \mathrm{Th}$. Benzoylchlorid und 80 bis 90 Th. Chloroform als Verdünnungsmittel auf dem Wasserbade am Rückflufskühler erhltzt, bis die Salzsäureentwickelung beendet ist. Nach Verdampfen des Chloroforms entfernt man den geringen Ueberschufs von Benzoylchlorid und die anorganischen Salze durch Auskochen mit verdünnter Sodalösung, wobei die vorher teigartige Masse krystallinisch wird, und krystallisirt das gelb gefärbte Rohproduct aus heifsem Alkohol um. Man erhält so das Dibenzoylphenylhydrazin leicht und fast quantitativ in feinen weifsen Prismen.

Die Analyse der bei $100^{\circ}$ getrockneten Krystalle gab folgende Zahlen :

1. 0,2482 Grm. gaben $0,691 \mathrm{CO}_{2}$ und $0,108 \mathrm{H}_{2} \mathrm{O}$.

0,4804 Grm. gaben 37 CC. Stickstoff bei $9,5^{\circ}$ und 756 MM. Druck. 
2. 0,2349 Grm. gaben $0,6533 \mathrm{CO}_{2}$ und $0,1105 \mathrm{H}_{2} \mathrm{O}$.

0,4482 Grm. gaben 34,5 CC. Stickstoff bei $12,5^{\circ}$ und $757 \mathrm{MM}$ Druck.

3. 0,2421 Grm. gaben $0,6729 \mathrm{CO}_{2}$ und $0,1089 \mathrm{H}_{2} \mathrm{O}$.

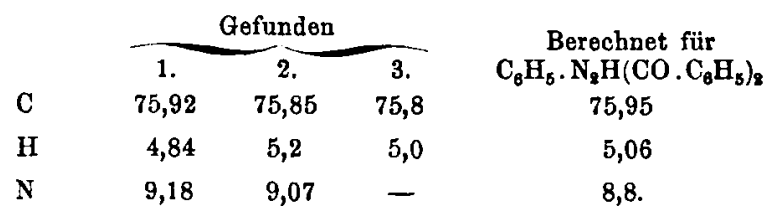

Der Vorgang wird durch folgende Gleichung veranschaulicht :

$$
\begin{gathered}
\left(\mathrm{C}_{6} \mathrm{H}_{5} \mathrm{~N}_{2} \mathrm{H}_{8} \cdot \mathrm{SO}_{8} \mathrm{~K}+\mathrm{H}_{8} \mathrm{O}\right)+2 \mathrm{C}_{6} \mathrm{H}_{5} \cdot \mathrm{COCl} \\
=\mathrm{C}_{6} \mathrm{H}_{5} \cdot \mathrm{N}_{8} \mathrm{H} \cdot\left(\mathrm{COC}_{6} \mathrm{H}_{5}\right)_{8}+\mathrm{KHSO}_{4}+2 \mathrm{HCl} .
\end{gathered}
$$

Die Substanz ist in Wasser sehr schwer löslich, ziemlich leicht in heifsem Alkohol; von verdünnten Alkalien wird sie beim Kochen langsam, aber in bedeutender Menge aufgenommen und durch Säuren unverändert wieder abgeschieden. In alkoholischer Lösung reducirt sie ammoniakalische Silberlösung sofort; beim Erhitzen mit rauchender Salzsäure im zugeschmolzenen Rohr auf $100^{\circ}$ wird sie glatt in Benzoësäure und Hydrazin gespalten. Schmelzpunkt 177 bis $178^{*}$ ); bei höherer Temperatur tritt Zersetzung ein; die Destillationsproducte bestehen zum Theil aus Benzoësäure, Bittermandelöl und Benzanilid und als Rückstand bleiben harzartige verkohlende Substanzen.

\section{Monacetylphenylhydrazin.}

Beim Vermischen von 1 Mol. Essigsäureanhydrid und 2 Mol. Phenylhydrazin findet starke Erwärmung statt, die Flüssigkeit färbt sich braun und erstarrt beim Erkalten langsam zu einer wenig gefärbten Krystallmasse; man löst das Product in heifsem Wasser, filtrirt von einer geringen Menge

*) In den Berichten der deutschen chemischen Gesellachaft 8, 591 ist in Folge eines Druckfehlers $187^{\circ}$ angegeben. 
harziger Producte ab und erhält beim Erkalten das Acetylhydrazin in feinen, fast farblosen Blättchen; durch Unkrystallisiren aus verdünntem Alkohol wird dasselbe ganz rein erhalten. Die Analyse gab die von der Formel :

$$
\mathrm{C}_{6} \mathrm{H}_{6} \cdot \mathrm{N}_{2} \mathrm{H}_{2} \cdot \mathrm{CO} \cdot \mathrm{CH}_{3}
$$

verlangten Werthe.

$0,213 \mathrm{Grm}$. gaben $0,5022 \mathrm{CO}_{2}$ und $0,13 \mathrm{H}_{2} \mathrm{O}$.

0,217 Grm. gaben 35,3 CC. Stickstoff bei $7^{0}$ und 717 MM. Druck.

$\begin{array}{ccc} & \text { Gefunden } & \text { Berechnet } \\ \text { C } & 64,3 & 64,0 \\ \text { H } & 6,78 & 6,66 \\ \text { N } & 18,6 & 18,67 .\end{array}$

Eben so leicht entsteht dieselbe Verbindung beim mehrstündigen Kochen der Base mit dem dreifachen Gewicht Eisessig; den Ueberschufs des letzteren entfernt man zum Schlufs durch Destillation bis $160^{\circ}$ und reinigt den Rückstand, wie vorher angegeben.

Das Monacetylhydrazin ist in kaltem Wasser und Aether schwer löslich, leicht in heifsem Wasser, Alkohol, Chloroform und Benzol; aus den meisten Lösungsmitteln krystallisirt es in sechsseitigen, häufig tafelartig ausgebildeten feinen Prismen von lebhaftem Seidenglanze; es schmilzt bei $128,5^{\circ}$ und destillirt bei höherer Temperatur gröfstentheils unzersetzt; beim Kochen mit concentrirten Säuren wird es in Essigsäure und Phenylhydrazin gespalten; seine wässerige Lösung reducirt Fehling'sche Lösung in gelinder Wärme sofort; in verdünnter schwefelsaurer Lösung mit salpetrigsaurem Natron behandelt liefert es ein unbeständiges Nitrosoderivat, welches in Alkalien lōslich ist und durch Säuren unverändert wieder abgeschieden wird. Beim längeren Kochen mit Essigsäureanhydrid wird es in eine syrupartige Masse verwandelt, welche wahrscheinlich ein Diacetylderivat enthält, dessen Isolirung aber bisher nicht gelang. 
Durch Oxydation mit Quecksilberoxyd in Chloroformlösung erleidet das Acetylphenylhydrazin eine ähnliche Umwandlung wie die Benzoylverbindung; die Flüssigkeit färbt sich dunkelroth und hinterläfst beim Verdampfun einen öligen Rückstand von stechendem Geruch. Derselbe ist leicht löslich in Alkohol und zersetzt sich schon beim Kochen dieser Lösung mit lebhafter Gasentwickelung. Die Substanz ist jedenfalls das dem Benzoyldiazobenzol entsprechende Acetyldiazobenzol $\mathrm{C}_{6} \mathrm{H}_{5}$. N=N.CO. $\mathrm{CH}_{3}$. Iltre weitere Untersuchung bleibt vorbehalten.

\section{Oxalyldiphenylhydrazin, $\left(\mathrm{C}_{6} \mathrm{H}_{5} \cdot \mathrm{N}_{2} \mathrm{H}_{2}\right)_{2}(\mathrm{CO})_{2}$.}

Erhitzt man ein Gemisch von 1 Mol. Oxaläther und $2 \mathrm{Mol}$. Phenylhydrazin im Oelbade auf $110^{\circ}$, so tritt bald ein lebhaftes Aufkochen der Flüssigkeit ein; es entweicht Alkohol und die Lösung erstarrt zu einer schwach gelb gefärbten, blätterigen Krystallmasse; dieselbe wurde mehrmals mil Alkohol ausgekocht, bei $100^{\circ}$ getrocknet und analysirt.

0,2695 Grm. gaben $0,611 \mathrm{CO}_{2}$ und $0,1272 \mathrm{H}_{2} \mathrm{O}$.

0,2265 Grm. gaben 41 CC. Stickstoff bei $20,5^{\circ}$ und 752 MM. Druck.

$\begin{array}{ccc} & \text { Gefunden } & \text { Berechnet } \\ \text { C } & 61,83 & 62,2 \\ \text { H } & 5,24 & 5,18 \\ \text { N } & 20,44 & 20,74 .\end{array}$

Der Körper fängt bei $260^{\circ}$ an zu erweichen und schmilzt vollständig bei 277 bis $278^{\circ}$; bei höherer Temperatur destillirt er gröfstentheils unzersetzt und das Destillat erstarrt beim Erkalten sofort krystallinisch; in den meisten Lösungsmitteln ist er schwer löslich; von concentrirter Schwefelsăure wird er in der Kälte unverändert mit rothvioletter Farbe gelöst und beim Kochen gänzlich zerstört.

- Seine Bildungsweise und Zusammensetzung entsprechen dem Oxamid aufs vollständigste. 
Phenylbenzolsulfazid, $\mathrm{C}_{6} \mathrm{H}_{5} . \mathrm{NH}-\mathrm{NH} . \mathrm{SO}_{2} \cdot \mathrm{C}_{6} \mathrm{H}_{5}$.

Versetzt man eine ätherische Lösung von Phenylhydrazin mit der berechneten Menge Benzolsulfochlorid, so scheiden sich neben salzsaurem Salz feine weifse Nadeln dieser Verbindung ab ; die abfiltrirte Krystallmasse wird zur Entfernung des Hydrochlorats mit Wasser ausgekocht und aus heifsem Alkohol umkrystallisirt.

0,2715 Grm. gaben 0,5757 $\mathrm{CO}_{2}$ und 0,1217 $\mathrm{H}_{2} \mathrm{O}$.

0,3814 Grm. gaben $40 \mathrm{CC}$. Stickstoff bei $20,5^{\circ}$ und $752 \mathrm{MM}$. Druck.

$\begin{array}{ccc} & \text { Gefunden } & \text { Berechnet } \\ \mathrm{C} & 57,84 & 58,06 \\ \mathrm{H} & 4,97 & 4,84 \\ \mathrm{~N} & 11,8 & 11,3 .\end{array}$

Die Substanz schmilzt bei $146^{\circ}$ unter geringer Gasentwickelung. In Aether ist sie schwer löslich, etwas leichter in heifsem Chloroform und Benzol, ziemlich leicht in heifsem Alkohol. Bei der Oxydation mit Quecksilberoxyd wird sie in die Diazoverbindung $\mathrm{C}_{6} \mathrm{H}_{5} . \mathrm{N}=\mathrm{N}$. $\mathrm{SO}_{2} \mathrm{C}_{6} \mathrm{H}_{5}$ umgewandelt, welche inzwischen von W. Königs*) aus Diazobenzol und Benzolsulfinsāure erhalten und ausführlicher beschrieben worden ist.

Trinitrohydrazobenzol, $\mathrm{C}_{6} \mathrm{H}_{5}$. NH-NH. $\mathrm{C}_{6} \mathrm{H}_{2}\left(\mathrm{NO}_{2}\right)_{3}$.

Diese Verbindung entsteht analog dem Pikramid aus Phenylhydrazin und Pikrylchlorid. Versetzt man eine alkoholische Lösung von $1 \mathrm{Mol}$. des letzteren mit $2 \mathrm{Mol}$. der Base, so färbt sich dieselbe sofort dunkelroth und scheidet neben salzsaurem Phenylhydrazin rothe glänzende Blättchen $a b$, welche mit Wasser ausgekocht und aus siedendem Alkohol umkrystallisirt wurden.

Die Analyse gab die obiger Formel entsprechenden Zahlen: $0,3067 \mathrm{Grm}$. gaben $0,51 \mathrm{CO}_{3}$ und 0,0816 $\mathrm{H}_{8} \mathrm{O}$.

$\begin{array}{ccc} & \text { Gefunden } & \text { Berechnet } \\ \mathrm{C} & \mathbf{4 5 , 3 5} & \mathbf{4 5 , 1 4} \\ \mathrm{H} & 2,96 & 2,82 .\end{array}$

*) Berichte der deutschen chemischen Gesellschaft 10, 1531. 
Das Trinitrohydrazobenzol schmilzt bei $181^{\circ}$ unter Gasentwickelung und verpufft beim stärkeren Erhitzen mit Feuererscheinung; es ist schwer löslich in heifsem Alhohol, Chloroform und Benzol und krystallisirt daraus beim Erkalten in glänzenden dunkelrothen Blättchen; von heilsem Eisessig und Aceton wird es leichter gelöst nnd scheidet sich daraus langsam in dunkelrothen kurzen, meist zu kugeligen Aggregaten vereinigten Prismen ab.

Dafs der Verbindung in der That obige Structurformel zukommt und dafs sie ein unsymmetrisches Trinitroderivat des Hydrazobenzols ist, geht mit Sicherheit aus ihrem Verhalten zu Reductions- und Oxydationsmitteln hervor; von ersteren wird sie in Anilin und eine nicht weiter untersuchte aromatische Base gespalten, durch letztere wird sie glatt in Trinitroazobenzol, $\mathrm{C}_{6} \mathrm{H}_{5} \cdot \mathrm{N}=\mathrm{N} \cdot \mathrm{C}_{6} \mathrm{H}_{2}\left(\mathrm{NO}_{2}\right)_{3}$, umgewandelt.

Versetzt man die heifse alkoholische Lösung mit einem Ueberschufs von gelbem Quecksilberoxyd, so wird dieses sofort geschwärzt und das Filtrat scheidet beim Erkalten das Trinitroazobenzol in dunkelrothen feinen Prismen ab.

Eine Stickstoff bestimmung gab für die bei $100^{\circ}$ getrocknete Substanz die von der Formel $\mathrm{C}_{18} \mathrm{H}_{7} \mathrm{~N}_{5} \mathrm{O}_{6}$ verlangten Werthe.

0,1846 Grm. gaben 37,8 CC. Stickstoff bei $21^{\circ}$ und 724 MM. Druck.

$\begin{array}{ccc} & \text { Gefunden } & \text { Berechnet } \\ \text { N } & 22,2 & 22,08\end{array}$

Von einer vollständigen Analyse wurde abgesehen, da die Differenzen mit den der vorigen Verbindung entsprechenden Zahlen zu gering sind, um über einen Mehr- oder Mindergehalt von zwei Wasserstoff zu entscheiden; indessen läfst die Bildungsweise und das gesammte Verhalten der Substanz keinen Zweifel über die Richtigkeit obiger Formel. Sie wird von den gewöhnlichen Oxydationsmitteln nicht weiter angegriffen, schmilzt constant bei $142^{\circ}$, also $39^{0}$ niedriger als der 
Hydrazokörper, erstarrt beim Erkalten wieder krystallinisch und verpufft bei höherer Temperatur mit Feuererscheinung. Sie ist leicht löslich in Chloroform und Benzol, etwas schwerer in heifsem Alkohol, woraus sie sich beim langsamen Erkalten in langen feinen rothen Prismen abscheidet.

Von Zinn und Salzsäure wird sie in alkoholischer Lösung leicht reducirt; es entsteht dabei Anilin und vielleicht, ana$\log$ der Zersetzung des Chrysoïdins in Anilin und Triamidobenzol *), ein Tetraamidobenzol.

Aehnliche Verbindungen entstehen aus Phenylhydrazin und Dinitrochlorbenzol und es scheint diese Reaction eine allgemeine Methode zur Darstellung der verschiedensten Substitutionsproducte des Azo- und Hydrazobenzols zu sein.

\section{Phenylhydrazin und Aldehyde.}

Das Phenylhydrazin verbindet sich mit fast allen Aldehyden unter Wasserabspaltung zu indifferenten, gut krystallisirenden Körpern und zwar im Gegensatz zu den gewöhnlichen Aminbasen meist in der Weise, dafs auf ein Molecul Aldehyd nur ein Molecul Basis in Reaction tritt; die Producte zeichnen sich zum Theil durch grofse Beständigkeit aus; andere werden dagegen schon durch Kochen mit Wasser oder beim längeren Liegen an der Luft vollständig zersetzt; alle werden beim Erhitzen mit rauchender Salzsäure in Phenylhydrazin und den betreffenden Aldehyd gespalten; genauer untersucht wurden die Verbindungen mit Bittermandelöl, Acetaldehyd und Furfurol.

\section{Benzylidenphenylhydrazin.}

Beim Zusammenbringen von Phenylhydrazin und Bittermandelöl erfolgt eine heftige Reaction, das Gemisch trübt sich

*) P. Griefs, Berichte der deutschen chemischen Gesellschaft 10, 390 und $O$. W itt, daselbst $10,654$. 
sofort durch Wasserabscheidung und erstarrt in der Kälte zu einer wenig gefärbten Krystallmasse; bei der Darstellung gröfserer Mengen ist es zweckmäfsig, die Heftigkeit der Einwirkung durch Zusatz von etwa zwei Volumen Alkohol zu mäfsigen und gleiche Molecule der Reagentien anzuwenden; die ausgeschiedene Krystallmasse wird abfiltrirt und zur weiteren Reinigung aus absolutem Alkohol umkrystallisirt.

Die Analyse gab folgende Zahlen :

$0,21 \mathrm{Grm}$. gaben $0,612 \mathrm{CO}_{2}$ und $0,1223 \mathrm{H}_{2} \mathrm{O}$.

$0,2269 \mathrm{Grm}$. gaben $29 \mathrm{CC}$. Stickatoff bei $9^{\circ}$ und 717 MM. Druck.

$\begin{array}{ccc} & \text { Gefunden } & \begin{array}{c}\text { Berechnet für } \\ \mathrm{C}_{18} \mathrm{H}_{12} \mathrm{~N}_{8}\end{array} \\ \text { C } & 79,48 & 79,59 \\ \mathrm{H} & 6,47 & 6,12 \\ \mathrm{~N} & 14,5 & 14,29 .\end{array}$

Die Reaction erfolgt nach der Gleichung :

$\mathrm{C}_{6} \mathrm{H}_{5} \cdot \mathrm{N}_{2} \mathrm{H}_{3}+\mathrm{C}_{6} \mathrm{H}_{6} \cdot \mathrm{COH}=\mathrm{C}_{6} \mathrm{H}_{6} \cdot \mathrm{N}_{8} \mathrm{H} \cdot \mathrm{CH} \cdot \mathrm{C}_{8} \mathrm{H}_{6}+\mathrm{H}_{8} \mathrm{O}$.

Die Verbindung, welche ich ihrer Zusammensetzung und Bildungsweise gemäls als Benzylidenphenylhydrazin bezeichnet hahe, schmilzt bei $152,5^{\circ}$, destillirt unzersetzt und ist leicht löslich in heifsem Alkohol, Aceton und Benzol, schwer in Aether; sie reducirt Fehling'sche Lösung auch in der Wärme nicht. Beim längeren Kochen mit rauchender Salzsäure oder besser noch mit 30 procentiger Schwefelsäure wird sie langsam in Bittermandelöl und Hydrazinbase gespalten; im reinen Zustande ist sie ganz farblos, färbt sich aber an der Luft leicht rosaroth.

Aus einer verdünnten alkoholischen Lösung wurde sie beim langsamen Verdunsten in gut ausgebildeten prismatischen Krystallen erhalten, deren Bestimmung Herr Dr. Arzruni*) freundlichst übernommen hat; derselbe theilt darüber Folgendes mit :

*) Vgl. Groth's Zoitschrift für Krystallographie und Mineralogie, 1877 , s. 388. 
Krystallsystem : monosymmetrisch.

a : b : $c=0,853: 1: 0,670$.

$\beta=87^{0} 40^{1} / \Omega^{\prime}$.

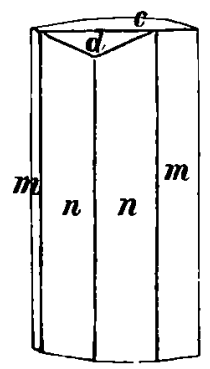

Langsäulige Krystalle von hellrosenrother Farbe.

Beobachtete Formen : $m=110=\infty P, n=210=\infty$ P 2, $\mathrm{c}=001=0 \mathrm{P}, \mathrm{d}=101=-\mathrm{P} \infty$.

Gemessen Berechnet

$(110)(1 \overline{10}) * 80^{\circ} 54^{\prime}$

$(110)(001) * 8814$

$(110)(101) \quad 6111$

$61^{\circ} 0^{\prime}$

$(210)(2 \overline{10} 04730$ circa

$4717 \frac{1}{2}$

$(001)(101) \quad * 3735$

Ebene der optischen Axen : Symmetrieebene. Durch eine Platte parallel $100=\infty \mathbf{P} \infty$ eine Axe im spitzen Axenwinkel $\beta$ sichtbar.

Aethylidenphenylhydrazin.

Zur Darstellung dieser Verbindung trägt man in eine ätherische Lösung der Base etwas mehr als die äquivalente Menge frisch destillirten Acetaldehyds ein, bis eine Probe F e hling'sche Lösung nicht mehr reducirt; der nach Abdampfen des Aethers bleibende ölige Rückstand erstarrt mit Wasser angerührt in der Kälte allmälig krystallinisch; man filtrirt, prefst die Krystallmasse zur Entfernung der öligen Beimengungen zwischen Fliefspapier und krystallisirt den Rückstand aus Ligroïn um; der gröfste Theil der gefärbten Verunreinigungen bleibt in der ersten Mutterlauge, hält aber auch beträchtliche Mengen der reinen Verbindung in Lösung, obschon dieselbe sonst in kaltem Ligroïn schwer löslich ist; durch mehrmalige Wiederholung der Operation gelingt es, ein vollständig farbloses Präparat zu gewinnen.

Die Analyse der im Vacuum getrockneten Substanz gab die für die Formel $\mathrm{C}_{6} \mathrm{H}_{5} \cdot \mathrm{N}_{2} \mathrm{H} . \mathrm{CH} \cdot \mathrm{CH}_{3}$ berechneten Zahlen : 0,2024 Grm. gaben $0,529 \mathrm{CO}_{2}$ und $0,1386 \mathrm{H}_{8} \mathrm{O}$.

0,1722 Grm. gaben 32 CC. Stickstoff bei $6^{0}$ und 706 MM. Druck. 


$\begin{array}{ccc} & \text { Gefunden } & \text { Berechnet } \\ \text { C } & 71,29 & \mathbf{7 1 , 6 4} \\ \text { H } & 7,61 & 7,46 \\ \text { N } & 21,01 & 20,9 .\end{array}$

Dieselbe ist in Aether und Alkohol leicht löslich, zerflief'st an der Luft langsam zu einer rothbraun gefärbten Flüssigkeit und wird schon beim Kochen mit Wasser oder verdünnten Säuren in Aldehyd und Hydrazin gespalten.

Ein hiervon wesentlich verschiedenes Product entsteht, wenn man das Gemisch von Phenylhydrazin und Aldehyd direct mit concentrirter Salzsäure erwärmt; die Lösung färbt sich dunkelgrün und scheidet auf Zusatz von Wasser oder Kalilauge eine gelbe, körnig-krystallinische Masse von complicirter Zusammensetzung ab. Dieselbe zeigt schwach basische Eigenschaften; sie löst sich in concentrirten Säuren, wird jedoch schon durch Wasser unverändert wieder abgeschieden; sie scheint ein durch weitere Aldehydcondensation entstandenes, wahrscheinlich den von H. Schiff*) aus Anilin erhaltenen Basen ähnliches Hydrazinderivat zu sein, wurde jedoch nicht weiter untersucht.

\section{Phenylfurfurazid.}

Furfurol wirkt ganz in derselben Weise auf die Hydrazinbase, wie die gewöhnlichen Aldehyde; wendet man äquivalente Mengen der Agentien an, so erwärmt sich das Gemisch stark, trübt sich durch Wasserabscheidung und erstarrt beim Erkalten langsam zu einer gelb gefärbten Krystallmasse; zur weiteren Reinigung löst man dieselbe direct in Aether, trocknet mit Chlorcalcium und fält mit Ligroïn.

Durch nochmalige Wiederholung dieser Operation erhält man die Verbindung schliefslich in schwach gelb gefärbten Blättchen von der Formel $\mathrm{C}_{6} \mathrm{H}_{5} \cdot \mathrm{N}_{2} \mathrm{H} . \mathrm{C}_{5} \mathrm{H}_{4} \mathrm{O}$.

*) Ann. Chem. Pharm. Suppl. 8, 343. 
0,219 Grm. gaben $0,5684 \mathrm{CO}_{2}$ und $0,115 \mathrm{H}_{2} \mathrm{O}$.

0,2082 Grm. gaben 28,8 CC. Stickstoff bei $18^{\circ}$ und 712 MM. Druck.

$\begin{array}{ccc} & \text { Berechnet } & \text { Gefunden } \\ \mathrm{C} & 70,97 & 70,78 \\ \mathrm{H} & 5,38 & 5,83 \\ \mathrm{~N} & 15,05 & 14,96 .\end{array}$

Die Reaction verläuft nach der Gleichung :

$\mathrm{C}_{6} \mathrm{H}_{5} \cdot \mathrm{N}_{2} \mathrm{H}_{3}+\mathrm{C}_{5} \mathrm{H}_{4} \mathrm{O}_{2}=\mathrm{C}_{6} \mathrm{H}_{5} \cdot \mathrm{N}_{2} \mathrm{H} \cdot \mathrm{C}_{5} \mathrm{H}_{4} \mathrm{O}+\mathrm{H}_{2} \mathrm{O}$.

Während das Furfurol sich mit Ammoniak, Anilin und voraussichtlich allen übrigen Aminbasen in complicirteren Verhältnissen verbindet, liegt hier also der einfachste Fall der Aldehydcondensation vor, und es dürfte deshalb die weitere Untersuchung dieses Products vorzüglich geeignet sein, neue Gesichtspunkte für die Aufklärung der Constitution des Furfuramids und Furfurins zu gewinnen.

Die Substanz schmilzt bei $96^{\circ}$ und zersetzt sich beim weiteren Erhitzen; sie ist leicht löslich in Alkohol und Aether, sehr schwer in Ligroïn und wird bein Kochen mit Salzsäure in Furfurol und Phenylhydrazin gespalten.

Einwirkung von Cyangas auf Phenylhydrazin.

Nach den Untersuchungen von A. W. Hofma $n n^{*}$ ) über das Cyananilin und seine Homologen war die Bildung eines ähnlichen Körpers aus Phenylhydrazin zu erwarten; in der That verbindet sich dieses aufserordentlich leicht mit gasförmigem Cyan; das hierbei entstehende Product zeigt jedoch in Zusammensetzung und Reactionen manche für die Kenntnifs der Hydrazine interessante Verschiedenheiten von dem Cyananilin.

Beim Einleiten von Cyangas in die freie Base findet starke Erwärmung statt, dieselbe bräunt sich und erstarrt nach nach einiger Zeit gröfstentheils zu einer dunkelbraunen Kry-

*) Ann. Chem. Pharm. 46, 129. 
stallmasse; die Reinigung der letzteren wird jedoch durch die verhältnifsmäfsig grofse Menge der dunkelgefärbten Nebenproducte so erschwert, dafs sich diese Methode zur Darstellung der Verbindung wenig eignet.

Noch schlechtere Resultate wurden bei dem Verfahren von Hofmann, bei der Behandlung der Base mit Cyan in alkoholischer Lösung erhalten; letztere färbt sich bald dunkelbraun, nimmt einen starken Geruch nach Blausäure an und giebt beim Fällen unit Wasser nur eine geringe Menge eines krystallinischen Körpers. Weit glatter verläuft dagegen die Reaction beim Einleiten von Cyangas in eine kalt gehaltene Emulsion von $1 \mathrm{Th}$. Phenylhydrazin und $10 \mathrm{Th}$. Wasser. Die Base verwandelt sich bald in eine gelbrothe krystallinische Masse; durch zeitweises starkes Unschütteln befördert man die Einwirkung des Reagens und unterbricht die Operation, sobald das Gas nicht weiter von der Flüssigkeit absorbirt wird. Die sofort von der Lösung getrennte und mit Wasser gut gewaschene Krystallmasse wird in etwa 20 procentigem Alkohol heifs gelöst und mit Thierkohle grö Istentheils entfärbt. Das heifse Filtrat giebt beim Erkalten eine reichliche Krystallisation von schönen gelbgefärbten Blättchen; die vollständige Reinigung der Substanz ist mit besonderen Schwierigkeiten verbunden, da die gelbe Farbe, obschon derselben nicht eigenthümlich, den Krystallen hartnäckig anhaftet und aufserdem das häufige Umkrystallisiren, besonders aus heifsen Lösungsmitteln, leicht eine theilweise Zersetzung zur Folge hat; mit nicht unbeträchtlichem Verluste gelang es erst durch wiederholtes Auflösen in Aether und Fällen mit Ligroïn, ein nahezu farbloses Präparat zu gewinnen.

Die Analyse der in Vacuum getrockneten Krystalle gab folgende Zahlen, aus welchen sich die Formel $\mathrm{C}_{6} \mathrm{H}_{5} \cdot \mathrm{N}_{2} \mathrm{H}_{3}(\mathrm{CN})_{2}$ berechnet. 
1. 0,2284 Grm. gaben $0,502 \mathrm{CO}_{2}$ und $0,1115 \mathrm{H}_{2} \mathrm{O}$.

0,1748 Grm. gaben 55,7 CC. Stickstoff bei $17^{\circ}$ und 719 MM. Druck.

2. $0,2214 \mathrm{Grm}$. gaben $0,488 \mathrm{CO}_{2}$ (Wassarbestimmung verunglückte). 0,1711 Grm. gaben $54,7 \mathrm{CC}$. Stickstoff bei $18^{\circ}$ und $712 \mathrm{MM}$. Druck.

\begin{tabular}{cccc} 
& \multicolumn{2}{c}{ Gefunden } & \\
\cline { 2 - 4 } C & 1. & 2. & Berechnet \\
H & 59,94 & 60,1 & 60 \\
N & 5,4 & - & 5 \\
& 34,97 & 34,6 & 35.
\end{tabular}

Die Verbindung entsteht also durch directe Vereinigung von 1 Mol. Phenylhydrazin und 1 Mol. Dicyan und man wird sie demgemäls passend als Dicyanphenylhydrazin bezeichnen.

Sie ist leicht löslich in Alkohol und Aether, sehr schwer in kaltem Wasser und fast unlöslich in Ligroïn. Aus heifsem Wasser krystallisirt sie in eigenthümlich gezackten, ineist aus federartig gestalteten Aggregaten bestehenden Blättchen; von heifsem Chloroform und Benzol wird sie in der Wärme leicht aufgenommen und krystallisirt daraus beim Erkalten in feinen glänzenden lanzettförmigen Blättchen; in derselben Form erhält man sie beim Fällen der ätherischen Lösung mit Ligroïn. Aus einer verdünnten, mit Chloroform und Ligroïn versetzten ätherischen Lösung wurde sie beim langsamen Verdunsten in grofsen dunkelbraunen glänzenden Krystallen erhalten, über deren Beschaffenheit Herr Dr. Arzruni mir Folgendes mittheilt :

Krystallsystem monosymmetriach (nach der optischen Untersuchung). Genaue Messungen waren bei der starken Krümmung dor Flachen nicht auszuführen; die Krystalle sind sebr wahrscheinlich Zwillinge nach einer zur Symmetrieebene senkrecht stehenden Fläche; sie sind gerade in dieser Richtung aufserordentlich leicht spaltbar. Durch die optische Untersuchung solcher dünnen Lamellen wurde das System festgestellt und aufserdem eine enorm starke Diepersion der Axen und Mittellinien für verschiedene Farben beobachtet. 
Beim Erhitzen auf $160^{\circ}$ fängt die Substanz an sich zu bräunen und schmilzt bei wenig höherer Temperatur zu einer dunkelgefärbten öligen Flüssigkeit; gleichzeitig findet geringe Gasentwickelung statt und es macht sich der Geruch nach Blausäure und Ammoniak bemerklich. Beim stärkeren Erhitzen entwickelt die geschmolzene Masse eine reichliche Menge brauner aromatischer Dämpfe und verwandelt sich gröfstentheils in glänzende Kohle.

Krystallisirte Salze der Verbindung habe ich bisher nicht erhalten; dafs sie aber basische Eigenschaften besitzt, wird wahrscheinlich durch die Beobachtung, dafs sie in verdünnter Salzsäure leicht löslich ist und erst beim Neutralisiren mit Kali wieder unverändert abgeschieden wird.

Die kalte wässerige Lösung giebt mit Fehling'scher Lösung eine blaugrüne Färbung und einen schmutziggrünen Niederschlag; beim Erwärmen verschwinden beide und es wird Kupferoxydul abgeschieden. Ammoniakalische Silberlösung wird von der Verbindung sofort reducirt. Bemerkenswerth ist ihr Verhalten in alkalischer wässeriger Lōsung; dieselbe absorbirt rasch Sauerstoff aus der Luft und färbt sich dunk elbraun. Gegen Säuren ist das Dicyanphenylhydrazin verhältnifsmälsig sehr beständig; nach vierstündigem Erhitzen mit rauchender Salzsäure im zugeschmolzenen Rohr auf $100^{\circ}$ war nur ein kleiner Theil desselben zersetzt und es hatte sich eine geringe Menge salzsaures Phenylhydrazin abgeschieden. Vollständige Zersetzung erfolgt dagegen beim mehrstündigen Erhitzen mit Wasser auf $150^{\circ}$; es bildet sich dabei ein aus heifsem Wasser in feinen weifsen Nadeln krystallisirender Körper, welcher der weiteren Untersuchung bedarf. In hohem Grade merkwürdig ist endlich die Einwirkung der salpetrigen Säure. Versetzt man eine nicht zu verdünnte schwefelsaure kalte Lösung der Verbindung mit salpetrigsaurem Natron, so scheidet sich sofort ohne Gasentwickelung ein weifser, flockig 
krystallinischer Körper ab, der keine basischen Eigenschaften mehr besitzt und möglicherweise eine Nitrosoverbindung ist, sich von den gewöhnlichen Nitrosoderivaten der Hydrazine aber durch grofse Beständigkeit unterscheidet.

Was die Constitution des Dicyanphenylhydrazins betrifft, so kann die vorstehende unvollständige Untersuchung darüber mit Sicherheit nicht entscheiden; wobl aber läfst sich dieselbe mit einiger Wahrscheinlichkeit entwickeln, wenn man die für das Cyananilin bekannten Thatsachen hier mit berücksichtigt und die daraus sich ergebenden Analogieschlüsse für statthuft bält.

Nach den Untersuchungen von A. W. Hofmann kann cs kaum zweifelhaft sein, dafs in dem Cyananilin je eine der beiden untereinander verbundenen Cyangruppen in die Amidogruppe je eines Anilins eingreift; die Umwandlung der Verbindung in Oxanilid findet nur in dieser Annahme eine ungezwungene Erklärung und man pflegt auch auf Grund dieser Reaction schon seit längerer Zeit die Constitution derselben durch die Formel :

$$
\|_{\mathrm{NH}}^{\mathrm{C}_{6} \mathrm{H}_{6} \cdot \mathrm{NH}} \stackrel{\mathrm{NH}-\mathrm{CH}}{\mathrm{C}_{6} \mathrm{H}_{5}}
$$

auszudrücken. Construirt man sich nun in ähnlicher Weise die Formel des Dicyanphenylhydrazins, so gelangt man zu dem Ausdruck :

$$
\mathrm{C}_{8} \mathrm{H}_{5}-\mathrm{N}-\mathrm{C}=\mathrm{NH}
$$

Diese Formel hat unstreitig auf den ersten Anschein viel Gewinnendes und steht mit keiner der bisher beobachteten Reactionen in Widerspruch; andererseits aber scheint es doch geboten, dieselbe nur mit Vorsicht aufzunehmen, da hier eine Atomgruppirung, für welche zur Zeit kein einziges Beispiel bekannt ist, ein aus zwei Atomen Stickstoff und zwei Atomen Kohlenstoff bestehender geschlossener Ring, angenommen ist ; ich möchte dieselbe deshalb auch nur als einen vorläufigen 
Versuch betrachtet wissen und verschiebe ihre weitere Discussion, bis die experimentelle Untersuchung die entscheidenden Thatsachen an die Hand giebt.

Einwirkung von Schwefel auf Phenylhydrazin.

Während das Anilin nach der Angabe von Merz und W e it $h{ }^{*}$ ) von Schwefel erst bei hoher Temperatur angegriffen wird und neben Schwefelwasserstoff und zahlreichen complicirteren harzartigen Producten geringe Mengen Thioanilin liefert, verläuft dieselbe Reaction beim Phenylhydrazin weit energischer und wesentlich verschieden in Betreff der Endproducte.

Erhitzt man die Base init Schwefelblumen, so erfolgt bereits bei $80^{\circ}$ eine lebhafte Einwirkung; es entweichen Ströme von Schwefelwasserstoff und Ammoniak; durch allmälig bis $130^{\circ}$ gesteigerte Temperatur wird die Reaction mit der vollständigen Zerstörung des Hydrazins in Kurzem zu Ende geführt. Zur Trennung und Erkennung der zahlreichen Producte diente folgendes Verfahren. Die flüchtigen Producte wurden gröfstentheils durch eine Kältemischung condensirt; das entweichende Gas bestand aus Stickstoff und wenig Ammoniak und Schwefelwasserstofr; in der Vorlage hatten sich grofse Mengen von Schwefelwasserstoff - Schwefelammonium als farblose Krystalimasse abgeschieden, welche beim Auflösen in Wasser ein Oel zurückliefsen, das durch Ueberführung in Anilin als Benzol erkannt wurde.

Der bei $130^{\circ}$ nicht flüchtige Rückstand enthielt viel unveränderten Schwefel, welcher beim Auflösen in Aether gröfstentheils zurückblieb; der ätherische Auszug wurde zur Isolirung von etwa vorhandenen Basen mit verdünnter Salzsäure ausgeschüttelt und die saure Lösung mit Alkalien übersältigt. Das abgeschiedene Oel bestand aus reinem Anilin und

*) Berichte der deutschen chemischen Gesellschaft 4, 384. 
zwar wurden aus $20 \mathrm{Grm}$. Hydrazin $6 \mathrm{Grm}$. desselben erhalten; beim Abdampfen der ätherischen Lösung blieb jetzt ein öliger gelbgefärbter Rückstand von schwefelhaltigen Producten, welcher von $150^{\circ}$ bis weit über $360^{\circ}$ siedete. Die Fraction von 150 bis $200^{\circ}$ enthielt beträchtliche Mengen Thiophenol, welches in das gut krystallisirende Mercaptid übergeführt wurde; der über $360^{\circ}$ siedende Theil erstarrte in einer Kältemischung theilweise und die abgeprefsten und mit Ligroīn gewaschenen Krystalle zeigten den Schmelzpunkt des Benzoldisulfids (gefunden $5^{\circ}$ ), ihre Menge war sehr gering. Das von 200 bis $320^{\circ}$ siedende Oel endlich enthielt hauptsächlich Benzolsulfid, welches durch chromsaures Kali und Schwefelsäure nach der Angabe von Stenhouse *) in Sulfobenzid übergeführt und als solches identificirt wurde.

Stickstoff, Ammoniak, Schwefelwasserstoff, Benzol, Anilin, Benzolsulf hydrat, Benzolsulfid und Benzoldisulfid waren mithin die nachweisbaren Producte der Reaction.

Die Einwirkung des Schwefels beschränkt sich demnach bei den Hydrazinen im Wesentlichen auf die stickstoffhaltige Gruppe und zeigt grofse Aehnlichkeit mit der Zersetzung dieser Basen durch Oxydation in alkalischer Lösung; es finden dabei offenbar zwei wesentlich verschiedene Vorgänge statt.

Die Bildung des Anilins einerseits kann nur durch Sprengung der Stickstoffkette erfolgen, vielleicht nach der Gleichung :

$$
2 \mathrm{C}_{8} \mathrm{H}_{5}-\mathrm{NH}-\mathrm{NH}_{2}+\mathrm{S}=2 \mathrm{C}_{8} \mathrm{H}_{5} \cdot \mathrm{NH}_{2}+\mathrm{H}_{8} \mathrm{~S}+\mathrm{N}_{2} \text {, }
$$

während die Entstehung des Benzols und der verschiedenen Schwefelverbindungen vielmehr an die gewöhnlichen Reactionen der Diazokörper erinnert. Die Stickstoffgruppe wird unter dem oxydirenden Einflufs des Schwefels entweder vollständig als freier Stickstoff, oder theilweise als Ammoniak eliminirt und es erfolgt dafür der Eintritt von Wasserstoff oder schwefelhaltiger Gruppen in den Benzolkernen.

*) Ann. Chem. Pharm. 140, 289. 


\section{Phenylhydrazin und Jod.}

Die schon mehrfach erwähnte Unbeständigkeit der primären Hydrazine gegen oxydirende Agentien kommit nicht minder deutlich in ihrem Verhalten gegen die Halogene Chlor, Brom und Jod zum Vorschein; anstatt hierbei ähnlich den gewöhnlichen aromatischen Basen Substitutionsproducte zu bilden, findet zunächst und ausschliefslich eine vollständige Zerstörung der Stickstoffgruppe statt und erst mit der Beendigung dieses Processes treten secundäre Reactionen zwischen den Zersetzungsproducten selbst und dem überschüssigen Halogen ein; bei Anwendung von Chlor und Brom ist der Vorgang wegen der Heftigkeit der Einwirkung schwer zu verfolgen; es findet dabei meist heftige Gasentwickelung und die Abscheidung dunkelgefärbter harziger Producte statt; ruhiger und einfacher verläuft die Zersetzung durch Jod.

Beim Schütteln einer wässerigen, kalten Emulsion von Phenylhydrazin mit Jod wird dieses leicht und ohne Gasentwickelung gelöst und es scheidet sich gleichzeitig Diazobenzolimid aus; der gröfste Theil der Base geht hierbei als jodwasserstoffsaures Salz in Lösung; durch abwechselnden, vorsichtigen Zusatz von Kalilauge und Jod kann man jedoch die ganze Menge derselben in Reaction ziehen. Als Endproducte derselben wurden Diazobenzolimid, Anilin und geringe Mengen jodhaltiger, wahrscheinlich substituirter Aniline erhalten.

Der Vorgang wird empirisch durch die Gleichung :

$$
2 \mathrm{C}_{6} \mathrm{H}_{6} \cdot \mathrm{N}_{2} \mathrm{H}_{3}+2 \mathrm{~J}_{2}=\mathrm{C}_{6} \mathrm{H}_{5} \cdot \mathrm{N}_{8}+\mathrm{C}_{6} \mathrm{H}_{5} \cdot \mathrm{NH}_{8}+4 \mathrm{HJ}
$$

veranschaulicht; seine weitere Interpretation bietet keine Schwierigkeiten, wenn man die Analogie desselben mit der Oxydation des Phenylhydrazins in saurer Lösung berücksichtigt; da im letzteren Falle unzweifelhaft zuerst Diazobenzol entsteht, welcher sich mit überschüssigem Hydrazin sofort zu Anilin und Diazobenzolimid umsetzt, so scheint dieselbe Annabme hier vollständig gerechtfertigt. 


\section{Secundäre aromatische Hydrazine.}

Die im Vorigen entwickelte Theorie der Hydrazine, wonach dieselben als Derivate der Verbindung $\mathrm{NH}_{2}-\mathrm{NH}_{2}$ aufzufassen sind, läfst für die zweifach-substituirten, sogenannten secundären Basen die Existenz von zwei Isomeren voraussehen, je nachdem die beiden eintretenden Gruppen nur mit einem Stickstoffatom in Bindung treten, oder auf beide gleichmäfsig vertheilt sind; zur letzteren Klasse gehören die längst bekannten Hydrazoverbindungen, wenn man für dieselben die wohlbegründete Formel R-NH-NH-R beibehält, zur ersteren die unsymmetrischen Basen von der Formel $\mathrm{R}_{2}=\mathrm{N}-\mathrm{NH}_{2}$.

Die gleichzeitige Bildung beider Isomeren war zu erwarten bei der Einwirkung von Alkylbromüren auf das Phenylhydrazin; die Isolirung derselben ist allerdings bis jetzt nicht gelungen; immerhin aber kann die Bildung der unsymmetrischen Basen bei dieser Reaction, wie die Entstehung des Diäthylphenylazoniumbromids beweist, als zweifellos angesehen werden und die Gewinnung der isomeren Hydrazokörper wird voraussichtlich nur von der Auffindung einer brauchbaren Trennungsmethode abhängen.

Weit leichter und zudem als einziges Product werden die Basen von der Formel $\mathrm{R}_{2}=\mathrm{N}-\mathrm{NH}_{2}$ aus den Nitrosaminen der secundären Amine durch Reduction mit Zinkstaub und Essigsäure erhalten. Da diese Reaction eine ganz allgemeine und für die Synthese der Hydrazine von der gröfsten Wichtigkeit ist, da ferner durch sie die zuvor wenig beachteten Nitrosamine für den Aufbau complicirterer Stickstoffverbindungen eine hervorragende Bedeutung erhalten haben, so mögen hier, bevor ich zur Beschreibung der einzelnen Versuche übergehe, eine kurze historische Uebersicht über das bezüglich dieser Körper Bekannte und im Anschlufs daran einige von mir seitdem gemachte, ergänzende Beobachtungen Platz finden. 
Die Nitrosaminbildung wurde zuerst von Werth heim *) beim Piperidin und fast gleichzeitig von Geuther**) beim Diäthylamin entdeckt; beide fanden, dafs diese Producte mit der gröfsten Leichtigkeit entweder durch gasförmige Salzsäure, oder Zinn und Salzsãure in die ursprüngliche Aminbase zurückverwandelt werden.

Die weitere Verallgemeinerung dieser Reaction ist das Verdienst von W. Hejntz ***); durch die Entdeckung der Nitrosodiglycolamidsäure und die Beobachtung, dafs die Triglycolaınidsäure nicht im Stande ist, ein ähnliches Product zu liefern, kam derselbe zu dem berechtigten Schlusse, dafs die Bildung von Nitrosoderivaten nur bei Imidbasen stattinde. Zur Stütze dieser Ansicht zeigte Heintz weiter, dafs die von $\mathrm{Geuth}$ er behauptete Entstehung von Diälhylnitrosamin aus Triäthylamin unrichtig ist und stellte in aller Schärfe das Gesetz auf, dafs bei Einwirkung der salpetrigen Säure die primären Aminbasen in die betreffenden Alkohole verwandelt werden, die secundären dagegen Nitrosoderivate liefern, während die tertiären überhaupt nicht angegriffen werden. Dieses Gesetz ist zwar heutzutage in der aromatischen Reihe dahin $\mathbf{z u}$ modificiren, dafs die primären Basen zunächst Diazoverbindungen und die tertiären die dem Nitrosodimethylanilin entsprechenden Verbindungen liefern; bezüglich der Nitrosamine speciell aber liegt bisher keine einzige mit Sicherheit bekannte Thatsache vor, welche dagegen spräche. Griefs $t$ ) giebt zwar an, dafs er aus Aethylanilin neben Aethylphenylnitrosamin geringe Mengen von salpetersaurem Diazobenzol erhalten habe, die Ent-

*) Ann. Chem. Pharm. 18\%, 75.

**) Daselbst 128, 151.

***) Daselbst 188,300 .

†) Berichte der deutschen chemischen Gesellschaft $z, 218$. 
stehung des letzteren ist jedoch unzweifelhaft auf eine geringe Verunreinigung des Aethylanilins mit Anilin zurückzuführen; bei einer Wiederholung des Versuchs mit ganz reinem, aus dem Nitrosamin dargestellten Aethylanilin habe ich keine Spur einer Diazoverbindung nachweisen können. Dasselbe gilt von einer noch zweifelhafteren Angabe von Limpricht ${ }^{*}$ ), dafs die Methylanilinsulfosäure beim Behandeln mit salpetriger Säure eine Diazoverbindung gebe, für welche er die Formel :

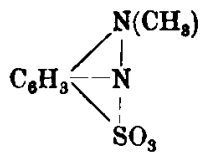

als wahrscheinlich aufstellt. Die Substanz ist wohl nichts anderes als die Diazoverbindung einer Anilinsulfosäure, deren Entstehung bei der gewöhnlichen Verunreinigung des Monomethylanilins mit Anilin leicht erklärlich ist.

Wenn somit die Ansicht von Heintz, dafs die Nitrosaminbildung nur bei Imidosubstanzen eintrete, sich in vollem Umfange bestätigt hat, so gilt darum doch nicht der umgekehrte Schlufs, dafs jede Imidgruppe dasselbe Verhalten zeigen müsse. Hierauf hat Bae yer **) zuerst aufmerksam gemacht, indem er, durch vergebliche Versuche beim Succinimid und Isatin veranlafst, als zweite Bedingung für die Nitrosaminbildung die Basicität der Imidosubstanz erklärt. Auch die Baeyer'sche Ansicht hat bis heute ihre Geltung nicht verloren. O. Fischer ***) hat zwar seitdem aus Acetanilid, Formanilid und Oxanilid Nitrosoderivate erhalten; es ist jedoch keineswegs als bewiesen anzusehen, dals diese Körper nicht noch schwach basische Eigenschaften besitzen,

\footnotetext{
*) Berichte der deutschen chemischen Gesellschaft $7,1351$.

**) Daselbst $2,682$.

***) Daselbst 9,463 und 10, 959.
} 
wenn auch beständige Salze derselben mit Säuren nicht bekannt sind; jedenfalls ist es sehr bezeichnend, dafs die Nitrosoderivate derselben weit unbeständiger als die gewöhnlichen Nitrosamine sind und dafs ferner das Benzanilid, welches bereits schwach saure Eigenschaften besitzt, nicht mehr im Stande ist, ein ähnliches Product zu bilden.

Dieselben Erfahrungen habe ich bei der Untersuchung einiger Nitrosoharnstoffe gemacht; es zeigte sich hier, dafs der Eintritt der NO-Gruppe nicht nur abhängig, sondern geradezu proportional der Basicität der Imidosubstanz ist : der einbasische Diäthylharnstoff *) nimmt nur eine Nitrosogruppe auf, unter Bildung eines vollständig indifferenten Products; dasselbe gilt von dem Aethylphenylharnstof **) und den vorher beschriebenen Harnstoffderivaten des Phenylhydrazins, bei welchen die Nitrosogruppe ausschliefslich mit der basischeren Imidgruppe des Aethylamins resp. des Hydrazins in Bindung tritt, während andererseits der indifferente Diphenylharnstoff * ) unter denselben Verhältnissen von salpetriger Säure ụberhaupt nicht angegriffen wird.

Eben so wie die Leichtigkeit der Bildung steht dann auch die Beständigkeit der Nitrosamine in naher Beziehung zur Basicität der Imidgruppe; während die Derivate des Dimethylund Diäthylamins unzersetzl destilliren und durch concentrirte Schwefelsäure erst bei hoher Temperatur zersetzt werden, sind die entsprechenden Verbindungen des Methyl- und Aethylanilins und des Diphenylamins sowohl gegen Wärme als concentrirte Säuren weit unbeständiger und noch stärker tritt diefs beim Nitrosoacetanilid und den von mir beschriebenen Nitrosoharnstoffen zum Vorschein. In directem Zusammen-

*) Berichte der deutschen chemischen Gesellschaft 8, 111.

**) Daselbst $\mathbf{9}, \mathbf{8 8 1}$. 
hang hiermit steht dann endlich auch die Leichtigkeit der Hydrazinbildung bei der Reduction mit Zinkstaub und Essigsäure. In der Fettreihe gelingt dieselbe bei vorsichtiger Operation leicht und in fast quantitativer Weise; beim $\mathrm{Me}-$ thylphenyl- und Diphenylnitrosamin wird gleichzeitig schon ein beträchtlicher Theil der Aminbase regenerirt und bei der Reduction des Nitrosoacetanilids u. s. w. konnte 0 . F is cher keine Spur der so leicht zu erkennenden Hydrazinverbindungen nachweisen.

Die ausführliche Untersuchung der aus den Nitrosaminen entstehenden secundären Hydrazine habe ich ebenfalls in der aromatischen Reihe begonnen, weil dieselbe hier bei der leichten Beschaffung des Materials und den guten Eigenschaften der Producte geringere Schwierigkeiten als in jeder anderen Gruppe bietet und weil die hier gemachten Erfahrungen die allerdings interessantere, aber auch weit mühsamere Untersuchung der fetten Hydrazinbasen wesentlich erleichtern werden.

Zufällig im Besitze gröfserer Mengen von Monomethylanilin wählte ich dazu das Methylphenylhydrazin und das wegen seiner Isomerie mit dem Hydrazobenzol doppelt interessante Diphenylhydrazin.

\section{Methylphenylhydrazin.}

Das Rohmaterial für die Darstellung dieser Base verdanke ich der Freundlichkeit der Herren Noelting und Monnet in Lyon, welche dasselbe in höchst zuvorkommender Weise speciell für meine Zwecke darstellen liefsen; das mir überlassene Präparat war ein Germenge von $25 \mathrm{pC}$. Mono- und 75 pC. Dimethylanilin. Zur Gewinnung des Nitrusamins benutzte ich die früher für das Aethylphenytnilrosamin ange- 
gebene Methode *), welche darin besteht, das Gemenge von primären, secundären und tertiären aromatischen Basen in saurer Lösung mit salpetriger Säure zu behandeln ; die ersteren liefern hierbei Diazokörper, letztere die dem Nitrosodimethylanilin entsprechenden Verbindungen, welche beide in Lösung bleiben, während das aus den secundären Basen entstehende Nitrosamin als Oel abgeschieden wird und mit Aether extrahirt werden kann.

Für Operationen in gröfserem Mafsstabe hat sich folgendes Verfahren bewährt.

3 Kilo des oben erwähnten Rohmaterials wurden in 4 Kilo Salzsäure (spec. Gew. 1,19) und 10 Kilo Wasser gelöst und das Gemisch in 20 Portionen (bei einiger Vorsicht kann man noch gröfsere Mengen in Arbeit nehmen) mit salpetrigsaurem Natron behandelt; letzteres wird in concentrirter, mit Schwefelsäure neutralisirter, wässeriger Lösung angewandt und dem durch Eiswasser gekühlten Gemisch allmälig zugesetzt. Nach jedesmaligem Zusatz ist rasches und kräftiges Umschütteln der Flüssigkeit nöthig um die frei werdende Säure sofort mit der secundären Base allenthalben in Berührung zu bringen, da andernfalls ein beträchtlicher Theil derselben zur Bildung von Nitrosodimethylanilin verbraucht wird.

Die Lösung färbt sich erst gêlb, später dunkelbraun und scheidet das Nitrosamin als dunkelgefärbtes Oel ab. Sobald ein geringer Ueberschufs von $\mathrm{NaNO}_{2}$ eingetragen und in Folge dessen die Ausscheidung des in kaltem Wasser schwer löslichen salzsauren Nitrosodimethylanilins stattindet, ist unter den angegebenen Bedingungen die Umwandlung der Imidbase eine vollständige; man extrahirt alsdann die noch saure Lōsung sofort mil Aether und erhält beim Verdampfen des letzteren das Nitrosamin in fast quantitativer Weise als

*) Berichte der deutschen chemischen Gesellschaft E, 1641. 
dunkelgefärbtes Oel; die wässerige Mutterlauge kann zur Darstellung von Nitrosodimethylanilin verwandt werden.

Eine weitere Reinigung des Products, dessen Eigenschaften von $\mathrm{P}$. Hepp *) näher beschrieben sind, ist zur Gewinnung des Hydrazins überflüssig.

Darstellung des Methylphenylhydrazins. - Die Reduction der Nitrosamine zu Hydrazinbasen ist, abgesehen von der bereits besprochenen Beständigkeit dieser Verbindungen selbst, hauptsächlich von der Wahl des Reductionsmittels, den Temperaturverhältnissen und dem Lösungsmittel abhängig. Die bei den Nitrokörpern allgemein gebräuchliche Reductionsmethode mit Zinn und Salzsäure bewirkt hier ausnahmslos die Rückbildung der ursprünglichen Aminbasen, wie diefs schon Werth heim beim Nitrosopiperidin und später Griefs beim Nitrosoäthylanilin gezeigt haben; ebenso wirken in den meisten Fällen Zink und Schwefelsäure. Die Abspaltung der Nitrosogruppe ist übrigens hierbei nicht ausschliefslich auf Rechnung der Wirkung des nascirenden Wasserstoffs zu setzen; sie wird vielmehr, wie es scheint, zum gröfsten Theil durch die Säuren selbst veranlafst, wie man diefs für die Salzsäure speciell aus den Versuchen von Geuther beim Diäthylnitrosamin weils. Vermieden werden diese nachtheiligen Bedingungen bei Anwendung von Natriumamalgam oder Zinkstaub und Essigsäure; beide Agentien sind für die Gewinnung der Hydrazine geeignet, nur verdient das letztere bei gröfseren Operationen wegen der leichteren Handhabung und gröfseren Billigkeit den Vorzug. Die Reduction der in Wasser unlöslichen aromatischen Nitrosamine gelingt am besten in alkoholischer Lösung und die bei der Reaction leicht eintretende, bedeutende Temperaturerhöhung wird möglichst

*) Berichte der deutschen chemischen Gesellschaft 10, 329. 
durch gute Kühlung der Gefälse und allmäligen Zusatz der Agentien vermieden.

Für die Darstellung gröfserer Mengen Methylphenylhydrazin aus dem rohen Nitrosamin nach dieser Methode diente folgendes Verfahren.

$30 \mathrm{Grm}$. Nitrosamin wurden mit $120 \mathrm{Grm}$. 50 procentiger Essigsäure vermischt, Alkohol bis zur vollständigen Lösung des ersteren zugesetzt und dieses Gemisch in $200 \mathrm{Grm}$. 90 procentigen, gut gekühlten Alkohols, in welchem 100 bis $150 \mathrm{Grm}$. Zinkstaub suspendirt sind, allmälig und unter Umschütteln eingetragen; auf diese Weise kann man die Tenıperatur, welche $30^{\circ}$ nicht übersteigen soll und am besten zwischen 10 und $20^{\circ}$ gehalten wird, bequem reguliren und bringt aufserdem das Nitrosamin sofort unter die zur Hydrazinbildung geeignetsten Bedingungen $d . h$. mit überschüssigem nascirendem Wasserstoff zusammen. Zinkstaub ist bei allen diesen Reductionen stets in grofsem Ueberschufs anzuwenden, da in dern Handelsproduct immer nur ein verhältnifsmäfsig geringer Theil in der feinvertheilten, besonders wirksamen, sog. molecularen Form vorhanden zu sein scheint. Nach Beendigung der Reaction werden mehrere solcher Portionen, die man zugleich verarbeitet hat, vereinigt, im Wasserbade erwärmt und heifs filtrirt. Wo keine Filterpresse zur Verfügung steht, colirt man zweckmäfsig zuerst die gröfste Menge des Zinkstaubs, prefst den Rückstand aus und entfernt die mit durchgetriebenen feineren Zinkstaubpartikelchen durch eine zweite Filtration durch Papier. Die so erhaltene klare alkoholische Lösung wird sofort in der Wärme mit ziemlich concentrirter Natronlauge übersättigl, wobei der grōfste Theil des erst abgeschiedenen Zinkoxydhydrats wieder in Lösung geht und nun entweder in einem gröfseren Dampfapparate mit Wasserdämpfen destillirt oder direct mit Aether extrahirt. Der ätherisch-alkoholische Auszug wird mit Schwefelsäure ange- 
säuert und verdampft; das Ansäuren ist nothwendig, weil sonst beträchtliche Mengen der Hydrazinbase sich mit den Alkoholdämpfen verflüchtigen. Der wässerige suure Rückstand liefert mit Natronlauge übersättigt letztere als dunkel gefärbtes 0el; dasselbe wird wieder mit Aether extrahirt, nach dem Abdampfen mit kohlensaurem Kali scharf getrocknet und über freiem Feuer destillirt, wobei man die von 190 bis $240^{\circ}$ siedende Fraction besonders auffängt; bei der ersten Destillation werden, ebenso wie beim Phenylhydrazin, nicht unbeträchtliche Mengen Ammoniak entwickelt, welche man, wie dort angegeben, entfernt. Das so erhaltene erste Destillationsproduct besteht keineswegs, wie schon das Schwanken des Siedepunkts zeigt, aus reinem Hydrazin, sondern enthält bedeutende, unter Umständen bis zu 30 pC. ansteigende Mengen von Monomethylanilin, dessen gleichzeitige Bildung bei der Reduction des Nitrosamins leicht verständlich ist. Die Entfernung des letzteren durch fractionirte Destillation wurde trotz der bedeutenden Differenz der Siedepunkte für die reinen Basen vergeblich versucht; das von Ammoniak sorgfältig befreite und mit $\mathrm{K}_{2} \mathrm{CO}_{3}$ wiederholt getrocknete Gemenge destillirte stets zwischen 195 und $230^{\circ}$, ohne auch nur die geringste Neigung $\mathrm{zu}$ constantem Siedepunkte zu zeigen und selbst die empirische Zusammensetzung der einzelnen Fractionen war nicht so sehr verschieden.

Eine bessere und leicht auszuführende, wenn auch nicht quantitative Trennungsmethode beider Basen beruht auf der verschiedenen Löslichkeit der schwefelsauren Salze in Wasser und Alkohol; das Sulfat des Hydrazins krystallisirt verhältnifsmäfsig leicht und ist in kaltem Alkohol schwer löslich. Zur Gewinnung desselben versetzt man die Rohbase mit der berechneten Menge 40 procentiger Schwefelsäure, kühit das Gemisch auf $0^{\circ} \mathrm{ab}$, verdünnt mit dem gleichen Volumen absoIuten Alkohols und filtrirt die abgeschiedene Krystallmasse 
auf einer gut wirkenden Saugpumpe; der Rückstand wird mit Alkohol gewaschen und durch Pressen zwischen Fliefspapier möglichst von der Mutterlauge befreit; der allergröfste Theil des Monomethylanilins geht hierbei, allerdings mit nicht unbeträchtlichen Mengen des Hydrazins, in Lösung. Das durch Uebersättigen der Mutterlauge mit Natronlauge wiedergewonnene Basengemenge kann man zur Darstellung einzelner Derivate der Hydrazinbase benutzen, welche leichter von dem Monomethylanilin zu trennen sind. Zur vollständigen Reinigung wird das abgeschiedene schwefelsaure Salz einmal aus siedendem absolutem Alkohol umkrystallisirt und die beim Erkalten abgeschiedene feine weilse Krystallmasse filtrirt und bei $100^{\circ}$ getrocknet. Durch Uebersättigen der wässerigen Lösung desselben mit concentrirten Alkalien erhält man die Base als fast farbloses Oel, welches nach dem Trocknen mit $\mathrm{K}_{2} \mathrm{CO}_{3}$ vollständig zwischen 220 und $225^{\circ}$ destillirte. Eine zweite Rectification lieferte ein von 222 bis $224^{\circ}$ constant siedendes Präparat, dessen Analyse die der Formel $\mathrm{C}_{6} \mathrm{H}_{5}$. $\mathrm{N}_{2} \mathrm{H}_{2} \cdot\left(\mathrm{CH}_{3}\right)$ entsprechenden Werthe ergab.

0,1928 Grm. gaben $0,487 \mathrm{CO}_{2}$ und $0,1497 \mathrm{H}_{8} \mathrm{O}$.

$\begin{array}{ccc} & \text { Gefunden } & \text { Berechnet } \\ \mathrm{C} & 68,87 & 68,85 \\ \mathrm{H} & 8,62 & 8,2 .\end{array}$

Das Methylphenylhydrazin ist frisch destillirt ein farbloses, schwach aromatisch riechendes $0 \mathrm{el}$, welches bei $-17^{\circ}$ nicht erstarrt; an der Luft färbt es sich bald durch Oxydation roth bis dunkelbraun. Der Siedepunkt liegt bei 715 MM. Barometerstand zwischen 222 und $224^{\circ}$, mithin ungefähr $10^{\circ}$ niedriger, als der des Phenylhydrazins; es ist diefs um so auffallender, als bei den gewöhnlichen Aminbasen jedes neueintretende Alkoholradical eine entsprechende Erhöhung des Siedepunkts zur Folge hat. Die Hydrazine zeigen in dieser Beziehung also eine merkwürdige Aehnlichkeit mit den sub- 
stituirten Harnstotfen, bei welchen ebenfalls, wie Michler ${ }^{*}$ ) speciell hervorgehoben hat, mit der Zahl der Alkoholradicale eine Erniedrigung des Siedepunktes eintritt.

Die Base ist in kaltem Wasser schwer löslich, etwas leichter in heifsem, mit Alkohol, Aether, Chloroform, Benzol, Schwefelkohlenstoff mischt sie sich in jedem Verhältnifs, schwieriger wird sie von kaltem Ligroïn aufgenommen, mit Wasserdämpfen ist sie ziemlich leicht flüchtig. Gegen oxydirende Agentien zeigt sie eine gröfsere Beständigkeit als das Phenylhydrazin und reducirt z. B. Fehling'sche Lösung erst in der Wärme; ähnlich verhalten sich alle unsymmetrischen secundären Hydrazine und man kann diese Reaction zur Unterscheidung von den primären Basen benutzen.

Das Methylphenylhydrazin ist eine einsäurige Base, wie die nachfolgende Analyse des Sulfats beweist; von ihren Salzen wurde nur dieses rein dargestellt und genauer untersucht; dasselbe bildet feine weifse glänzende Blättchen von der Formel $\left(\mathrm{C}_{6} \mathrm{H}_{5}, \mathrm{~N}_{2} \mathrm{H}_{2}, \mathrm{CH}_{3}\right)_{2} \mathrm{H}_{2} \mathrm{SO}_{4}$ und ist in Wasser sehr leicht, in kaltem Alkohol sehr schwer löslich.

0,3168 Grm. gaben 0,220 BaSO.

0,2025 Grm. gaben 30,5 CC. Stickstoff bei $20^{\circ}$ und 720 MM. Druck.

$\begin{array}{ccc} & \text { Gefunden } & \text { Berechnet } \\ \text { s } & 9,54 & 9,36 \\ \text { N } & 16,32 & 16,37 .\end{array}$

Die übrigen Verbindungen der Base mit Salzsäure, Salpetersäure, Platinchlorid u. s. w. sind in Wasser und Alkohol sehr leicht löslich und nur schwierig krystallisirt zu erhalten.

Ueber die Constitution der Base kann ihrer Synthese zufolge kein Zweifel herrschen; sie entsteht aus dem Nitros-

*) Berichte der deutschen chemischen Gesellschaft Q, 1665. 
amin, für welches die Formel $\mathrm{CH}_{6} \mathrm{C}_{5}>\mathrm{N}$-NO keiner weiteren Begründung bedarf, durch einfache Reduction der NO- zur

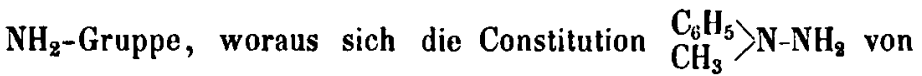
selbst ergiebt. Keine der im Nachfolgenden heschriebenen Reactionen der Substanz steht mit dieser Anschauung im Widerspruch, vielmehr liefsen sich die meisten als gewissermafsen nothwendige Consequenzen derselben voraussehen.

Wie man aus der Formel selbst ersieht, ist die als Methylphenylhydrazin hier bezeichnete Base ein unsymmetrisches zweifach - substituirtes Derivat der Atomgruppe $\mathbf{N H}_{2}-\mathrm{NH}_{2}$, oder, wenn man sie mit den gewöhnlichen Aminbasen vergleicht, die Combination einer terliären und einer primären Amingruppe; von dem Phenylhydrazin unterscheidet sie sich nur durch die Veränderung, welche die Imidgruppe durch den Eintritt eines zweiten Alkoholradicals erfahren hat und auf diesen Umstand allein läfst sich denn auch in der That das theilweise so total verschiedene Verhalten beider Basen in ungezwungener Weise zurückführen. Alle Reactionen des Phenylhydrazins, bei welchen nur die Amidogruppe in Betracht kommt, lassen sich mit Leichtigkeit auch hier ausführen, dagegen wurde keine einzige beobachtet, bei welcher die Imidogruppe der ersteren als solche direct betheiligt ist.

Methylphenylhydrazin und Alkyljodïre.

Als tertiäre Base verbindet sich das Methylphenylhydrazin direct mit einem Molecul Brom- oder Jodäthyl zu gut krystallisirenden Körpern, welche in jeder Beziehung das Verhalten der Ammoniumverbindungen zeigen und dem bereits beschriebenen Diäthylphenylazoniumbromid entsprechen; die- 
selben sind vorläufig von untergeordnetem Interesse und wurden deshalb nicht weiter untersucht.

\section{Einwirkung der salpetrigen Säure.}

Das Phenylhydrazin giebt bei der Behandlung mit salpetriger Säure zunächst ein Nitrosoderivat $\mathrm{C}_{6} \mathrm{H}_{5} \cdot \mathrm{N}_{2} \mathrm{H}_{2} \cdot \mathrm{NO}$, welches durch Wasserabspaltung aufserordentlich leicht in Diazobenzolimid übergeht; die Bildung eines ähnlichen Products aus dem secundären Methylphenylhydrazin blieb bei der Annahme obiger Structurformel, wenigstens wenn das Gesetz von Heintz auch hier noch volle Gültigkeit haben sollte, ausgeschlossen. Das Vorhandensein einer primären und einer tertiären Amingruppe liefs vielmehr nach Analogie der aromatischen und fetten Aminbasen die Entstehung einer Verbindung voraussehen, welche den Diazokörpern oder Phenolen resp. Alkoholen entsprechen würde. Der Versuch hat nun allerdings diese Erwartung nicht bestätigt, sondern es findet eine andere, sehr merkwürdige und für die Hydrazine in hohem Grade charakteristische Reaction statt, welche übrigens mit der Formel $\frac{\mathrm{C}_{6} \mathrm{H}_{5}}{\mathrm{CH}_{3}}>\mathrm{N}-\mathrm{NH}_{2}$ nicht minder leicht in Einklang gebracht werden kann.

Versetzt man die mit verdünnter Schwefelsäure angesäuerte Lösung der reinen Base mit salpetrigsaurem Natron, so erfolgt momentan die Abscheidung eines schwach gelb gefärbten Oeles und bei nicht zu verdünnten Lösungen gleichzeitig die Entwickelung eines durch geringe Mengen von Untersalpetersäure schwach gefärbten Gases; wird letzteres durch Waschen mit Kalilauge von den höheren Oxyden des Stickstoffs befreit, so besteht es aus reinem Stickoxydul; mit Luft gemengt giebt es keine rothen Dämpfe, entzündet einen glimmenden Spahn, wird von Wasser vollständig absorbirt und zeigt mit $W$ asserstoff verpufft keine Volumveränderung. 
Das erwähnte indifferente Oel ist reines Methylphenylnitrosamin, was durch die Li eberman n'sche Reaction, den Geruch und die Umwandlung in das Hydrazin leicht festgestellt werden konnte.

Stickoxydul und Methylplienylnitrosamin sind hiernach, bei vorsichtig geleiteter Operation wenigstens, die einzigen nachweisbaren Producte der Reaction, welche in der empirischen Gleichung :

$$
\mathrm{C}_{6} \mathrm{H}_{5}>\mathrm{N}_{3} \mathrm{H}_{8}+2 \mathrm{HNO}_{8}={\stackrel{\mathrm{CH}_{6}}{\mathrm{CH}_{8}}}_{\mathrm{CH}_{5}}>\mathrm{N}_{2} \mathrm{O}+\mathrm{N}_{8} \mathrm{O}+2 \mathrm{H}_{8} \mathrm{O}
$$

einen einfachen Ausdruck findet.

Versucht man nun mit Zugrundelegung obiger Structurformeln die weitere Interpretation dieses Vorganges, so liegt die Annahme am nächsten, dafs derselbe die umgekehrte Reaction der Hydrazinbildung, d. h. auf eine einfache Oxydation der Amido-- zur Nitrosogruppe zurückzuführen sei; zu diesem Zwecke würden 2 Mol. salpetriger Säure 2 At. Sauerstoff abgeben müssen und dadurch selbst zu Stickoxydul reducirt werden. So einfach diese Hypothese auf den ersten Anschein sein mag, so wenig steht sie mit anderen Thatsachen in Uebereinstimmung; zunächst würde es in hohem Grade auffallend, wenn nicht gradezu unverständlich bleiben, dafs dieselbe Reaction durch kein einziges anderes Oxydationsmittel eingeleitet werden kann. Ferner liegt für die directe Oxydation einer $\mathrm{NH}_{2}$ - zur NO-Gruppe bisher kein mit Sicherheit bekannter Analogiefall vor; man weifs zwar durch die vereinzelt dastehenden Versuche von Glaser*), dafs hei der Behandlung von Anilin mit übermangansaurem Kali geringe Mengen von Azobenzol entstehen und es wäre leicht denkbar, dafs sich lierbei vorübergehend Nitrosobenzol bildet, welches nach den Angaben von $B$ a ey e ${ }^{* *}$ ) mit überschüs-

*) Ann. Chem. Pharm. 148, 364.

**) Berichte der deutschen chemischen Gesellschaft $7,1638$. 
sigem Anilin sofort Azobenzol liefern müfste; indessen ist diese Annahme doch so wenig sicher gestellt und aufserdem die Oxydation des Anilins selbst ejn so wenig glatter Vorgang, dafs man darin kaum eine Stütze für jene Interpretation finden kann. Aus diesen und anderen, später zu erōrternden Gründen ist es in Gegentheil viel wahrscheinlicher, dafs der Vorgang complicirterer Natur ist und in verschiedenen Phasen, etwa in folgender Weise verläuft. Zunächst kann hier, ebenso wie es früher bei der Zersetzung des Phenylhydrazins durch Diazohenzolsalze angenommen wurde, unter dem Einflufs der salpetrigen Säure eine Sprengung der Hydrazingruppe etwa durch Wasseraufnahme erfolgen, wobei das Methylphenylhydrazin in Methylanilin und Hydroxylamin zerfallen würde nach der Gleichung :

$$
\stackrel{\mathrm{C}_{6} \mathrm{H}_{5}}{\mathrm{CH}_{3}}>\mathrm{N}-\mathrm{NH}_{2}+\mathrm{H}_{2} \mathrm{O}={\stackrel{\mathrm{C}}{6} \mathrm{H}_{3}}_{\mathrm{CH}_{3}}^{\mathrm{C}_{3}}>\mathrm{NH}+\mathrm{H}_{3} \mathrm{NO} .
$$

Beide Producte dieser Reaction sind aber bei Gegenwart von $\mathrm{HNO}_{2}$ nichl existenzfähig; sie werden schon in stat. nasc. weiter verändert, wobei das erstere das entsprechende Nitrosamin und das andere, wie man aus den Versuchen von V. Meyer ${ }^{*}$ ) weifs, reines Stickoxydul liefert.

Alle Versuche zur Entscheidung dieser Frage die intermediäre Bildung von Monomethylanilin nachzuweisen, waren bisher vergeblich, weil die Reaction nur in saurer Lösung eintritt und hier, wie es scheint, das Monomethylanilin leichter als das Hydrazin von salpetriger Säure angegriffen wird. Nichtsdestoweniger halte ich die letztere Erklärung einstweilen für die verständlichste und den Thatsachen am besten Rechnung tragende.

$\mathrm{Ob}$ die vorliegende, zunächst nur in der aromatischen Reihe untersuchte Reaction auch bei den übrigen secundären

*) Ann. Chem. Pharm. 1 5, 141. 
unsymmetrischen Basen der Fettgruppe u. s. w. zutrifft, murs einstweilen dahingestellt bleiben; sollte es sich jedoch bestätigen, so würden daraus für die Hydrazine bezüglich ihres Verhalten gegen salpetrige Säure ähnliche Gesetzmäfsigkeiten, wie bei den Aminbasen, zu folgern sein und es würde die letzlere zugleich als bequemes Reagens zur Unterscheidung derselben dienen können. Die primären Basen liefern bekanntlich zunächst Nitrosokörper, welche durch Wasserabspaltung leiclit in die dem Diazobenzolimid entsprechenden Verbindungen übergehen, die unsymmetrischen secundären werden in die correspondirenden Nitrosamine zurückverwandelt und die symmelrischen liefern ähnlich den primären stickstoffreichere, aber beständigere Nitrosoderivate.

Ebenso werden sich voraussichtlich die tertiären Basen verhalten; bei den quaternären dagegen darf man mit ziemlicher Sicherheit erwarten, dafs sie von dem Reagens entweder überhaupt nicht angegriffen, oder in solche Körper verwandelt werden, welehe dem von Baeyer und Caro entdeckten Nitrosodinethylanilin analog constituirt sind.

\section{Methylphenylhydrazin und Diazobenzol.}

Eine kalte wässerige Emulsion der reinen Base wird bei Zusatz von reinem salpetersaurem Diazobenzol rasch verändert; es findet dabei stets auch in verdünnter und sehr gut gekühlter Lösung geringe Gasentwickelung statt; gleichzeitig tritt der Geruch von Diazobenzolimid auf. Um secundäre Zersetzungen des Diazobenzols möglichst zu vermeiden, war es nothwendig, einen Ueberschufs der Base in Anwendung zu bringen; die Reaction verläuft alsdann aufserordentlich rasch.

Zur Isolirung der verschiedenen Producte wurde die mit Alkali übersättigte Lösung mit Aether extrahirt und dieser Auszug mit verdünnter Schwefelsäure zur Entfernung aller 
basischen Producte ausgeschüttelt; beim Abdampfen des Aethers blieb alsdann cin dunkelgefärbter, öliger Rückstand, der zum gröfsten Theile aus Diazobenzolimid bestand; nach Entfernung des letzteren durch Destillation mit Wasserdämpfen erstarrte die Masse beim Erkalten krystallinisch. Dieselbe wurde mit Ligroin gewaschen, wobei der grölste Theil der öligen Nebenproducte in Lösung ging und der krystallinische Rückstand aus Aether umkrystallisirt; die hierbei in farblosen Blättchen anschiefsende Substanz wurde durch die Analyse und sämmtliche Reactionen als identisch mit der später beschriebenen, durch Oxydation mit Quecksilberoxyd aus dem Methylphenylhydrazin entstehenden Verbindung erkannt.

Die ätherischen Mutterlaugen hinterliefsen beim Verdampfen eine stark dunkelgefärbte, halbfeste Masse, welche geringe Mengen der Verbindung von Diazobenzol mit Monomethylanilin zu enthalten schien, deren Isolirung aber nicht gelang.

Die wässerige schwefelsaure Lösung enthielt neben unverändertem Hydrazin nur Monomethylanilin; um letzteres mit Sicherheit nachzuweisen, wurde noch in einem besonderen Versuche ein Ueberschufs von Diazobenzol angewandt, um alle Hydrazinbase zu zersetzen; die schwefelsaure Lösung enthielt alsdann nur Methylanilin, welches leicht durch die bekannten Reactionen identificirt werden konnte.

Sieht man also von der Bildung des indifferenten krystallinischen Körpers ab, welcher jedenfalls durch die oxydirende Wirkung der Salpetersäure entstanden ist, so sind Diazobenzolimid und Monomethylanilin die wesentlichsten Producte der Reaction, welche durch die Gleichung :

$\left(\begin{array}{c}\mathrm{C}_{6} \mathrm{H}_{8} \\ \mathrm{CH}_{8}\end{array}\right) \cdot \mathrm{N}-\mathrm{NH}_{8}+\mathrm{C}_{6} \mathrm{H}_{8} \cdot \mathrm{N}_{8} \cdot \mathrm{NO}_{8}=\left(\begin{array}{c}\mathrm{C}_{6} \mathrm{H}_{5} \\ \mathrm{CH}_{8}\end{array}\right) \mathrm{NH}+\mathrm{C}_{6} \mathrm{H}_{8} \cdot \mathrm{N}_{8}+\mathrm{HNO}_{8}$ veranschaulicht wird. 
Die gleichzeitige Bildung eines dem Diazoamidobenzol ähnlichen Derivates der Hydrazinbase wurde hier eben so wenig, wie beim Phenylhydrazin, beobachtet; im Gegentheil hat der ganze Vorgang die gröfste Aehnlichkeil mil dem dort beschriebenen und es spricht diese Uebereinstimmung nachdrücklich für die Annahme, dafs hier wie dort eine Sprengung der Hydrazingruppe etwa in der früher angenommenen Weise durch Wasseraufnahme stattindet.

Bis zu einem gewissen Grade entscheidend für diese Ansicht wird das Verhalten der tertiären Hydrazine gegen Diazobenzol sein, deren jedenfalls gröfsere Beständigkeit die Bildung der dem Diazoamidobenzol entsprechenden Verbindungen erwarten läfst.

Derivate des Methylphenylhydrazins.

Die Untersuchung der durch Einführung von Säureradicalen oder Harnstoffgruppen entstehenden Abkömmlinge des Methylphenylhydrazins, welche gröfstentheils vorläufig nur ein untergeordnetes Interesse haben, wurde wegen der Kostbarkeit des Materials nicht in so ausgedehnter Weise unternommen, wie diefs beim Phenylhydrazin geschehen ist; durch qualitative Versuche wurde indessen festgestellt, dafs die meisten Reactionen, welche bei den gewöhnlichen Aminbasen für die Darstellung dieser Körper bekannt sind, auch bier in Anwendung kommen können. Benzoylchlorid liefert ein leicht krystallisirendes Säureamid; mit Bittermandelöl verbindet sich die Base unter Wasserabspaltung zu einem beständigen, gut charakterisirten Körper ; Essigsäureanhydrid und Isocyansäureäther wirken energisch auf dieselbe ein; mit Schwefelkohlenstoff verbindet sie sich in der Kälte nicht, beim Erhitzen entweicht Schwefelwasserstoff und das Gemisch erstarrt krystallinisch. 
Genauer untersucht wurden nur einige Harnstoffabkömmlinge, zu deren Darstellung man am besten das rohe, durch Reduction des Nitrosamins erhaltene Basengemenge benutzt, da ihre Reinigung leichter und mit geringerem Verluste als die Gewinnung der reinen Base gelingt.

\section{Methylphenylsemicarbazid $\underset{\mathrm{CH}_{3}}{\mathrm{CH}_{3} \mathrm{H}_{5}}>\mathrm{N}-\mathrm{NH}-\mathrm{CO}-\mathrm{NH}_{2}$.}

Diese Verbindung scheidet sich als dunkelbraunes, beim Erkalten allmälig krystallinisch erstarrendes Oel ab, wenn man eine schwach salzsaure concentrirte Lösung der Rohbase mit der äquivalenten Menge von reinem Kaliumcyanat versetzt.

Die abfiltrirte und zwischen Fliefspapier geprefste Krystallmasse wird zur weiteren Reinigung in möglichst wenig heifsem Benzol gelöst; beim Erkalten krystallisirt ein Theil derselben aus, den Rest fâllt man mit Aether, wobei die dunkelroth gefärbten Mutterlaugen einen nur geringen Theil des Harnstoffs zurückhalten. Durch Wiederholen der Operation erhält man den Harnstoff als blendend weifse, feine Krystallmasse. Zur Analyse wurde die Substanz bei $100^{\circ}$ getrocknet.

0,2083 Grm. gaben $0,447 \mathrm{CO}_{2}$ und $0,1355 \mathrm{H}_{8} \mathrm{O}$.

$0,1701 \mathrm{Grm}$. gaben $39,5 \mathrm{CC}$. Stickstoff bei $13^{\circ}$ und $711 \mathrm{MM}$. Druck.

$\begin{array}{ccc} & \text { Gefunden } & \begin{array}{c}\text { Berechnet } \\ \text { für } \mathrm{C}_{8} \mathrm{H}_{12} \mathrm{~N}_{3} \mathrm{O}\end{array} \\ \mathrm{C} & 58,52 & 58,18 \\ \mathrm{H} & 7,2 & 6,66 \\ \mathrm{~N} & 25,62 & 25,46 .\end{array}$

Die Substanz ist in heifsem Wasser ziemlich leicht löslich, weit schwieriger in kaltem Wasser, Aether und Ligroin, sehr leicht aber in Alkohol und heifsem Benzol. Von concentrirter warmer Salzsäure wird sie leicht aufgenommen und es scheidet sich beim Erkalten ein unbestāndiges Hydrochlorat in feinen weifsen Krystallen ab; beim längeren Erhitzen mit rauchender Salzsäure im zugeschmolzenen Rohr auf $100^{\circ}$ wird 
sie in Ammoniak, Kohlensäure und Hydrazin gespalten; gleichzeitig färbt sich die Lösung in Folge einer geringen Zersetzung violettroth. Schmelzpunkt $133^{\circ}$.

Fehling'sche Lösung wird von der Verbindung auch in der Wärme nicht verändert; dagegen wirkı salpetersaures Silber beim Kochen noch oxydirend auf dieselbe. Bei der Behandlung mit salpetriger Säure wird sie ähnlich den Harnstoffabkömmlingen des Phenylhydrazins in ein stickstoffreicheres Nitrosoderivat verwandelt. Zur Darstellung des letzteren wird eine gut gekühlte und mit etwas mehr als der berechneten Menge rauchender Salzsäure versetzte alkoholische Lösung des Harnstoffs allmälig mit einem Ueberschurs von salpetrigsaurem Natron in sehr concentrirter wässeriger Lösung versetzt. Auf Zusatz von Wasser scheidet sich dann die Nitrosoverbindung in feinen goldglänzenden Blättchen $a b$, welche nach dem Abfiltriren und Waschen mit Wasser fast chemisch rein sind. Das zur Analyse verwandte Präparat war nochmals in Alkohol in gelinder Wärme gelöst und mit Wasser gefällt worden.

0,194 Grm. gaben 50,5 CC. Stickstoff bei $13^{\circ}$ und 712 MM. Druck.

$\begin{array}{ccc} & \text { Gefunden } & \begin{array}{c}\text { Berechnet } \\ \text { für } \mathrm{C}_{8} \mathrm{H}_{10} \mathrm{~N}_{6} \mathrm{O}_{2}\end{array} \\ 28,8 & 28,86\end{array}$

Die Verbindung ist unzweifelhaft ein Nitrosoderivat des Methylphenylsemicarbazids und ihre Constitution ist durch die Formel $\underset{\text { No }}{\mathrm{CH}_{6} \mathrm{H}_{5}}>\mathrm{N}-\mathrm{N}-\mathrm{CO} . \mathrm{NH}_{2}$ ausgedrückt. Mit Phenol und

Schwefelsäure giebt sie die Liebermann'schen Farbstoffe. Sie schmilzt bei $\mathbf{7 7}^{\circ}$ unter geringer Gasentwickelung und verwandelt sich in ein dunkelgefärbtes $0 \mathrm{el}$, welches nicht weiter untersucht wurde.

Alle Versuche, in dieser Verbindung die NO-Gruppe zu reduciren, um später durch Abspaltung der Harnstoffgruppe 
eine Base ${\stackrel{\mathrm{C}}{6} \mathrm{H}_{5}}_{\mathrm{CH}_{3}}^{\mathrm{H}_{3}}>\mathrm{N}-\mathrm{NH}-\mathrm{NH}_{2}$ zu gewinnen, sind bisher ebenso wie bei den entsprechenden Verbindungen des Phenylhydrazins an der Unbeständigkeit der Substanz selbst gescheitert und es wurde als einziges Product der regenerirte Harnstoff erhalten; ich werde dieselben jedoch unter veränderten Bedingungen wieder aufnehmen.

\section{Methyldiphenylsulfosemicarbazid $\begin{aligned} & \mathrm{C}_{6} \mathrm{H}_{5} \\ & \mathrm{CH}_{3}\end{aligned}$ N-NH CS . NH . $\mathrm{C}_{6} \mathrm{H}_{5}$.}

Beim Vermischen von 1 Mol. reinem Methylphenylhydrazin und 1 Mol. Phenylsenföl tritt starke Erwärmung ein und beim Erkalten erstarrt die Masse vollständig. Wendet man statt der reinen Base das Rohproduct an, so ist es besser, das Gemenge sofort mit dem 1 bis 2 fachen Volumen Alkohol zu versetzen; nach einiger Zeit scheidet sich dann der Sulfoharnstoff gröfstentheils in schönen, fast farblosen Krystallen ab; derselbe wird am besten aus siedendem Alkohol umkrystallisirt.

0,2267 Grm. gaben 34,5 CC. Stickstoff bei $14^{0}$ und 709 MM. Druck.

$\begin{array}{ccc} & \text { Berechnet } \\ \mathrm{N} & 16,68 & \text { für } \mathrm{C}_{14} \mathrm{H}_{16} \mathrm{~N}_{3} \mathrm{~S} \\ 16,34\end{array}$

Die Substanz ist in heifsem Alkohol, Chloroform und Benzol leicht löslich, schwer in kaltem Alkohol und Aether. Schmelzpunkt 1540. In Chloroformlösung wird sie beim Kochen durch gelbes Quecksilberoxyd entschwefelt ; die Producte der Reaction wurden nicht weiter untersucht.

\section{Oxydation des Methylphenylhydrazins.}

Nächst der Einwirkung der salpetrigen Säure ist das Verhalten gegen oxydirende Agentien wohl die empfindlichste und sicherste Reaction zur Unterscheidung der primären und secundären Hydrazinbasen. Es ist bereits erwähnt, dafs das 
Methylphenylhydrazin von Fehling'scher Lösung erst in der Wärme angegriffen wird und dafs man diese Erscheinung zur Erkennung der Base neben Phenylhydrazin, welches schon in der Kälte vollstăndig zerstört wird, benutzen kann; noch auffallender kommt dieser Unterschied in den Zersetzungsproducten zum Vorschein. Die beim Phenylhydrazin beschriebene Bildung von Diazobenzol und dessen Derivaten oder von Benzol und Anilin wurde hier in keinem Falle beobachtet und es ist diefs um so erklärlicher, als die dazu erforderliche $\mathbf{A b}$ spaltung der Methylgruppe unter dem Einflufs der hier verwandten 0xydationsmittel kaum zu erwarten war.

Erwärmt man die wässerige Lösung der Base mit einem Ueberschufs von Fehling'scher Lösung, so erfolgt eine starke Gasentwickelung und gleichzeitig die Abscheidung von Kupferoxydul; nach beendeter Einwirkung enthält die Lösung Monomethylanilin und das entweichende Gas besteht aus fast reinem Stickstoff.

Die Reaction entspricht der Bildung von Anilin aus Phenylhydrazin und wird durch die Gleichung :

$$
2\left(\begin{array}{c}
\mathrm{C}_{6} \mathrm{H}_{6} \\
\mathrm{CH}_{3}
\end{array}\right) \mathrm{N}_{2} \mathrm{H}_{2}+\mathrm{O}=2\left(\begin{array}{c}
\mathrm{C}_{6} \mathrm{H}_{5} \\
\mathrm{CH}_{3}
\end{array}\right) \mathrm{NH}+\mathrm{H}_{3} \mathrm{O}+\mathrm{N}_{8}
$$

ausgedrückt. Ein hiervon total verschiedener Vorgang findet statt, wenn man energischer wirkende Oxydationsmittel anwendet und in der Kälte arbeitet. Die durch Zerstörung der Hydrazingruppe bedingte Stickstoffentwickelung kann hierbei ziemlich vollständig vermieden werden und es entsteht statt dessen durch Vereinigung von $2 \mathrm{Mol}$. der Base ein indifferenter Körper, welcher zu dieser in einem ähnlichen Verhältnifs steht, wie die Azoverbindungen der aromatischen Gruppe zu den Aminbasen. Die Darstellung dieser interessanten Substanz gelingt am leichtesten bei Anwendung von gelbem Quecksilberoxyd. Versetzt man eine Lösung der Base (am besten des Rohproducts) in der 8 fachen Menge 
Chloroform allmälig mit kleinen Mengen Quecksilberoxyd, so giebt sich der Eintritt der Reaction sehr bald durch Schwärzung des letzteren zu erkennen, gleichzeitig färbt sich die Lösung dunkelbraun; durch gute Abkühlung und fortwährendes Umschütteln wird die leicht eintretende Stickstoffentwickelung, welche Folge eines secundären Vorgangs ist, möglichst verhindert. Sobald ein Ueberschufs des Oxydationsmittels eingetragen und beim ruhigen Stehen keine Gasentwickelung mehr sichtbar ist, oder eine abfiltrirte Probe nach dem Verdampfen des Chloroforms Fehling'sche Lösung nicht mehr verändert, ist die Umwandlung der Hydrazinbase beendet. Die von den Quecksilberverbindungen abfiltrirte, dunkelbraune Lösung wird im Wasserbade möglichst stark eingedampft und der Rückstand mit Alkohol versetzt. Die hierdurch sofort abgeschiedene, dunkelbraune Krystallmasse wird durch Filtriren, Auswaschen mit Alkohol und Pressen zwischen Fliefspapier möglichst von der Mutterlauge getrennt und durch Umkrystallisiren aus heifsem Alkohol oder durch wiederholtes Lösen in Chloroform und Fällen mit Alkohol gereinigt. Die den Krystallen schliefslich noch anhaftende schwachgelbe Färbung läfst sich indessen auf diesem Wege kaum vollständig entfernen; leichter gelingt diefs durch reducirende Agentien; versetzt man die heifse alkoholische Lösung mit etwas Zinkstaub und sehr wenig Eisessig, so wird dieselbe zunächst vollständig entfärbt und das Filtrat scheidet beim raschen Abkühlen die Substanz in ganz farblosen feinen Blättchen $a b$, während die Mutterlauge sich gewöhnlich in Folge einer geringen Zersetzung der in Lösung gebliebenen Masse durch die Essigsäure blauviolett färbt.

Durch weiteres Umkrystallisiren aus Alkohol werden dieselben leicht aschenfrei erhalten. Die Analyse verschiedener, so dargestellter und im Vacuum getrockneter Präparate, welche 
alle Zeichen der Reinheit trugen, führten übereinstimmend zu der Formel $\mathrm{C}_{7} \mathrm{H}_{8} \mathrm{~N}_{2}$.

1. $0,2145 \mathrm{Grm}$. gaben $0,548 \quad \mathrm{CO}_{2}$ und $0,138 \mathrm{H}_{\mathrm{z}} \mathrm{O}$.

0,0987 Grm. gaben 20,5 CC. Stickstoff bei $13^{\circ}$ und 709 MM.

Druck.

0,1504 Grm. gaben $31,5 \mathrm{CC}$. Stickstoff bei $15^{\circ}$ und $713 \mathrm{MM}$.

Druck.

2. 0,2349 Grm. gaben $0,6015 \mathrm{CO}_{2}$ und $0,1495 \mathrm{H}_{8} \mathrm{O}$.

3. 0,2117 Grm. gaben $0,543 \mathrm{CO}_{2}$ und $0,1342 \mathrm{H}_{2} \mathrm{O}$.

$0,184 \mathrm{Grm}$. gaben 40,5 CC. Stickstoff bei $25^{\circ}$ und $717 \mathrm{MM}$.

Druek.

4. 0,2202 Grm. gaben $0,566 \mathrm{CO}_{2}$ und $0,1377 \mathrm{H}_{2} \mathrm{O}$.

\begin{tabular}{ccccccc} 
& \multicolumn{9}{c}{ Gefunden } & $\begin{array}{c}\text { Berechnet } \\
\text { für } \mathrm{C}_{7} \mathrm{H}_{8} \mathrm{~N}_{2}\end{array}$ \\
$\mathrm{H}$ & 69,67 & - & 2. & 3. & 4. & 70,00 \\
$\mathrm{~N}$ & 7,15 & - & 7,093 & 69,96 & 70,1 & 6,67 \\
& 22,9 & 22,9 & - & 23,13 & - & $23,33$.
\end{tabular}

Die Differenzen zwischen den gefundenen und berechneten Zahlen für Wasserstoff können kaum in Betracht kommen, da sämmtliche Verbrennungen wegen der leichten Zersetzlichkeit der Substanz im Bayonnetrohr ausgeführt werden mufsten, wobei bekanntlich, besonders bei Sommertemperatur, stets 0,3 bis $0,4 \mathrm{pC}$. $\mathrm{H}$ zu viel gefunden werden.

Die Substanz ist in Chloroform und Schwefelkohlenstoff leicht, in Aether und kaltem Alkohol schwer löslich. Sie schmilzt bei $133^{\circ} \mathrm{zu}$ einem unter Gasentwickelung sich rasch dunkelfärbenden $0 \mathrm{el}$; bei grölseren Mengen dauert die Gasentwickelung auch nach Entfernung der Flamme noch kurze Zeit an, worauf plötzliche, ziemlich heftige Verpuffung erfolgt und gleichzeitig ein intensiver Geruch nach Cyanphenyl auftritt.

Von oxydirenden oder gelinde reducirenden Agentien wird sie nicht weiter verändert, eben so wenig durch Kochen mit Wasser; um so unbeständiger ist sie gegen verdünnte Mineralsäuren und selbst etwas concentrirte Essigsäure. Ver- 
setzt man eine alkoholische Lösung derselben init verdünnter Salz- oder Schwefelsäure, so färbt sich dieselbe tielblau; dieselbe Farbenveränderung zeigt sich beim gelinden $\mathrm{Er}-$ wärmen der festen Substanz mit verdünnten Säuren; zugleich wird dieselbe zersetzt und es entweicht genau die Hälfte des Stickstoffs in Gasform.

0,2597 Grm. Substanz gaben mit verdünnter Schwefelsuure gekocht 28,5 CC. Stickstoff bei $24^{\circ}$ und 720 MM. Druck.

\begin{tabular}{|c|}
\hline Gefunden \\
\hline 11,7 \\
\hline
\end{tabular}

Die rückständige saure Lösung bleibt hierbei zuerst schön blau, verliert jedoch beim länguren Kochen diese Farbe gröfstentheils und enthält alsdann reichliche Mengen von Monomethylanilin. Diese Reaction, welche anscheinend glatt verläuft, steht mit der oben aus den Analysen hergeleiteten Formel nicht in Einklang, da die ausschliefsliche Bildung von Monomethylanilin und Stickstoff die Zufuhr von $1 \mathrm{At}$. Wasserstoff verlangen würde, dessen Herkunft bei den hier gegebenen Bedingungen unverständlich bleibt:

$$
\mathrm{C}_{7} \mathrm{H}_{8} \mathrm{~N}_{2}+\mathrm{H}=\mathrm{C}_{7} \mathrm{H}_{9} \mathrm{~N}+\mathrm{N} \text {. }
$$

Es würde dieselbe vielmehr für die wasserstoffreichere Formel $\mathrm{C}_{7} \mathrm{H}_{9} \mathrm{~N}_{2}$ sprechen und ich habe aus diesem Grunde, zumal da die analytischen Differenzen nicht bedeutend sind, lange geschwankt, der einen oder anderen dieser Formeln den Vorzug zu geben.

Erst die Uebereinstimmung aller mit besonderer Sorgfalt ausgeführten Analysen von Präparaten, welche alle Charaktere der Reinheit trugen, veranlafste mich, die erstere für die wahrscheinlichere zu halten und hier definitiv aufzustellen. Es führt diefs natürlich weiter zu der Annahme, dafs bei der Zersetzung mit Säuren secundäre Vorgänge stattfinden, welche die Bildung von Methylanilin ermöglichen; in welcher Weise das geschieht, bleibt zur Zeit unentschieden; die vorüber- 
gehende Blaufärbung der Substanz und der wässerigen Lösung, selbst nachdem bereits aller gasförmige Stickstoff ausgetrieben ist, mithin der Procefs beendet zu sein scheint, und der Unstand, dafs neben Methylanilin stets geringe Mengen harziger, dunkelgefärbter Producte erhalten werden, deuten allerdings auf solche Nebenreactionen hin, zu deren Untersuchung mir jedoch bisher das Material fehlte; aufserdem ist auch zu erwarten, dafs das wieder aufgenommene Studium der fetten Hydrazine, bei welchen die analytischen Differenzen für solche Producte weit gröfser sind, diese Frage rascher und sicherer entscheiden wird.

Versucht man nun mit Zugrundelegung der augenblicklich wahrscheinlicheren empirischen Formel $\mathrm{C}_{7} \mathrm{H}_{8} \mathrm{~N}_{2}$ die Constitution der Verbindung aus den bekannten Thatsachen zu entwickeln, so gelangt man zu dem Schlusse, dafs dieselbe nur nach Art der Azokörper aus zwei Molecülen der Hydrazinbase durch Stickstoffverkettung entstanden sein kann, mithin die Formel $\mathrm{C}_{7} \mathrm{H}_{8} \mathrm{~N}_{2}$ zu verdoppeln ist. Alle anderen Möglichkeiten werden durch das gesammte Verhalten des Körpers ausgeschlossen; die Annahme, dafs eine Verkettung zwischen dem Methyl und der Amidgruppe des Hydrazins durch Verlust von zwei Wasserstoffatomen eintrete, wird widerlegt durch die Beobachtung, dafs auch das spăter beschriebene Diphenylhydrazin ein ähnliches Product liefert; eine Condensation zwischen dem Benzol und der Stickstoffgruppe dagegen würde für die Verbindung ganz andere, etwa dem Diimidonaphtol ähnliche Eigenschaften erwarten lassen und noch weniger lärst sich die Annahme einer Kohlenstoffverkettung zwischen dem Benzolkern und der Methylgruppe mit dem Verhalten der Substanz in Einklang bringen. Es bleibt mithin nur die der Constitution der Azokörper entsprechende Formel $\mathrm{CH}_{6} \mathrm{H}_{5}>\mathrm{N}-\mathrm{N}=\mathrm{N}-\mathrm{N}\left\langle\mathrm{CH}_{6} \mathrm{CH}_{6} \mathrm{H}_{5}\right.$, als bester Ausdruck der bekannten 
Thatsachen, zu berücksichtigen. Dieselbe würde den indifferenten Charakter der Substanz, die bei der Zersetzung mit Säuren eintretende Stickstoffentwickelung und, wenn man will, auch die explosiven Eigenschaften derselben ungezwungen erklären. Für ihre Entstehung hätte man dann schliefslich noch ein Analogon in der von G I as er beobachteten Bildung von Azobenzol durch Oxydation des Anilins, wie aus folgenden Gleichungen ersichtlich wird;

$$
\begin{aligned}
& 2 \mathrm{C}_{6} \mathrm{H}_{6} \cdot \mathrm{NH}_{2}+2 \mathrm{O}=\mathrm{C}_{6} \mathrm{H}_{6} \cdot \mathrm{N}=\mathrm{N} \cdot \mathrm{C}_{6} \mathrm{H}_{6}+2 \mathrm{H}_{8} \mathrm{O} \text {; }
\end{aligned}
$$

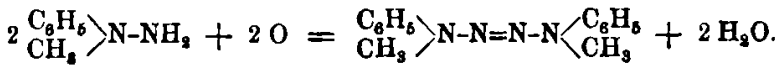

Sollte sich diese einstweilen bestbegründete Ansicht im Laufe der Untersuchung bestätigen, so hahen wir in dieser Substanz den ersten Repräsentanten einer neuen Körperklasse mit einer aus vier Atomen bestehenden Stickstoffkette, für welche ich den Namen "Tetrazonverbindungen" vorschlage; die beschriebene Substanz würde hiernach die Bezeichnung „Dimethyldiphenyltetrazon" erhalten.

Auffallend könnte man es allerdings finden, dafs ein Körper von dieser Constitution nicht ähnlich dem Azobenzol bei der Einwirkung von reducirenden Agentien zwei Wasserstoff fixirt und in die Verbindung $\left(\begin{array}{l}\mathrm{C}_{6} \mathrm{H}_{5} \\ \mathrm{CH}_{3}\end{array}\right)=\mathrm{N}-\mathrm{NH}-\mathrm{NH}-\mathrm{N}=\left(\begin{array}{l}\mathrm{C}_{6} \mathrm{H}_{5} \\ \mathrm{CH}_{3}\end{array}\right)$ übergeht; dieser Einwurf wird jedoch hinfällig, wenn man andererseits die Beständigkeit desselben gegen Oxydationsmittel in Betracht zieht und ferner berücksichtigt, dafs die Anwendung von energisch wirkenden Reductionsmitteln bei der leichten Zersetzlichkeit durch Säuren hier nicht zulässig ist.

Eine weitere Bestätigung enthält die obige Formel endlich noch durch dic Zusammensetzung und Eigenschaften des eiuzigen Derivats, welches ich bisher gewinnen konnte, einer Verbindung der Substanz mit Jod. 
Man erhält dieselbe durch Zusatz von Jod zu einer kalt gehaltenen Lösung des Dimethyldiphenyltetrazons in Chloroform als schwarzen, aus mikroscopisch feinen Nadeln bestehenden Niederschlag; durch rasches Abfiltriren und Auswaschen mit Chloroform wird jeder Ueberschurs des einen oder anderen Reagens leicht entfernt. Das Product selbst ist höchst unbeständig und mit grofser Vorsicht zu behandeln; sobald die Masse trocken wird, tritt schon bei Zimmertemperatur plötzliche Verpuffung ein, wobei Joddämpfe in reichlicher Menge entweichen und eine blasige, halbverkohilte, aber noch jodhaltige Masse zurückbleibt. Von einer Analyse der Substanz nach der gewöhnlichen Methode mufste unter diesen Umständen natürlich abgesehen werden; ihre Zusammensetzung konnte indessen auf indirectem Wege ermittelt werden, da dieselbe durch moleculares Silber glatt in den ursprünglichen Körper zurückverwandelt wird. Zu diesem Zwecke wurde eine unbestimmte, noch feuchle Menge eines aus ganz reinem Material frisch dargestellten Präparats in Schwefelkohlenstoff suspendirt und mit einem grofsen Ueberschufs von reinem molecularen Silber bis zur Entfärbung der Lösung geschüttelt. Das Filtrat lieferte beim Verdampfen die ganze Menge des regenerirten Tetrazons als schwach grau gefärbte Krystallmasse; das rückständige Gemenge von Silber und Jodsilber wurde nach dem Trocknen mit Salpetersäure ausgezogen und das ungelöste Jodsilber wie gewöhnlich bestimmt.

Aus den so erhaltenen Zahlen berechnet sich annähernd die Formel $\mathrm{C}_{14} \mathrm{H}_{16} \mathrm{~N}_{4} \mathrm{~J}_{4}$.

Auf 0,511 Grm. regenerirtes Dimethyldiphenyltetrazon wurden 1,86 AgJ gefunden.

$\begin{array}{ccc} & & \text { Berechnet für } \\ \mathbf{J} & \text { Gefunden } & \mathbf{C}_{\mathbf{1 4}} \mathbf{H}_{\mathbf{1 8}} \mathbf{N}_{\mathbf{4}}+\mathbf{4} \mathbf{J} \\ \text { Tetrazon } & \mathbf{6 6 , 4} & 67,9 \\ & 33,6 & 32,1 .\end{array}$

Die Substanz ist in Aether, Alkohol und Chloroform sehr schwer löslich, etwas leichter in Schwefelkohlenstoff mit dun- 
kelbrauner Farbe. Leichter noch als durch Silber wird sie beim Schülteln mit verdünnten Alkalien zersetzl; hierbei entsteht ebenfalls theilweise Dimethyldiphenyltetrazon, während ein anderer Theil gleichzeitig in harzige Producte verwandelt wird.

Durch ihre grofse Unbeständigkeit und Explosivität erinnert die Verbindung lebhaft an den Jodstickstoff, bezüglich ihrer Zusammensetzung und Constitution dagegen Jürfte sie mehr den Perjodiden des Tetraäthylanmoniums *) und mancher Pfanzenalkalö̈de zu vergleichen sein.

\section{Diphenylhydrazin.}

Diese Base wird analog der vorher beschriebenen Verbindung aus dem Diphenylamin erhalten. Dieselbe ist isomer mit dem Hydrazobenzol, welches man ebenfalls, wie schon früher hervorgehohén wurde, als ein Derivat des Hydrazins $\mathrm{NH}_{2}-\mathrm{NH}_{2}$ betrachten kann; ihre Kenntnifs giebt mithin Gelegenheit, die dieser Körperklasse eigenthümlichen Isomerieverhältnisse an der Hand der Thatsachen eingehender zu besprechen.

Bildung und Eigenschaften des aus dem Diphenylamin entstehenden Nitrosamins sind von 0 . Witt**) ausführlich beschrieben.

Zur Darstellung gröfserer Mengen wende ich statt der dort angegebenen Methoden folgendes Verfahren an, welches bei ergiebiger Ausbeute den Vorzug gröfserer Bequemlichkeit hat.

Zu einer gut gekühlten Lösung von $40 \mathrm{Th}$. käuflichem Diphenylamin in $200 \mathrm{Th}$. Alkohol und $30 \mathrm{Th}$. Salzsäure (spec. Gewicht 1,19) werden allmälig $35 \mathrm{Th}$. salpetrigsaures Natron

*) Weltzien, Ann. Chem. Pharm. 91, 33.

**) Berichte der deutschen chemischen Gesellschsft B, 855. 
(28 pC. $\mathrm{N}_{2} \mathrm{O}_{3}$ enthaltend) in concentrirter wässeriger Lösung (2:3) unter gutem Umschütteln eingetragen. Die Flüssigkeit färbt sich Anfangs dunkelgrün, gegen Ende der Operation meist dunkelbraun und scheidet neben Chlornatrium reichliche Mengen des Nitrosamins in blätterigen Krystallen ab. Durch starke Abkühlung und vorsichtigen Zusatz von wenig Wasser wird auch der Rest des letzteren ziemlich vollständig ausgefällt, während die dunkelgefärbten, öligen, vorzüglich von Verunreinigungen des Diphenylamins herstamınenden Nebenproducte gröfstentheils in Lösung bleihen. Durch Abfiltriren und Auswaschen mit kleinen Mengen Alkohol erhält man eine hellgelbe Krystallmasse, welche nach Entfernung des beigemengten Kochsalzes durch Waschen mit Wasser aus fast reinem Nitrosamin besteht. Die alkoholischen Mutterlaugen scheiden auf Zusalz von Wasser ein dunkles Oel ab, welches nur geringe Mengen der reinen Verbindung enthält und dessen Verarbeitung sich nicht mehr lohnt.

Zur vollständigen Reinigung des Rolhproducts genügt einmaliges Umkrystallisiren aus heifsem Ligroin (Siedepunkt 70 bis $100^{\circ}$ ), worin dasselbe in der Wärme aufserordentlich leicht, in der Kälte sehr schwer löslich ist.

Die nach diesem Verfahren erzielte Ausbeute betrug durchschnittlich 85 bis $90 \mathrm{pC}$. der von der Theorie verlangten Menge.

Zur Umwandlung in die Hydrazinbase wird die Lösung des Nitrosamins in der fünffachen Menge Alkohols mit überschüssigem Zinkstaub versetzt und allmälig Eisessig in kleinen Mengen zugegeben; die hierbei alsbald eintretende bedeutende Temperaturerhöhung ist durch gute Kühlung des Gefäfses und fortwährendes Uınschütteln möglichst zu mäfsigen. Die Reaction ist beendet, wenn auf erneuten Zusatz von Eisessig keine merkbare Erwärmung mehr stattindet und eine abfiltrirte Probe auf Zusatz von concentrirter Salzsäure nicht 
mehr die dem Nitrosamin eigenthümliche grünblaue Färbung zeigt. Die heifs vom Zinkstaub abfiltrirte Lösung wird auf $1 / 4$ ihres Volums eingedampft, mit der gleichen Menge Wasser verdünnt und mit einem grofsen Ueberschufs von rauchender Salzsäure allmälig unter Abkühlung und Umrühren versetzt.

Beim Erkalten scheidet sich das in concentrirter Salzsäure schwer lösliche Hydrochlorat der Base zum gröfsten Theil in feinen, blau gefärbten Nadeln ab. Das Salz ist durch nicht unbeträchtliche Mengen Diphenylamin, dessen gleichzeitige Bildung bei der Reduction des Nitrosamins kaum vollständig vermieden werden kann, verunreinigt; dasselbe läfst sich jedoch leicht entfernen durch Unkrystallisiren des Rohproducts aus heifser, sehr verdünnter Salzsäure, wobei es gröfstentheils als Oel zurückbleibt und abfiltrirt werden kann.

Aus dem Filtrat wird die Hydrazinbase durch concentrirte Salzsäure wieder ausgefällt; durch mehrmalige Wiederholung dieser Operation erhält man leicht und sicher ein diphenylaminfreies Präparat. Das so dargestellte Hydrochlorat ist stets schwach blau gefärbt, was von einer geringen Veränderung der Substanz durch die concentrirte Salzsäure herrührt. Durch einmaliges Umkrystallisiren aus heifsem Alkohol wurde dasselbe in farblosen feinen Nadeln gewonnen, welche im Vacuum getrocknet bei der Analyse die von der Formel $\left(\mathrm{C}_{6} \mathrm{H}_{5}\right)_{2} \mathrm{~N}_{2} \mathrm{H}_{2}$. $\mathrm{HCl}$ verlangten Zahlen gaben :

$0,2017 \mathrm{Grm}$. gaben $0,4833 \mathrm{CO}_{2}$ und $0,110 \mathrm{H}_{8} \mathrm{O}$.

$0,2311 \mathrm{Grm}$. gaben 27 CC. Stickstoff bei $17^{\circ}$ and $714 \mathrm{MM}$. Druck.

$\begin{array}{ccc} & \text { Gefunden } & \text { Berechnet } \\ \text { C } & 65,35 & 65,31 \\ \text { H } & 6,06 & 5,89 \\ \text { N } & 12,73 & 12,7 .\end{array}$

Durch Zersetzung des reinen Hydrochlorats mit Natronlauge erhält man die freie Base als schwach gelbgefärbtes Oel, welches selbst in einer Kältemischung nicht erstarrt; bei $-17^{0}$ wird sie wohl dickflüssig, ohne indessen zu krystalli- 
siren; es ist möglich, dafs diese Erscheinung durch geringe Mengen schwer zu entfernender Verunreinigungen veranlafst wird; jedenfalls aber ist die geringe Krystallisationsfähigkeit der Substanz um so auffallender, als das Monophenylhydrazin und das isomere Hydrazobenzol gerade durch die gegentheilige Eigenschaft ausgezeichnet sind. Eben so wenig lärst sich die Base durch Destillation reinigen; bei gewöhnlichem Druck ist sie nur theilweise unzersetzt flüchtig, ein anderer Theil zerfällt dabei in Ammoniak, Diphenylamin und nicht flüchtige harzartige Producte. Von der Analyse der Substanz wurde deshalb abgesehen, zumal da die Formel $\left(\mathrm{C}_{6} \mathrm{H}_{5}\right)_{z} \mathrm{~N}_{2} \mathrm{H}_{2}$ durch die Analysen der Salze hinreichend festgestellt ist.

Sie ist leicht löslich in Aether, Alkohol, Benzol und Chloroform, sehr schwer in Wasser; in Folge dieser Schwerlöslichkeit wird sie von Fehling'scher Lösung selbst beim Kochen kaum angegriffen, obschon sie gegen andere $0 x y-$ dationsmittel nicht beständiger, als die übrigen secundären Hydrazine ist; an der Luft färbt sie sich bald durch $0 x y-$ dation dunkelbraun. Von concentrirter Schwefelsäure wird sie ähnlich dem Nitrosamin beim gelinden Erwärmen ohne wesentliche Veränderung mit tiefblauer Farbe gelöst und beim Verdünnen mit Wasser gröfstentheils als schwefelsaures Salz wieder abgeschieden. Das Diphenylhydrazin ist eben so wie das Phenyl- und Methylphenylhydrazin eine einsäurige Base; seine Salze sind jedoch weit unbeständiger, sie werden bereits durch Wasser theilweise zersetzt.

Das Hydrochlorat bildet feine weifse Nadeln und ist in kaltem Wasser und concentrirter Salzsäure sehr schwer löslich; eine kalt gesälligte Lösung in reinem Wasser zeigt beim gelinden Erwärmen eine auffallende Dissociationserscheinung : sie trübt sich durch Abscheidung der freien Base, welche bei höherer Temperatur jedoch wieder gelöst wird; in verdünnter Salzsäure ist das Salz ganz beständig. 
Das Sulfat krystallisirt aus heifser verdünnter Schwefelsäure in feinen, meist blaugefärbten Nadeln und hat die $\mathrm{Zu}$ sammensetzung $\left[\left(\mathrm{C}_{6} \mathrm{H}_{5}\right)_{2} \mathrm{~N}_{2} \mathrm{H}_{2}\right]_{2} \mathrm{H}_{2} \mathrm{SO}_{4}$.

0,2277 Grm. gaben 0,116 $\mathrm{BaSO}_{4}$.

$\begin{array}{cc}\text { Gefunden } & \text { Berechnet } \\ 7,0 & 6,87 .\end{array}$

Es ist in heifser verdünnter Schwefelsäure ziemlich leicht, in der Kälte schwer löslich; von reinem Wasser wird es ebenfalls theilweise zersetzt.

Das salpetersaure Salz bildet gleichfalls feine, in kaltem Wasser schwer, in heifsem etwas leichter lösliche Nadeln.

In dem Diphenylhydrazin lassen sich die beiden an Stickstoff gebundenen Wasserstoffatome mit Leichtigkeit durch Säure- oder Alkoholradicale ersetzen.

\section{Monobenzoyldiphenylhydrazin.}

Zur Darstellung dieser Verbindung fügt man allmälig 1 Mol. Benzoylchlorid zu einer Lösung von 2 Mol. Basis in der zehnfachen Menge Aether. Die alsbald sich abscheidende Krystallmasse wird abfiltrirt und zur Entfernung des Hydrochlorats mit schwach saurem Wasser ausgekocht; beim Umkrystallisiren des Rückstands aus heifsem Aceton scheidet sich das Benzoylderivat in feinen weifsen glänzenden Nadeln ab.

Die Analyse der bei $100^{\circ}$ getrockneten Substanz gab folgende Zahlen.

$0,2324 \mathrm{Grm}$. gaben 21,5 CC. Stickstoff bei $21^{\circ}$ und 714 MM. Druck. $0,193 \mathrm{Grm}$. gaben $0,5577 \mathrm{CO}_{3}$ und $0,1024 \mathrm{H}_{2} \mathrm{O}$.

$\begin{array}{ccc} & \text { Gefunden } & \begin{array}{c}\text { Berechnet für } \\ \left(\mathrm{C}_{6} \mathrm{H}_{8}\right)_{\mathbf{8}} \mathrm{N}_{\mathbf{2}} \mathrm{H} . \mathrm{CO} . \mathrm{C}_{6} \mathrm{H}_{5}\end{array} \\ \text { C } & \mathbf{7 8 , 8 1} & 79,16 \\ \text { H } & 5,88 & \mathbf{5 , 5 6} \\ \text { N } & 9,9 & 9,72 .\end{array}$

Die Verbindung ist in heifsem Aceton und Chloroform ziemlich leicht löslich, schwerer in Alkohol und Aether. 
Schmelzpunkt $192^{\circ}$. Beim stärkeren Erhitzen tritt Zersetzung ein. Durch concentrirte Säuren wird sie langsam in Benzoësaure und Hydrazinbase gespalten.

\section{Benzylidendiphenylhydrazin.}

Beim Vermischen von gleichen Moleculen Bittermandelöl und Basis trübt sich die Lösung sofort durch Wasserabscheidung und erstarrt beim Erkalten zu einer gelb gefärbten Krystallmasse, welche durch Umkrystallisiren aus heifsem Alkohol gereinigt wurde.

Die Analyse der im Vacuum getrockneten Substanz führte zu der Formel $\left(\mathrm{C}_{6} \mathrm{H}_{5}\right)_{2} \cdot \mathrm{N}_{\mathbf{z}} \cdot \mathrm{CH} . \mathrm{C}_{6} \mathrm{H}_{5}$.

$0,1912 \mathrm{Grm}$. gaben $0,594 \mathrm{CO}_{2}$ und $0,110 \mathrm{H}_{2} \mathrm{O}$.

0,271 Grm. gaben 26,5 CC. Stickstoff bei $21^{\circ}$ und 717 MM. Druck.

$\begin{array}{ccc} & \text { Gefunden } & \text { Berechnet } \\ \text { C } & 83,44 & 83,82 \\ \text { H } & 6,29 & 5,88 \\ \text { N } & 10,5 & 10,3 .\end{array}$

Das Benzylidendiphenylhydrazin bildet kleine, meist schwach gelb gefärbte Krystalle von wenig charakteristischer Form; es ist leicht löslich in Aether, Chloroforin und Benzol, schwer in kaltem Wasser. Der Schmelzpunkt liegt bei $\mathbf{1 2 2}^{\circ}$, mithin auffallenderweise $30^{\circ}$ niedriger als der des Benzylidenmonophenylhydrazins.

Was die Constitution der Base betrift, so ist man nach der Synthese wohl berechtigt, dieselbe eben so wie das Methylphenylhydrazin als ein unsymmetrisches Substitutionsproduct der Atomgruppe $\mathrm{NH}_{2}-\mathrm{NH}_{2}$, als ein diphenylirtes Hydrazin von der Formel $\left(\mathrm{C}_{6} \mathrm{H}_{5}\right)_{2} \mathrm{~N}-\mathrm{NH}_{2}$ aufufassen.

Diese Formel trägt nicht nur in allen Punkten dem Verhalten der Base Rechnung, sie giebt auch in einfacher Weise Rechenschaft von ihren Beziehungen zu dem isomeren $\mathrm{Hy}-$ drazobenzol. Behält man nämlich für letzteres die seiner Bildung aus Azobenzol am besten entsprechende Formel 
$\mathrm{C}_{6} \mathrm{H}_{5}-\mathrm{NH}-\mathrm{NH}-\mathrm{C}_{6} \mathrm{H}_{5}$ bei, so liegt es nahe, dasselbe ebenfalls als ein Derivat des Hydrazins, in welchem die beiden Phenylreste symmetrisch auf die beiden Stickstoffgruppen vertheilt. sind, aufzufassen und seine Beziehungen zu obiger Base dem Verhältnifs der Aethylen- zu den Aethylidenverbindungen an die Seite zu stellen. Man erkennt ferner aus den Formeln selbst, dafs vorliegender Fall die einzige Art von Isomerie ist, welche die moderne Theorie für die substituirten Hydrazine bei Gleichartigkeit der substituirenden Gruppen voraussehen läfst.

In wie weit diese Betrachtungsweise aber durch die experimentellen Thatsachen gerechtfertigt ist, wird am besten aus einer vergleichenden Zusammenstellung der meist total verschiedenen Reactionen beider Körper ersichtlich werden.

Das Diphenylhydrazin, wie ich die beschriebene Base zum Unterschied vom Hydrazobenzol kurzweg benannt habe, bildet mit Mineralsäuren beständige Salze; eine moleculare Umlagerung zu Benzidin, wie sie sein Isomeres durch diese Agentien so leicht erleidel, wurde in keinem Falle beobachtet.

Bei der trockenen Destillation zerfällt das eine theilweise in Ammoniak und Diphenylamin, das andere vollständig in Anilin und Azohenzol.

Substitutionsproducte des Hydrazobenzols, entstanden durch Einführung von Alkohol- oder Saureradicalen in die stickstoffhaltige Gruppe, sind zwar der Theorie nach mỏglich, indessen bisher wohl in Folge von experimentellen Schwierigkeiten nicht erlıalten worden; beim Diphenylhydrazin gelingt die Darstellung solcher Producte, wie oben gezeigt, mit der gröfsten Leichtigkeit.

Während das Hydrazobenzol durch 0xydationsmittel leicht und glatt in Azobenzol verwandelt wird, liefert sein Isomeres unter ähnlichen Bedingungen meist mit lebhafter Stickstoffentwickelung Diphenylamiu, blauviolette Farbstoffe von com- 
plicirterer Zusammensetzung und in geringerer Menge einen indifferenten stickstoffreicheren Körper, welcher dem Dimethyldiphenyltetrazon analog constituirt und unten näher beschrieben ist.

Am auffallendsten und deutlichsten endlich wird die Isomerie beider Verbindungen durch ihr verschiedenes Verhalten gegen salpetrige Säure illustrirt, welche nach allen bisher bekannten Thatsachen jedenfalls das sicherste und bequemste Mittel zur Unterscheidung von primären, secundären und tertiären Amingruppen ist.

Für das Hydrazobenzol ist bereits durch Versuche von Ba eyer*) nachgewiesen, dafs es unter geeigneten Bedingungen durch salpetrige Säure in einen Körper, welcher mit den gewöhnlichen Nitrosaminen die gröfste Aehnlichkeit zeigt, umgewandelt wird, mithin sich den Imidbasen oder Harnstoffabkömmlingen des Phenylhydrazins analog verhält.

In ganz anderem Sinne verläuft dieselbe Reaction beim Diphenylhydrazin, welches dabei ähnlich dem Methylphenylhydrazin glatt Stickoxydul und Diphenylnitrosamin liefert.

Beide Producte wurden durch die Analyse und sämmtliche Reactionen identificirt; aufser ihnen konnte kein drittes nachgewiesen werden :

$$
\left(\mathrm{C}_{6} \mathrm{H}_{5}\right)_{2} \mathrm{~N}_{8} \mathrm{H}_{3}+2 \mathrm{HNO}_{8}+\left(\mathrm{C}_{6} \mathrm{H}_{6}\right)_{2} \mathrm{~N}_{2} \mathrm{O}+\mathrm{N}_{2} \mathrm{O}+2 \mathrm{H}_{8} \mathrm{O} .
$$

*) Berichte der deutschen chemischen Gesellschaft 2, 683. Baeyer stellt dafür die Formel :<smiles>O=[N+]([O-])N(c1ccccc1)c1ccccc1</smiles>

auf, obne dieselbe jedoch durch eine Analyse der sebr unbestandigen Verbindung begründen zu können. Die von mir seitdem gemachte Beobaclitung, dale die Hydrazinharnstoffe und dor ebenfalls zwei Imidgruppen enthaltende Diäthylbarnstoff alle nur eine Nitrosogruppe fixiren, macht die Formel :

wahrscheinlicher.

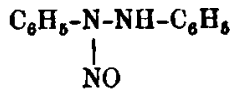


Bezüglich der weiteren Interpretation dieses Vorgangs verweise ich auf die ausführlichere Besprechung desselben beim Methylphenylhydrazin.

Oxydation des Diphenylhydrazins.

Die Zersetzung des Diphenylhydrazins durch Oxydationsmittel ist ebenso wie bei den vorher beschriebenen Hydrazinen verschieden, je nach der Wahl der Agentien, der Temperatur und der Concentration der Lösungen, sowohl was die Art der Producte, als ihre relativen Mengen betriff. Von Fehling'scher Lösung wird die Base, wie bereits angegeben, auch in der Wärme nur sehr langsam angegriffen; rasch erfolgt ibre Zersetzung durch Quecksilberoxyd, Silberoxyd, Eisenchlorid u. s. w. schon in der Kälte; bei höherer Temperatur zerfällt hierbei der gröfste Theil der Base in Stickstoff und Diphenylamin vielleicht nach der Gleichung :

$$
2\left(\mathrm{C}_{6} \mathrm{H}_{6}\right)_{2}-\mathrm{N}-\mathrm{NH}_{2}+\mathrm{O}=2\left(\mathrm{C}_{6} \mathrm{H}_{6}\right)_{8} \mathrm{NH}+\mathrm{H}_{2} \mathrm{O}+\mathrm{N}_{8} \text {. }
$$

Gleichzeitig bildet sich eine mehr oder weniger grofse Menge eines blauvioletten, in Alkohol leicht löslichen stickstoffhaltigen Farbstoffs, welcher nicht weiter untersucht wurde. Wird die Oxydation dagegen in der Kälte und in sehr verdünnter Lösung ausgeführt, so erhält man neben diesen Producten noch einen farblosen indifferenten Körper in wechselnder Menge, den ich wegen seiner Aehnlichkeit mit dem Dimethyldiphenyltetrazon als Tetraphenyltetrazon bezeichne. Die beste Ausbeute erhielt ich bei Anwendung von Eisenchlorid. Schüttelt man das Diphenylhydrazin mit einer sehr verdünnten, möglichst neutralen und gut gekühlten Lösung von Eisenchlorid, so färbt sich dieselbe bald blauviolett und erstarrt allmälig krystallinisch. Sobald die Masse vollständig fest geworden, ist die Reaction beendet; man filtrirt und wäscht das Rohproduct zuerst mit Wasser, später wiederholt mit Alkohol; hierbei 
gehen das gleichzeitig gebildete Diphenylamin und der Farbstoff in Lösung und es bleibt das in Alkohol sehr schwer lösliche Tetrazon als wenig gefärbte Krystallmasse zurück; dasselbe wird zerrieben, nochmals mit kleinen Mengen Alkohol ausgekocht und schliefslich aus reinem, warmem Schwefelkohlenstoff mehrmals umkrystallisirt.

Die Analyse der so gereinigten und im Vacuum getrockneten farblosen Substanz gab die der Formel $\mathrm{C}_{24} \mathrm{H}_{20} \mathrm{~N}_{4}$ entsprechenden Werthe.

0,2131 Grm. gaben 29,5 CC. Stickstoff bei $14^{\circ}$ und 717 MM. Druck. $0,2171 \quad \rightarrow \quad 0,627 \mathrm{CO}_{2}$ and $0,1142 \mathrm{H}_{2} \mathrm{O}$.

\begin{tabular}{|c|c|c|}
\hline $\mathbf{C}$ & $\begin{array}{c}\text { Gefunden } \\
78,76\end{array}$ & $\begin{array}{c}\text { Berechnet } \\
\text { für } \mathrm{C}_{\mathbf{8 4}} \mathbf{H}_{\mathbf{2 0}} \mathrm{N}_{\mathbf{4}} \\
\mathbf{7 9 , 1 2}\end{array}$ \\
\hline H & 5,85 & 5,5 \\
\hline $\mathbf{N}$ & 15,35 & $15,38$. \\
\hline
\end{tabular}

Die Substanz schmilzt bei $1 \mathbf{2 3}^{\circ}$ unter Gasentwickelung zu einer gelb gefärbten Flüssigkeit; hierbei entsteht neben nicht flüchtigen Producten Diphenylamin.

Sie ist in Aether, Alkohol, Chloroform und Ligroin schwer löslich, ziemlich leicht aber in warmem Schwefelkohlenstoff.

Mit concentrirten Säuren übergossen färbt sie sich blau und wird langsam unter Zersetzung gelöst, beim Erhitzen verschwindet die blaue Farbe und geht in schmuizig Gelb über.

Was ihre Constitution betriff, so dürfte die für das Dimethyldiphenyltetrazon entwickelte Ansicht auch hier malsgebend sein; dieselbe wird höchst wahrscheinlich durch die Formel $\left(\mathrm{C}_{6} \mathrm{H}_{3}\right)_{2}=\mathrm{N}-\mathrm{N}=\mathrm{N}-\mathrm{N}=\left(\mathrm{C}_{6} \mathrm{H}_{5}\right)_{2}$ richtig wiedergegeben. 